UNIVERSIDADE DE SÃO PAULO

FACULDADE DE ECONOMIA, ADMINISTRAÇÃO E CONTABILIDADE DEPARTAMENTO DE ADMINISTRAÇÃO PROGRAMA DE PÓS-GRADUAÇÃO EM ADMINISTRAÇÃo

MODELO DE NEGÓCIOS. TEORIA E PRÁTICA: UM ESTUDO EM EMPRESAS DE TECNOLOGIA

Maks Wilhem Gutiérrez Rocha

Orientador: Prof. Dr. Edison Fernandes Polo 
Prof. Dr. Marco Antonio Zago Reitor da Universidade de São Paulo

Prof. Dr. Adalberto Américo Fischmann Diretor da Faculdade de Economia, Administração e Contabilidade Prof. Dr. Roberto Sbragia Chefe do Departamento de Administração

Prof. Dr. Moacir de Miranda Oliveira Junior Coordenador do Programa de Pós-Graduação em Administração 
MAKS WILHEM GUTIERREZ ROCHA

\title{
MODELO DE NEGÓCIOS. TEORIA E PRÁTICA: UM ESTUDO EM EMPRESAS
} DE TECNOLOGIA

\author{
Dissertação apresentada ao Programa de Pós- \\ Graduação em Administração do \\ Departamento de Administração da Faculdade \\ de Economia, Administração e Contabilidade \\ da Universidade de São Paulo como requisito \\ parcial para a obtenção do título de Mestre em \\ Ciências.
}

Orientador: Prof. Dr. Edison Fernandes Polo

\section{Versão Corrigida}

(versão original disponível na Faculdade de Economia, Administração e Contabilidade)

SÃo PAULO 
FICHA CATALOGRÁFICA

Elaborada pela Seção de Processamento Técnico do SBD/FEA/USP

Rocha, Maks Wilhem Gutierrez.

Modelo de negócios: teoria e prática: um estudo em empresas de tecnologia / Maks Wilhem Gutierrez Rocha. -- São Paulo, 2015. $168 \mathrm{p}$.

Dissertação (Mestrado) - Universidade de São Paulo, 2015.

Orientador: Edison Fernandes Polo.

1. Negócios - Modelos. 2. Administração estratégica. 3. Estratégia I. Universidade de São Paulo. Faculdade de Economia, Administração e Contabilidade. II. Título.

CDD -650 
Dedico o meu trabalho a minha pátria Bolívia, esperando que esta desenvolva todo o seu potencial latente algum dia. 


\section{AGRADECIMENTOS}

Primeiramente, agradeço a meu orientador, Prof. Edison Polo porque ademais de ser uma pessoa com muito conhecimento e experiência, é uma pessoa acessível, generosa, compreensiva, e que confiou em mim. Trabalhar com ele foi um privilégio. Qualquer erro conceitual ou idiomático presente na dissertação é de minha exclusiva responsabilidade.

Agradeço às empresas e executivos que acederam a participar desta investigação, concedendo tempo pessoal e de suas organizações para que eu consiga estudar o proposto. Fico pessoalmente obrigado com o executivo da empresa X, Adriane Rêgo e Alexandre Leitão. Também agradeço aos membros de minha banca de qualificação; professores Polo, Corrêa e Toledo; pelas sugestões para abordar o tema de minha pesquisa. Fico muito agradecido com pessoas que colaboraram de uma ou outra forma para a realização deste documento: Maicol P., Marcel C. e Vanessa G.

Agradeço também a todos os professores que eu tive durante minha passagem pelas aulas do programa de mestrado em Administração da FEA, por terem contribuído a minha formação acadêmica: Prof. de Almeida, Prof. Fischmann, Profa. Marinho, Prof. Yu, Prof. Tromboni, Prof. Salles, Profa. Montini, Prof. Toledo e Prof. Feldmann. Quero agradecer especialmente ao Prof. Gilmar Masiero pela sua generosidade para compartilhar conhecimento e toda sua confiança para trabalhar comigo. Fico obrigado também com o prof. Urdan pela confiança e oportunidade para trabalhar na sua disciplina.

Agradeço a todos e cada um dos meus companheiro(a)s de aula por terem sido parte de uma experiência pessoal e acadêmica que eu lembro com muito afeto. Apenas cito às pessoas com as quais trabalhei mais diretamente em tarefas e apresentações (em ordem alfabética): Ana Maria, Daniela, Fernando, Julia, Katia, Leticia, Marcel (obrigado por escutar meus monólogos existenciais durante os almoços universitários), Marcileni, Marina, Petrus e Romain.

Agradeço a todo o pessoal da Secretaria do PPGA (especialmente a Eloisa), da Secretaria da PG, e da Biblioteca da FEA por toda a colaboração durante a realização do meu mestrado.

Por fim, agradeço ao Brasil e suas instituições educativas e de fomento que permitem que estrangeiros como eu cumpram com seus sonos. 


\section{RESUMO}

ROCHA, M. W. G. Modelo de Negócios. Teoria e prática: Um estudo em empresas de tecnologia. 2015. 168 p. Dissertação (Mestrado em Administração) - Faculdade de Economia, Administração e Contabilidade, Universidade de São Paulo, São Paulo, 2015.

Com suas origens há mais de meio século atrás e um auge experimentado nos últimos 20 anos, "Modelo de Negócios" é um termo frequentemente presente nas conversas tanto acadêmicas quanto corriqueiras. Apesar deste uso massivo, parece existir pouca clareza na compreensão do seu significado em ambas as esferas, dando-se este como subentendido em muitos casos. Referências na literatura falam sobre a falta de consenso sobre questões básicas na sua definição até poucos anos atrás. Outros autores citam uma situação paradoxal devido a sua grande popularidade em domínios relacionados à prática junto a seu uso em inúmeras publicações acadêmicas, e certa relutância por alguns setores na Academia. Por fim, vários autores se mostram esperançados com os avanços atingidos na procura de estabelecer o constructo de modelo de negócios como robusto e passível de progressos na direção de seu uso em pesquisa. Ante este panorama, a presente investigação se propôs, por uma parte, fazer uma revisão das principais abordagens discutidas até a data, com o intuito de se aproximar de melhor forma a sua compreensão, e por outra, explorar em campo os temas identificados na revisão, realizando estudos de caso múltiplos em três empresas relacionadas ao setor de tecnologia no Brasil. Valendo-se de uma busca bibliográfica sistemática em bases científicas como são as da Web of Science, Scopus, Google Acadêmico e portal CAPES de periódicos, apresenta-se uma aproximação do Estado da Arte sobre o assunto e se propõe um constructo sobre modelo de negócios. Como resultado se identificou que os elementos "Valor", "Atividades" e "Modelo de lucro" são importantes para a definição do conceito. Funções como alinhamento; análise e formulação estratégicas; e exploração, foram identificadas. Propriedades como mutabilidade, dinamismo e imitabilidade são apresentadas e discutidas. Pela sua importância, uma seção é dedicada à discussão da relação entre estratégia e modelo de negócios. Aplicando o método de estudo de caso e suas técnicas específicas de análise, respondemos algumas questões. De forma geral, pode-se dizer que os estudos realizados em campo corroboraram com muitas das ideias propugnadas na teoria revisada, porém, diferenças e novos insights também surgiram. No fim, são apresentadas todas as considerações decorrentes da interpretação dos dados na pesquisa, as limitações desta, e as sugestões de pesquisa futura. Considerando que aportes nesta direção permitem esclarecer ainda mais a compreensão sobre modelo de negócios, ao explorar seus fundamentos teóricos e suas conceitualizações na prática, espera-se que o estudo contribua ao debate e linha de pesquisa empreendidas globalmente e, por sua vez, aporte com os seus resultados a pesquisas futuras na área de Administração Estratégica e a outras linhas de pesquisa relacionadas.

Palavras-chave: Modelos. Negócios. Administração Estratégica. Estratégia. 


\begin{abstract}
ROCHA, M. W. G. Business Model. Theory and practice: A study in technological enterprises. 2015. 168 p. Dissertação (Mestrado em Administração) - Faculdade de Economia, Administração e Contabilidade, Universidade de São Paulo, São Paulo, 2015.

With its origins almost a half century ago and a heyday experienced during the last 20 years, "Business model" is a term frequently present in academic and commonplace talks. Despite this massive use, it seems that not much clarity exists on its understanding in both circuits, in many cases taken it for granted. References in literature speak about lack of consensus about basic issues in its definition, until not long ago. Other authors speak about a paradoxical situation due its huge popularity in domains related to practice, together with its use in countless academics publications, and some kind of reluctance by some scholarly sectors. Finally, some authors manifest themselves as hopeful with the achieved advances in the search of a business model construct as robust and susceptible of progress on its use in research. Facing this panorama, the present study propose to itself, on one side, to do a review about the main approaches discussed until today, with the intention of getting closer, in the best manner, to its comprehension, and by other side, to explore in field, the topics identified on the review, conducting multiple-case studies in three organizations related to Brazil's technology sector. Resorting to a systematic bibliographic search in scientific bases as Web of Science, Scopus, Scholar Google and CAPES journals portal; an approximation to State of Art about the topic is presented and a construct about business model is proposed. As a result, it was identified that elements as "Value", "Activities", and "Revenue model" are important to define the concept. Functions as alignment, strategic formulation and analysis, and exploration-exploitation, were identified. Properties as mutability, dynamism and imitability are presented and discussed. Because of its importance, a section is devoted to the discussion about the relationship between strategy and business model. Applying the case study method and its specific analytical tools, we answered some questions. In general, it can be said that the studies conducted in field corroborate many of the ideas stated in the theory reviewed, although some differences and new insights also appeared. In the end are presented all the considerations derived from the data interpretation in the research, its limitations, and future research suggestions. Regarding that contributions in this direction, allow to clarify even more the understanding about business model, by exploring their theoretical underpinnings and their conceptualizations in practice, we hope that the study will contribute to the debate and research line undertaken globally, and also, subsidize with its findings to future research in Strategic Management and other related research streams.
\end{abstract}

Keywords: Models. Business. Strategic Management. Strategy. 


\section{SUMÁRIO}

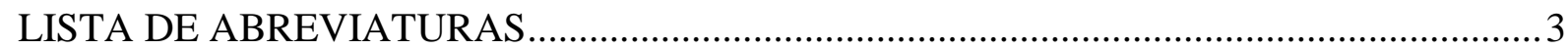

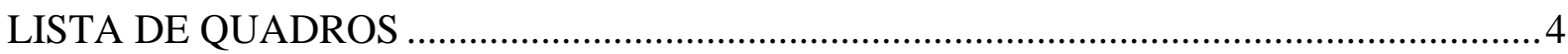

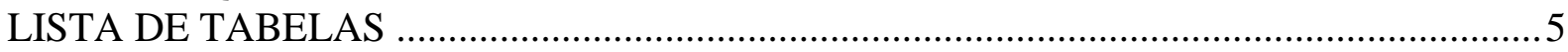

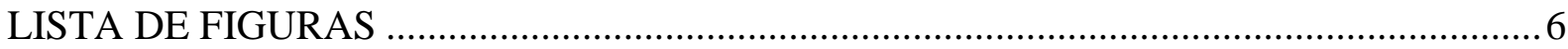

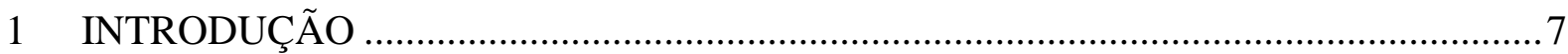

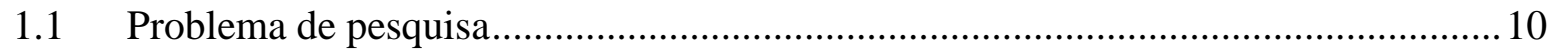

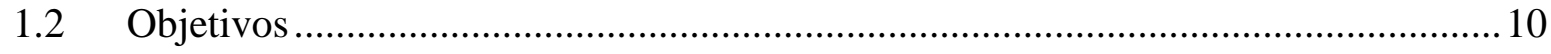

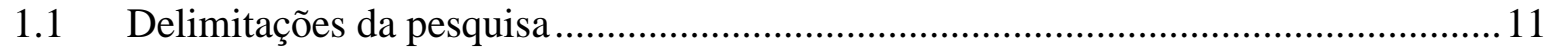

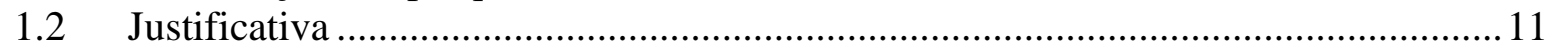

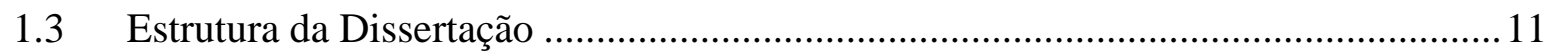

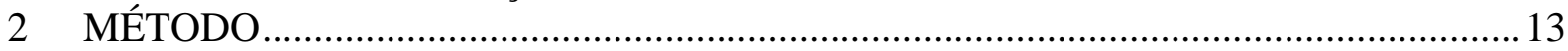

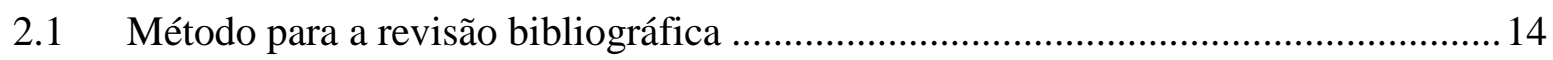

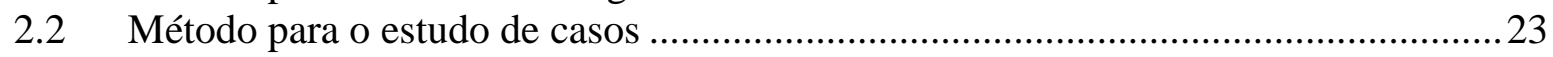

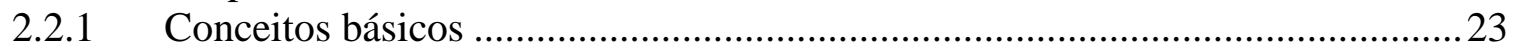

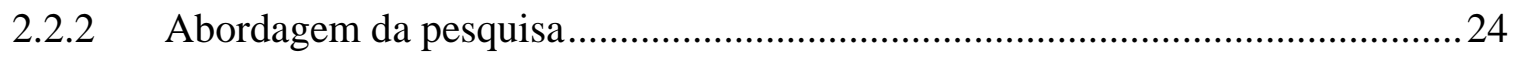

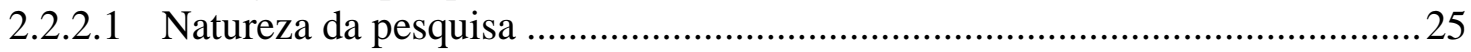

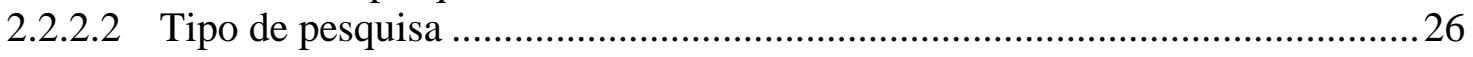

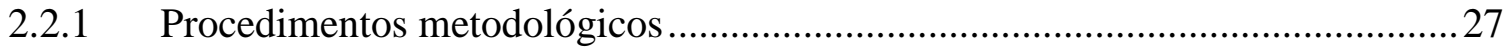

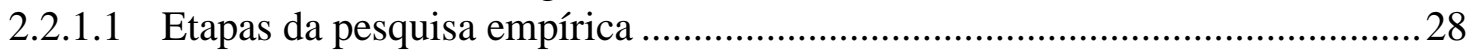

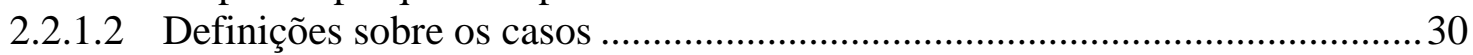

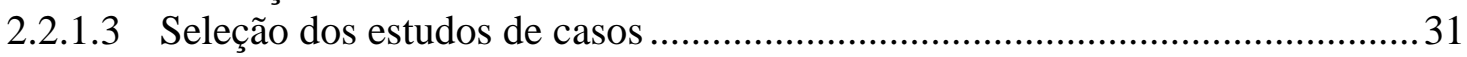

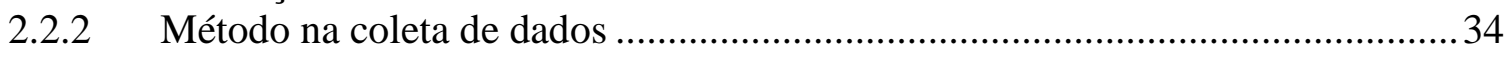

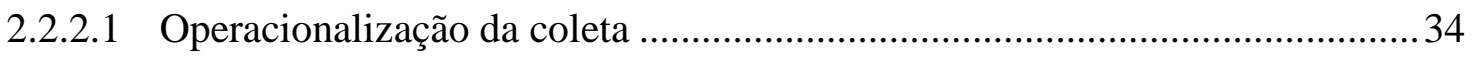

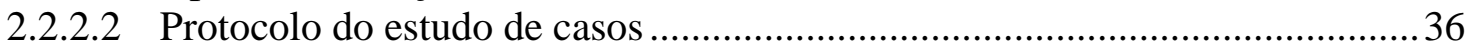

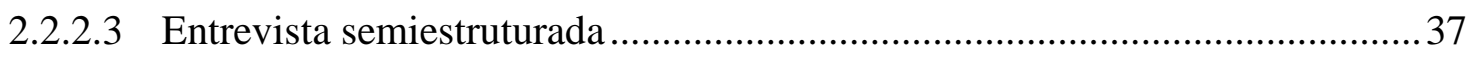

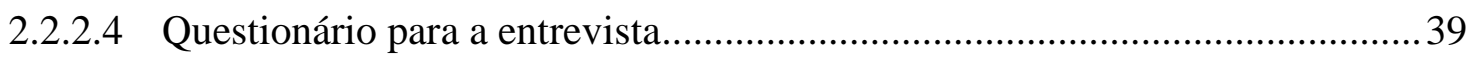

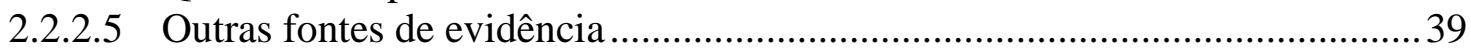

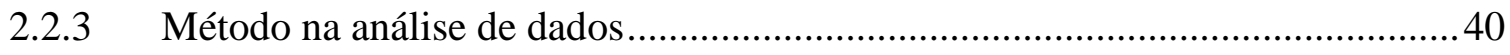

2.2.3.1 Análise dos dados nos estudos de casos múltiplos ......................................... 41

2.2.4 Qualidade da pesquisa com estudo de casos ..................................................... 41

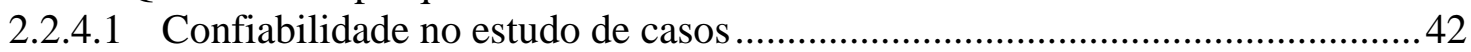

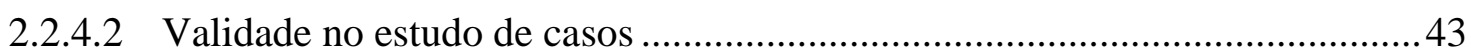

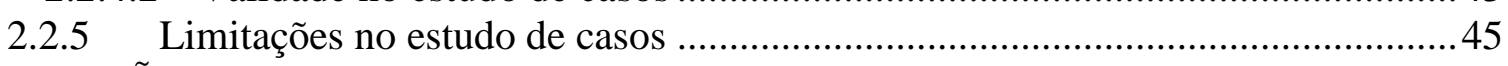

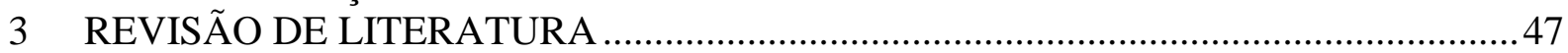

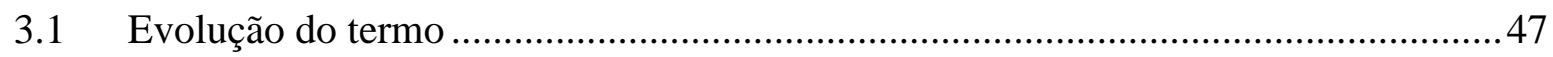

3.2 Abordagens e definição...................................................................................... 49

3.2.1 O modelo de negócios e sua relação com o conceito de valor ............................55

3.2.2 O modelo de negócios relacionado com as atividades ......................................61

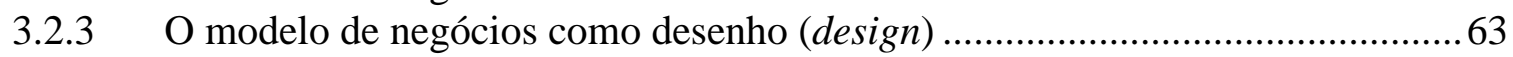

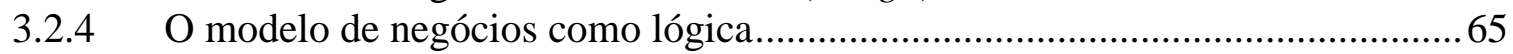

3.2.1 O modelo de negócios como narrativa .............................................................66

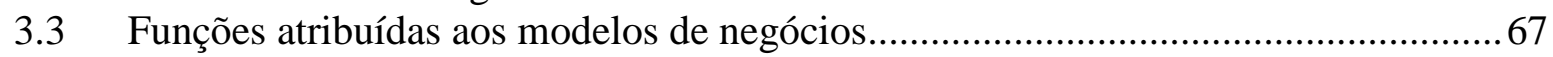

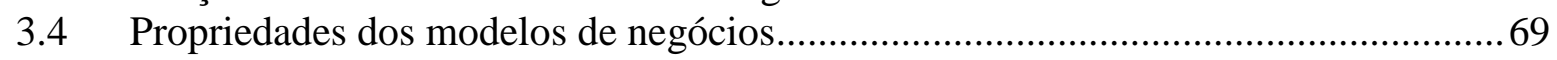

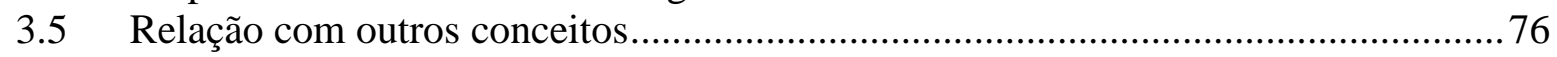

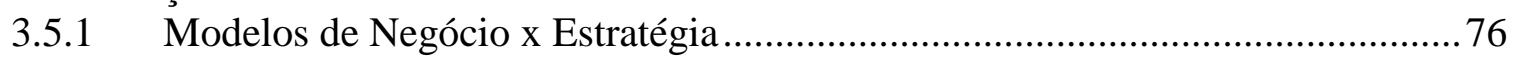

3.5.2 Modelos de Negócio x Modelo de Receita ou Lucro ......................................... 81

3.6 Conceitos de Modelo de Negócios em publicações em português .............................82 
3.7 Síntese conclusiva da revisão de literatura sobre modelo de negócios ..................... 90

3.8 Abordagem integrada do constructo de Modelo de Negócios ............................... 93

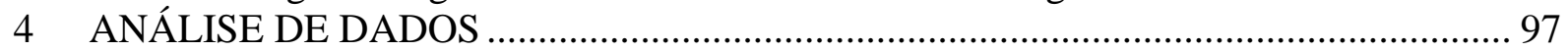

4.1 Apresentação da primeira empresa - Empresa " $\mathrm{X}$ "................................................... 97

4.2 Apresentação da segunda empresa - RTM ............................................................. 98

4.3 Apresentação da terceira empresa - INW Group ................................................. 99

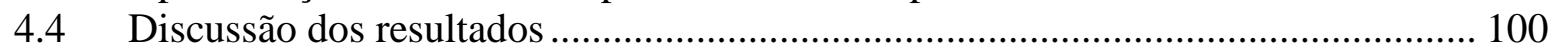

4.4.1 Discussão sobre a definiçãa e as funções dos modelos de negócios nas empresas

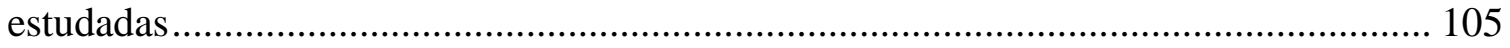

4.4.2 Discussão sobre os elementos dos modelos de negócios ................................ 109

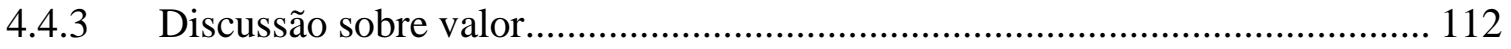

4.4.4 Discussão sobre a representação dos modelos de negócios nas empresas

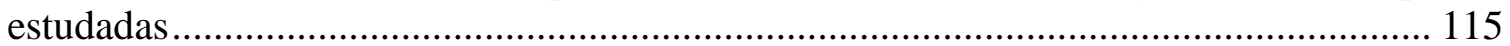

4.4.5 Discussão sobre a abordagem de narrativa nos modelos de negócios ............. 116

4.4.6 Discussão sobre as propriedades dos modelos de negócios.............................. 117

4.4.7 Discussão sobre a relação estratégia-modelo de negócios ................................. 121

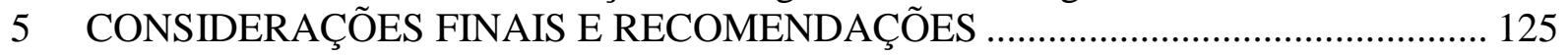

5.1 Considerações sobre a definição do modelo de negócios ...................................... 125

5.2 Considerações sobre a correspondência entre teoria e prática no assunto "modelo de

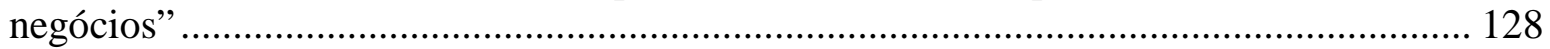

5.3 Considerações sobre elementos comuns na definição de "modelo de negócios"

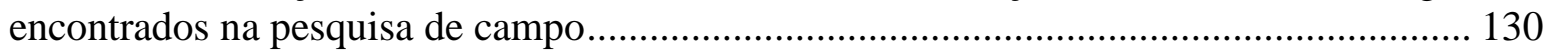

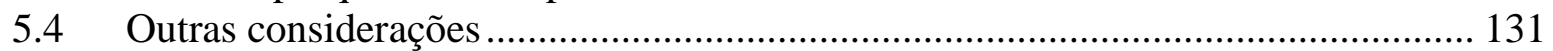

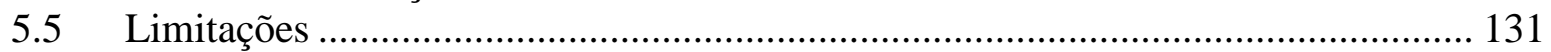

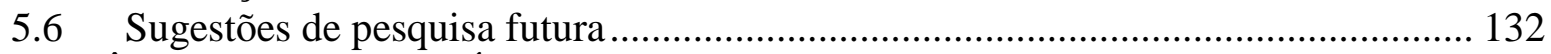

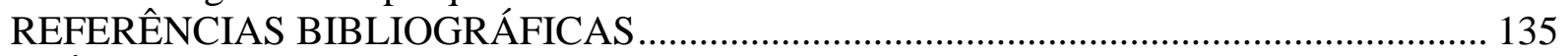

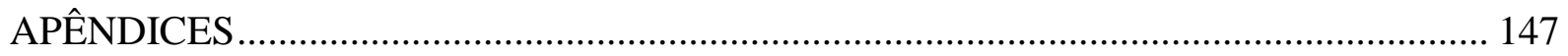

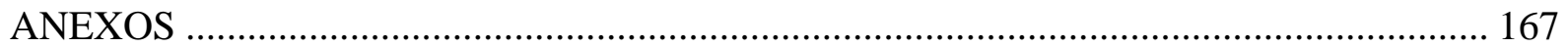




\section{LISTA DE ABREVIATURAS}

ABNT: Associação Brasileira de Normas Técnicas

ANBIMA: Associação Brasileira das Entidades dos Mercados Financeiros e de Capitais BM: Business model

CAPES: Coordenação de Aperfeiçoamento de Pessoal de Nível Superior

DOAJ: Directory of Open Access Journals

E1: Entrevistado 1

E2: Entrevistada 2

E3: Entrevistado 3

ERP: Enterprise Resource Planning

MN: Modelo de negócio

PMEs: Pequenas e médias empresas

P\&L: Profit and Loss

RBV: Resource Based View

TI: Tecnologias de Informação

VBR: Visão baseada em Recursos

WoS: Web of Science 


\section{LISTA DE QUADROS}

Quadro 1 - Situações relevantes em relação a diferentes métodos de pesquisa ...................... 25

Quadro 2 - Perfil dos indivíduos participantes na coleta de dados nas suas organizações no

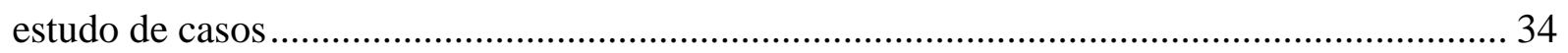

Quadro 3 - Dados das visitas e entrevistas realizadas na pesquisa de estudo de casos múltiplos 38

Quadro 4 - Critérios de qualidade em pesquisa de estudo de casos em relação às táticas usadas na pesquisa

Quadro 5 - Tensões paradoxais na pesquisa sobre modelo de negócios e características....... 51

Quadro 6 - Definições encontradas em publicações seletas nos resultados da revisão

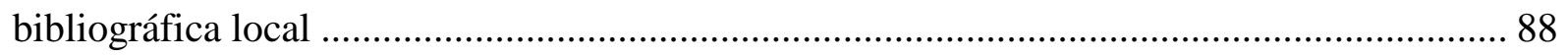

Quadro 7 - Síntese conclusiva da literatura revisada sobre modelo de negócios .................... 90

Quadro 8 - Síntese cruzada no estudo de casos múltiplos sobre modelo de negócios ........... 100 


\section{LISTA DE TABELAS}

Tabela 1 - Número de publicações resultantes da busca no portal CAPES, segundo variante e

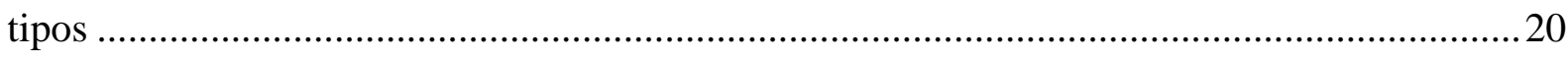

Tabela 2 - Número de publicações resultantes da busca no portal Google Acadêmico segundo variante 22

Tabela 3 - Número de publicações derivadas da busca sistemática consideradas para a pesquisa 23

Tabela 4 - Classificação das definições encontradas em publicações sobre modelos de negócios realizadas no Brasil 


\section{LISTA DE FIGURAS}

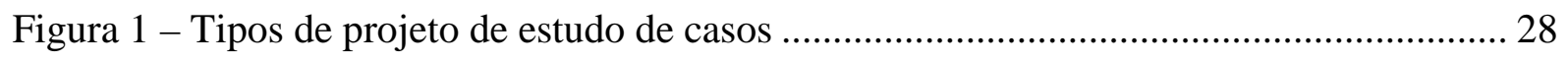

Figura 2 - Etapas da pesquisa empírica com estudo de casos ............................................. 29

Figura 3 - Posição na escolha de unidade de análise e de coleta de dados para os estudos de

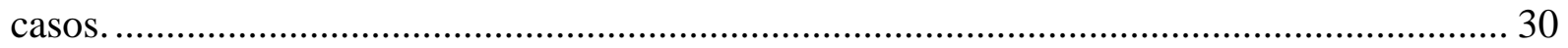

Figura 4 - Evolução do conceito modelo de negócios segundo alguns autores ...................... 48

Figura 5 - Representação gráfica do constructo e das proposições ........................................ 94 


\section{Modelo de Negócios. Teoria e prática: Um estudo em empresas de tecnologia}

\section{INTRODUÇÃO}

O termo modelo de negócios é frequentemente e amplamente utilizado, tanto no âmbito profissional quanto no acadêmico, podendo aparecer em reuniões de trabalho, matérias de jornais, livros, aulas em universidades, artigos acadêmicos, dissertações ou teses.

Seu uso se evidencia em publicações que vão, desde as mais relacionadas, como podem ser Estratégia ou Inovação, passando por áreas como Engenharia, Contabilidade Financeira (PAGE, 2014) ou Sustentabilidade Ambiental, e chegando até as áreas nas quais seu uso pode ser menos previsível, como as de Saúde (PARENTE, 2000) ou Legislação Criminal (SHELLEY, 2003).

As possibilidades atribuídas ao modelo de negócios em tais publicações são também muito diversas, podendo ele se "criar", "praticar", “exportar", "pensar", “adotar", “desenvolver", “evoluir", "replicar", “canibalizar" etc.

Uma busca geral, nas bases científicas mais conhecidas e utilizadas, gera dezenas de milhares de resultados, observando-se um crescimento e ganho de relevância, principalmente nos últimos anos. Precisamente ante este crescimento é que começaram a surgir diversas observações sobre a sua existência e essência.

Na sua extensiva revisão, Zott, Amit e Massa (2011, p. 1022) encontraram que, um pouco mais de um terço das publicações consultadas não tinham definido explicitamente o termo “modelo de negócios" (“business model”), dando-o por subentendido. Ghaziani e Ventresca (2005) evidenciaram que a concepção tácita representa uma porcentagem importante na conversa sobre o tema, advertindo uma natureza "tomada-por-dada" (taken-for-granted) no que respeita à definição do termo (Ibid., p. 544).

A divergência no entendimento do conceito do Modelo de Negócios aparece como outro problema e é apontado recorrentemente na literatura internacional (OSTERWALDER; 
PIGNEUR; TUCCI, 2005; ZOTT; AMIT; MASSA, 2011; AL-DEBEI; AVISON, 2010; GEORGE; BOCK, 2011; GHAZIANI; VENTRESCA, 2005; ALT; ZIMMERMANN, 2001).

Autores como Osterwalder, Pigneur e Tucci (2005) notaram essa mesma heterogeneidade, indicando que na literatura existente tal expressão é usada para aludir partes de um modelo de negócios, tipos de modelo de negócios, exemplos de modelos no mundo real ou conceitos. Klang, Wallnöfer e Hacklin (2014, p. 455) advertem sobre a confusão com termos como ideia de negócios ou plano de negócios. Dasilva e Trkman (2013, p. 6-7) acham similar o problema no caso da comparação com o termo: "conceito de negócios".

Zott, Amit e Massa (2011), listando algumas das publicações identificadas, que trabalharam com o termo "business model" na literatura internacional, mostram que ele é referido como descrição, representação, arquitetura, molde (template) estrutural, framework, padrão, conjunto, entre outros. Para George e Bock (2011, p. 84) a maioria dos estudos falham em distinguir o conceito de outros já existentes na literatura, por ele ter emergido originalmente como termo de conveniência na imprensa e comunidade praticante.

Alguns autores apontam à existência de um paradoxo em referência ao conceito (KLANG; WALLNOFER; HACKLIN, 2014), aludindo uma popularidade excepcional por um lado, mas defrontando algumas críticas ou relutância (BADEN-FULLER; MORGAN, 2010, p. 156) por outro. Para Teece (2010, p. 192) o termo é frequentemente mencionado, mas pouco analisado.

Por um momento, alguns autores (PORTER, 2001; SEDDON ET AL.; 2004) questionaram se o termo poderia ser merecedor de uma participação na conversa acadêmica como constructo válido. Outros tantos chamaram a atenção à necessidade de trabalhar no estudo e na discussão do significado dele, na procura de maior clareza (KLANG; WALLNOFER; HACKLIN, 2014). E, por outro lado, alguns autores dedicaram sua pesquisa ao estudo específico de seu conceito.

Aqueles que alguma vez criticaram o seu uso, mencionaram que a sua existência simplesmente pode ser uma movimentação terminológica "inócua" (PORTER, op. cit., p. 73) e que seu uso poderia conduzir a um pensamento estratégico errôneo. Para Seddon et al. (2004, p. 439) as definições de "business model” são confusas e dificilmente podem-se distinguir na sobreposição com o conceito de estratégia, salvo em condições específicas. 
Arend (2013) indica que a sua utilização pode ser redundante sob algum dos enfoques específicos também.

O exame dos documentos resultantes de uma pesquisa bibliográfica própria, demonstra que o termo modelo de negócios é utilizado como substituto, sinônimo ou metáfora de estratégia, lógica dominante ou modelo de receita, entre outros. De forma similar, pode-se verificar que o termo é utilizado para fazer referência a unidades de análise tão diferentes como os indivíduos (SVEJENOVA; PLANELLAS; VIVES, 2010), empresas, indústrias (FOX, 2004; TEECE, 2010, p. 177-178), cidades (KUK; JANSSEN, 2011), ou até países (CAPPELLI, 2009).

Alguns dos defensores e estudiosos do conceito (ZOTT; AMIT, 2013; BADEN-FULLER; MORGAN, 2010; BADEN-FULLER; MANGEMATIN, 2013) postulam que os avanços teóricos e empíricos atingidos nos últimos anos, legitimam o seu uso e a sua utilidade, estimulando o seu estudo futuro, contrariamente às proposições citadas anteriormente.

Para autores como Osterwalder, Pigneur e Tucci (2005, p. 4), o conceito é candidato a substituir a indústria como unidade de análise. Zott, Amit e Massa (2011) também identificaram esta emergência do conceito como nova unidade de análise na sua revisão de literatura.

Na sua pesquisa de há alguns anos, Zott, Amit e Massa $(2010,2011)$ argumentaram que a falta de consenso na definição é um estágio que caracteriza a qualquer novo conceito emergente. Makinen e Seppanen (2007, p. 744) partilham da mesma ideia. O transcorrer dos anos levanta questões sobre o sentido no qual podem ter avançado ou não tais interesses científicos e discussões.

Não ter clareza sobre a definição de um termo tão utilizado e não possuir relativo consenso sobre alguns dos seus aspectos mais básicos, supõe uma dificuldade para avançar em uma linha de pesquisa com bases sólidas e reconhecidas. Portanto, trabalhos que incrementem os conhecimentos existentes podem significar valiosa contribuição.

Com esta pesquisa busca-se entender de forma mais clara qual é a conceitualização de modelos de negócios, e será realizada uma revisão da literatura mais relevante, que possa se aproximar do Estado da Arte sobre o tema e conduzido um estudo de casos. Alguns dos 
estudos que pesquisaram o tema a nível internacional, previamente abordaram esta preocupação científica, estudando em campo a conceitualização de grupos importantes ligados ao término. Pontualmente, George e Bock (2011) estudaram um grupo de gerentes britânicos e indianos no Reino Unido, objetivando realizar uma ponte entre a teoria existente sobre o conceito e o fenômeno na prática. Decidiu-se seguir essa linha condutora.

Foi proposto pesquisar a literatura mais relevante e recente sobre modelo de negócios, identificando as principais abordagens e linhas teóricas existentes, para posteriormente realizar os estudos de casos, mediante entrevistas semiestruturadas e utilizar a técnica mais adequada de análise no método estudo de casos.

\subsection{Problema de pesquisa}

A literatura sobre modelo de negócios apresenta diversas abordagens, em termos de definições, componentes, funções e propriedades. Do mesmo modo, os executivos de organizações devem ter diferentes entendimentos e prática de modelo de negócios. Entendese, portanto, ser importante trabalhar questões acerca dessas duas dimensões, ou seja, literatura sobre o conceito e prática do conceito, para identificar o quanto convergem ou se afastam uma da outra.

Tratar a problemática apresentada implica trabalhar com dois aspectos: realizar uma busca sistemática da bibliografia sobre o tema, e elaborar o constructo necessário à pesquisa empírica; posteriormente, realizar a pesquisa de campo mediante o uso de um método que possibilite identificar convergências e divergências entre o constructo proposto e a prática das empresas estudadas.

\subsection{Objetivos}

O objetivo geral da pesquisa é entender de modo consistente os conceitos e os conteúdos do modelo de negócios, tanto ao nível da literatura disponível, quanto ao nível de casos 
específicos de empresas, estudando as divergências e convergências citadas na colocação do problema.

Os objetivos específicos são os seguintes:

Obter um constructo de modelo de negócios mediante uma busca sistemática na literatura existente.

- $\quad$ Identificar principais divergências e convergências entre o constructo e os resultados empíricos obtidos.

\subsection{Delimitações da pesquisa}

A escolha de bases reconhecidas se limitou a duas bases científicas de avaliação por pares (WoS e Scopus), uma base de conhecimento mista (CAPES) e uma base de conhecimento pública (Google Acadêmico); bases que têm ligação com a área da pesquisa, a saber: a de Administração.

Na parte empírica, o estudo de casos se realizou em empresas da região de São Paulo, do setor privado e da área de tecnologia. Assim mesmo, a coleta se orientou especificamente a pessoas do nível executivo das respectivas organizações.

\subsection{Justificativa}

Uma revisão sistemática da literatura sobre o tema com a definição de um constructo, e uma pesquisa de campo, podem ser úteis em termos de uma aproximação do Estado da Arte sobre o assunto e de uma exploração inicial, o que possibilitaria estudos mais avançados sobre o tema.

\subsection{Estrutura da Dissertação}


Após este capítulo introdutório, apresenta-se o capítulo sobre o método, que inclui o processo seguido para a busca da bibliografia e o processo empregado nos estudos de casos. Segue o capítulo que apresenta o resultado da revisão bibliográfica sobre o tema e a elaboração do constructo, os quais constituem a fundamentação teórica da pesquisa. O quarto capítulo está dedicado a apresentar, analisar e discutir os resultados obtidos nos estudos de casos. Por fim, a quinta parte apresenta as considerações finais, limitações e sugestões de pesquisa futura. 


\section{MÉTODO}

Como Martins (2002, p. 19) assinala, se espera que um trabalho de dissertação demonstre sólidos conhecimentos sobre uma área de estudos específica. Perante esse objetivo, para a presente pesquisa estabeleceram-se como fundamentos metodológicos a realização de uma busca sistemática de bibliografia sobre o tema e uma posterior aplicação do método de estudo de casos para a verificação empírica em campo. Na segunda etapa, utilizam-se técnicas para a coleta de dados, como as entrevistas semiestruturadas, e a síntese cruzada de casos para a sua análise específica, na busca de respostas às questões propostas nessa pesquisa.

A primeira ação tem uma dupla função. A primeira é providenciar uma base teórica sólida para abordar o tema, utilizando a publicação de maior relevância e qualidade, segundo alguns critérios referenciais. A segunda é fornecer insumos para a análise posterior. Flick (2009, p. 49) considera que na pesquisa qualitativa, a revisão da literatura existente sobre um tema providencia insights e informação que podem ser usados como conhecimento de contexto.

Já no caso da segunda decisão, o objetivo é a aplicação de uma estratégia metodológica como é o estudo de casos, tendo trabalhado no seu desenho e na aplicação dos seus instrumentos de coleta e técnicas de análise, na espera de demonstrar destreza na parte empírica de uma pesquisa.

Por fim, com a aplicação das técnicas específicas de análise, espera-se contribuir à resposta da pergunta da pesquisa acerca da convergência-divergência entre teoria e prática, demonstrando, tanto adequabilidade na seleção de um método de análise quanto, capacidade analítica para a obtenção de conhecimento.

Flick (2009, p. 216, tradução nossa) apregoa que na pesquisa qualitativa: “Os métodos devem ser selecionados e avaliados segundo sua propriedade com o sujeito sob estudo."1

A pesquisa utiliza um enfoque misto pois, na revisão de literatura e seleção de obras, utilizaram-se tanto critérios quantitativos, como é o número de citações, quanto critérios

\footnotetext{
1 "methods should be selected and evaluated according to their appropriateness to the subject under study."
} 
qualitativos, como são os conteúdos ou a relevância. No método de estudo de casos se segue uma tradição qualitativa predominantemente. Nas partes de coleta de dados e análise de dados, utiliza-se uma abordagem qualitativa nessa aproximação à "realidade/verdade" ansiada da qual fala Martins (2002, p. 13).

Flick (2009, p. 24) inclui os desenhos de pesquisa que combinam ou integram o uso de dados e/ou métodos qualitativos e quantitativos como um dos níveis de relação entre ambos os tipos de pesquisa. O autor (Ibid., p. 33) providencia algumas questões-guia; relacionadas com a equiponderância das abordagens, a integração na sua aplicação, a sua lógica relacional, e os seus critérios de avaliação; úteis para um desenvolvimento do desenho da pesquisa em forma reflexiva.

Martins e Theóphilo (2007, p. 135) discorrem sobre a coexistência de abordagens indicando que: "O fato de apresentarem características avaliativas distintas não impede que pesquisas científicas adotem avaliações quantitativas e qualitativas. É descabido o entendimento de que possa haver pesquisa exclusivamente qualitativa ou quantitativa.".

Do ponto de vista do alcance da pesquisa, o presente trabalho científico se posiciona como uma pesquisa de caráter exploratório segundo a classificação de Sampieri, Collado e Lucio (2010, p. 78-80).

A seguir, apresenta-se o detalhe do desenho metodológico, no que concerne aos componentes sobre os quais se construiu a pesquisa: a revisão bibliográfica, o estudo de casos múltiplos e a análise de dados.

\subsection{Método para a revisão bibliográfica}

Como Creswell (2009, p. 25-29) mostra, a revisão da literatura cumpre vários propósitos na pesquisa acadêmica. Um deles é relacionar um estudo com o diálogo vigente e extenso sobre o tema na literatura (Ibid., p. 25). 
Embora não exista uma única forma de realizar uma revisão de literatura (CRESWELL, 2009, p. 29) alguns passos como a identificação e uso de palavras-chave (Ibid., p.29), a busca em bases computadorizadas (Ibid., p. 30-32) e a criação de um mapa de literatura (Ibid., p. 33-36) resultam de utilidade para sistematizar esta busca.

As palavras-chave consideradas para este estudo foram "business model" nas buscas no idioma inglês e "modelo de negócio" com suas variantes: "modelo de negócios" e "modelos de negócios" nas buscas no idioma português.

Buscas foram realizadas procurando tanto as publicações que contivessem a palavra-chave literalmente na sua integridade, quanto as combinações das palavras "modelo" e "negócio", e suas variantes usando caracteres base, em um mesmo resultado.

No caso das bases de propriedade internacional, a escolha das bases computadorizadas foi realizada sob os critérios seguintes:

- $\quad$ Ter grande abrangência no número de journals cobertos;

- $\quad$ Ser conhecida pela qualidade das publicações indexadas nas suas bases;

- Considerar como desejável um maior nexo com a área desta pesquisa que é a Administração.

Vieira e Wainer (2013, p. 46) assinalam que os três serviços mais conhecidos na contagem de citações são: Web of Science (WoS), Scopus e Scholar Google. Eles (VIEIRA E WAINER, 2013, p. 48) fazem referência ao fato da sobreposição de citações entre WoS e Scopus é relativamente pequena e que o número de citações encontradas exclusivamente no Scopus é relativamente alto.

Os mesmos autores (VIEIRA; WAINER, 2013, p. 48-49) destacam que pesquisas relacionadas encontraram que existe maior diferença entre os resultados obtidos mediante o Scholar Google e os outros dois serviços.

Assim mesmo é notável que (VIEIRA; WAINER, 2013, p. 50) o número de publicações encontradas mediante o Scholar Google é múltiplas vezes maior que os resultados encontrados na WoS. 
Vieira e Warner (2013), na sua pesquisa sobre produção científica brasileira, observaram que na área de administração existe correlação significativa entre as citações dos três serviços, sugerindo que poderia se intercambiar entre eles.

Uma busca inicial na base da Web of Science (THOMSON REUTERS, 2014) com a palavra "business" produziu um total de 327.346 resultados. Incluindo uma refinação com a segunda palavra chave "model*" em uma forma que incluísse diferentes variantes como "model", "models", "modeling" etc., reduziu o número inicial a 73.807 resultados. Os domínios aparecidos incluem "Science Technology", "Social Sciences" e "Arts Humanities" com mais de 100 subáreas.

Utilizou-se uma delimitação por subárea, considerando áreas afins à área de administração: "Business Economics", "Engineering”, "Operations Research Management Science", "Social Sciences Other Topics", "Public Administration", e "Science Technology Other Topics" os resultados se reduzem a um total de 40.385. Fazendo um filtro segundo tipo de documento de forma a incluir apenas documentos do tipo "article", "meeting", "review", "editorial", "book", "news", e "other" deixando de fora opções como "patent" ou "letter", por exemplo, produziu 40.326 publicações. São 26 os idiomas reportados dentro desses resultados. A delimitação a documentos somente nos idiomas inglês e português produziu como resultado 39.488 publicações.

Num segundo teste de busca na WoS, utilizando a expressão conjunta "business model*", novamente com o intuito de obter resultados correspondentes a "business model", "business models", "business modelizing" e afins. Nessa oportunidade foram 9.839 os resultados encontrados. Preferimos não aplicar os mesmos filtros que na primeira busca para explorar e obter insights com todos os resultados presentes.

Um terceiro teste foi realizado utilizando a expressão conjunta "business model*" restringida ao título da publicação. Nesse caso 2.418 documentos surgiram.

O mesmo exercício realizado na segunda base considerada, Scopus (ELSEVIER, 2014), produziu os seguintes resultados: 
A busca geral com a palavra "business" produziu um total de 842.277 resultados. Incluindo uma refinação com a segunda palavra chave "model*" numa forma que adicionasse diferentes variantes como "model”, “models", “modeling”, etc. reduziu o número inicial a 379.288 resultados. Nesse caso, 28 subáreas apareceram. Novamente se realizou uma busca com filtro focado nas áreas afins à área de administração. "Engineering", "Social Sciences", "Business, Management and Accounting", "Economics, Econometrics and Finance", "Decision Sciences", e "Multidisciplinary" foram selecionadas. 172.904 publicações foram as resultantes.

De forma similar ao anterior exercício com a plataforma Google, a busca de um segundo tipo de documento, considerando somente os tipos "article", "conference paper", "review", "book chapter", "article in press", "book", "editorial", e "business article", atingiu 171.030 documentos resultantes. Dentro desse grupo, 35 idiomas são listados. Para fins comparativos, aplicou-se a mesma delimitação a documentos apenas nos idiomas inglês e português, produzindo-se 167.386 resultados.

O segundo teste utilizando a expressão conjunta "business model*" nessa base, produziu 13.914 resultados. Novamente, preferiu-se não aplicar nenhum dos filtros usados na primeira busca para explorar e obter insights com todos os resultados existentes.

Uma necessária delimitação para a literatura internacional aos 100 documentos mais citados em cada base, permitiu identificar 128 documentos únicos entre os conjuntos de resultados obtidos em cada base, dando um indício de muita convergência nos principais resultados.

Para cada grupo de resultados se decidiu considerar as primeiras 2000 publicações segundo número de citações para sua análise.

Como Vilhena e Crestana (2002, p. 20) afirmam: "Não há como medir quanto um artigo foi utilizado pelos profissionais, mas pode-se medir seu efeito para outros pesquisadores e autores, examinando com que frequência e onde foram citados em outros artigos.”.

Silva e Bianchi (2001, p. 8), por sua vez, sugerem que "O número de citações recebidas por um artigo é um indicador da influência ou impacto que o seu conteúdo produziu na comunidade científica da área.”. 
Uma revisão dos títulos e "abstracts" dos 100 documentos mais citados em cada base, permitiu depurar os resultados com a intenção de ficar especificamente com publicações que pudessem ajudar a responder as questões da presente pesquisa. Por isto, foram consideradas as publicações que:

- Apresentam uma definição do conceito "business model" ou sugerem a sua conceitualização do termo de forma identificável;

- Pelo menos desenvolvam, discutam, discorram algo sobre o conceito ou o utilizem, além de só aparecer como uma frase isolada;

- Deu-se especial atenção às publicações ligadas à área de Estratégia.

Assim mesmo, é necessário explicitar que foram excluídas publicações por:

- $\quad$ Pertencer à área de modelização de negócios em Computação;

- $\quad$ O termo "business model" não ser um elemento principal na publicação;

- O foco central da pesquisa é claramente outro e o uso do termo o conceito "Business model" é mínimo ou notoriamente esporádico;

- A utilização do termo é ambígua podendo significar diferentes coisas (Atividades, Receita, Processo, etc.) pelo que não aportaria ao propósito desta pesquisa;

- $\quad$ Livros, com uma exceção apenas pelo relativamente importante número de citações: Business Model Generation: A handbook for visionaries, game changers, and challengers de Osterwalder e Pigneur, 2010.

Está avaliação prévia, permitiu ficar com $\mathbf{2 4}$ publicações especificamente ligadas à temática de interesse da presente pesquisa.

Com o propósito de não deixar fora alguma outra publicação relevante para a realização desta pesquisa, examinaram-se os títulos dos 1900 resultados seguintes nas duas bases, consultando ante a dúvida adicionalmente o "abstract". Esta etapa produziu 25 documentos adicionais (17 na Web of Science e 8 em Scopus) considerados de ajuda para resolver as tarefas propostas.

Considera-se que esse número possivelmente é uma boa estimativa (captura de alguma forma) do "Estado da Arte" a nível internacional da pesquisa sobre a concepção do termo. 
Para explorar possíveis publicações relevantes por fora das duas bases estudadas, também se aplicou uma busca na base do Google Acadêmico (GOOGLE, 2014). Dadas as funcionalidades da plataforma, realizamos buscas separadas dos termos "Business model" e "Business models" como variantes. Assim mesmo, dada a possibilidade foi aplicado um filtro a resultados apenas no idioma inglês nessa parte da pesquisa.

A primeira exploração, com o termo "Business model", produziu um aproximado de 391.000 resultados. Uma revisão dos 100 primeiros resultados segundo a opção "Relevância" da mesma plataforma Google, produziu 17 documentos adicionais as dos das outras bases.

Por precaução, para não deixar fora algum outro documento importante, foram sondados os 100 resultados seguintes, resultando em apenas 3 documentos que poderiam ser considerados relevantes e essa tendência parecia prosseguir.

Devido a que algumas recentes publicações poderiam trazer luz à pesquisa, mas não estar figurando porque ainda não obtiveram um número maior de citações ${ }^{2}$, decidiu-se realizar uma exploração nas publicações mais novas sobre o tema.

Uma busca com as mesmas características prévias, mas delimitada ao último ano significou 580 resultados na base WoS e 1468 na base Scopus. A depuração dos títulos repetidos permitiu identificar 1.665 documentos únicos entre as duas bases. Cabe destacar que dentre este grande número, apenas 188 têm pelo menos uma citação e só 49 mais de uma citação nas suas bases, pelo que esse passo parece importante para explorar algo do conhecimento atual sobre o tema pesquisado.

Uma posterior revisão permitiu ficar com 7 publicações adicionais às já encontradas para serem analisadas e incluídas dentro da pesquisa por sua potencial contribuição para resolver as questões planteadas.

No caso da base administrada localmente, escolheu-se o Portal de Periódicos da Coordenação de Aperfeiçoamento de Pessoal de Nível Superior (CAPES, 2014b), por ser um instrumento especializado com uma relativamente longa antiguidade, sendo reconhecido por sua

\footnotetext{
${ }^{2}$ O ponto de corte dos artigos revisados foi de um mínimo de 2 citações no artigo No. 2000 da WoS e 6 citações no artigo No. 2000 da base Scopus.
} 
importante cobertura da produção científica brasileira. Os dados disponibilizados pela CAPES (CAPES, 2014a) indicam que o acervo do portal inclui 130 bases referenciais e 37.073 periódicos com texto completo.

A busca sem filtro do termo modelo de negócio produziu 4.502 resultados na mencionada plataforma. A busca sem filtro do termo modelos de negócio produziu 2800 resultados. A busca sem filtro do termo modelos de negócios produziu 3.230 resultados. Por fim, a busca do termo modelo de negócios produziu 5.368 resultados.

Um exame rápido de tais resultados, detectou a presença de muitos artigos pouco relacionados com o tema de interesse dessa pesquisa, pelo que se decidiu o seguinte nível de especificação.

Uma busca literal usando a funcionalidade de busca avançada na plataforma, com a opção é exato, foi realizada. Um detalhe dos resultados obtidos na busca literal de 4 variantes relativas ao termo modelo de negócio pode ser observada na Tabela 1.

Tabela 1 - Número de publicações resultantes da busca no portal CAPES, segundo variante e tipos

\begin{tabular}{|c|c|c|c|c|}
\hline Termos & $\begin{array}{ll}\text { "modelo } & \mathrm{de} \\
\text { negócio" } & \end{array}$ & $\begin{array}{ll}\text { "modelo } & \mathrm{de} \\
\text { negócios" } & \end{array}$ & $\begin{array}{ll}\text { "modelos } & \mathrm{de} \\
\text { negócio" } & \end{array}$ & $\begin{array}{ll}\text { "modelos } & \mathrm{de} \\
\text { negócios" } & \end{array}$ \\
\hline Resultados & 207 & 83 & 149 & 76 \\
\hline $\begin{array}{l}\text { Resultados } \\
\text { expandidos }\end{array}$ & 481 & 172 & 345 & 146 \\
\hline Revisados por pares & 32 & 7 & 21 & 6 \\
\hline $\begin{array}{l}\text { Revisados por pares } \\
\text { expandido }\end{array}$ & 38 & 9 & 22 & 11 \\
\hline $\begin{array}{l}\text { Data: } \\
\text { Antes } 2003 \\
2003-2004 \\
2005-2006 \\
2007-2009 \\
\text { Após } 2009 \\
\end{array}$ & $\begin{array}{c}9 \\
19 \\
38 \\
126 \\
291 \\
\end{array}$ & $\begin{array}{c}2 \\
2 \\
21 \\
57 \\
90\end{array}$ & $\begin{array}{c}4 \\
17 \\
23 \\
88 \\
213\end{array}$ & $\begin{array}{c}6 \\
3 \\
14 \\
53 \\
74 \\
\end{array}$ \\
\hline $\begin{array}{l}\text { Tipo: } \\
\text { Artigos } \\
\text { Dissertations } \\
\text { Livros } \\
\text { Artigos de Jornal } \\
\text { Atas de Congressos }\end{array}$ & $\begin{array}{c}309 \\
37 \\
13 \\
18 \\
15 \\
\end{array}$ & $\begin{array}{c}83 \\
32 \\
12 \\
32 \\
4 \\
\end{array}$ & $\begin{array}{c}236 \\
22 \\
5 \\
7 \\
21 \\
\end{array}$ & $\begin{array}{c}73 \\
37 \\
12 \\
11 \\
8 \\
\end{array}$ \\
\hline $\begin{array}{l}\text { Idioma: } \\
\text { Português } \\
\text { Inglês } \\
\text { Espanhol } \\
\text { Indeterminado } \\
\text { Alemão }\end{array}$ & $\begin{array}{c}144 \\
100 \\
133 \\
24 \\
0 \\
\end{array}$ & $\begin{array}{c}88 \\
30 \\
21 \\
2 \\
0\end{array}$ & $\begin{array}{c}94 \\
58 \\
118 \\
17 \\
2\end{array}$ & $\begin{array}{c}66 \\
28 \\
17 \\
7 \\
1\end{array}$ \\
\hline
\end{tabular}

Nota: Se observa que os resultados agregados em muitos casos não coincidem com a soma dos parciais, sendo só o reflexo dos resultados aparecidos no motor de busca. 
Nesse caso, por ser um número de resultados mais manejável do que no caso das outras bases internacionais usadas previamente, decidiu-se não aplicar nenhum filtro ou depuração apesar do serviço permitir realizar filtros segundo revisão por pares, data ou idioma, entre outros. Realizou-se uma revisão dos títulos, resumos e, no caso de dúvida, conteúdo, do agregado de 1.144 resultados obtidos.

Novamente, estabeleceram-se critérios para a consideração ou não de um documento na presente pesquisa. Por isto, foram consideradas publicações sob os seguintes critérios:

- Dado que se pretendeu explorar a pesquisa brasileira e uma delimitação foi necessária, focamos em documentos redigidos em português e em documentos em outros idiomas, mas com alguma ligação com a pesquisa brasileira, seja pela autoria, revista, vinculação académica, ou outros parecidos;

- $\quad$ Pelo menos apresentam uma breve definição do conceito "business model" (própria ou adotada), ou sugerem sua conceptualização do termo.

Assim mesmo, se deve aclarar que foram excluídas as seguintes publicações:

- $\quad$ Publicações da área de Ciências da Computação;

- $\quad$ Teses e Dissertações. Dentro delas, somente um caso (RAUSCH, 2012) abordava significativamente na pesquisa do conceito;

- Livros ou capítulos. Nenhum dos resultados registrados abordava significativamente no conceito, salvo uma exceção considerada pelo grande número de citações (Business Model Generation: Inovação em Modelos de Negócios de Osterwalder e Pigneur, 2011);

- Publicações nas quais a utilização do termo ou conceito modelo de negócio foi claramente noutro sentido ao da área da presente pesquisa.

Este estágio permitiu identificar inicialmente $20(10+5+2+3)$ publicações para uma revisão mais aprofundada. Depois da mesma, decidiu-se incluir 9 publicações na pesquisa.

$\mathrm{Na}$ exploração geral dos resultados das buscas, pode-se constatar que muitos dos resultados se repetiram por aparecer como indexados na revista publicada e em plataformas como Directory of Open Access Journals (DOAJ), Fundación Dialnet ou mais de uma vez na mesma plataforma. 
Outro achado foi que se utiliza muito em títulos de dissertações e teses internacionais (Portugal, Espanha, Latino América). Assim mesmo, observa-se um uso massivo e comum nos artigos de jornal (quase $25 \%$ dos últimos resultados em cada variante).

Por fim, aparentemente a publicação em espanhol sobre o tema parece superar amplamente a pesquisa existente em idioma português.

Para constatar que publicações não estejam se perdendo da exploração, também se realizou uma busca no portal da CAPES utilizando o termo "business model" e filtrando por idioma ao português e se observou que os mesmos resultados surgidos nas anteriores buscas apareciam novamente.

Com fins exploratórios da produção literária sobre a temática no idioma português, também se realizaram buscas nas bases da plataforma Google Acadêmico (GOOGLE, 2014) e na base de difusão científica SciELO (SCIELO, 2014), as quais permitem um filtro segundo este idioma.

Uma busca das 4 variantes: "modelo de negócio", "modelo de negócios", "modelos de negócio" e "modelos de negócios"; na plataforma do Google Acadêmico, utilizando o filtro de publicações no idioma português, produziu os seguintes resultados (Tabela 2):

Tabela 2 - Número de publicações resultantes da busca no portal Google Acadêmico segundo variante

\begin{tabular}{|l|l|l|l|l|}
\hline Termos & $\begin{array}{l}\text { "modelo } \\
\text { negócio" }\end{array}$ & $\begin{array}{l}\text { "modelo } \\
\text { negócios" }\end{array}$ & $\begin{array}{l}\text { "modelos } \\
\text { negócio" }\end{array}$ & $\begin{array}{l}\text { "modelos } \\
\text { negócios" }\end{array}$ \\
\hline Resultados & $\begin{array}{c}\text { Aproximadamente } \\
7.870\end{array}$ & $\begin{array}{c}\text { Aproximadamente } \\
\text { Aproximadamente }\end{array}$ & $\begin{array}{c}\text { Aproximadamente } \\
5.510\end{array}$ & 4.720 \\
\hline
\end{tabular}

Uma sondagem nos primeiros 200 resultados ordenados por relevância para cada busca sugeriu revisar 35 publicações adicionais $(10+11+8+6)$ às das outras bases previas, decidindose posteriormente ficar com $10(5+2+2+1)$ para seu estudo.

Uma rápida revisão dos resultados obtidos na base SciELO sugeriu que não existiriam maiores diferenças com os resultados já encontrados, pelo que decidiu se circunscrever aos resultados da plataforma do Google Acadêmico, neste caso. 
De forma geral, observaram-se muitos resultados ligados ás áreas temáticas de Software, Engenharia e ERP. Também se encontram outros tantos ligados ao tema Televisão Digital. Como comentário se deve mencionar similar associação aparente com o tema "Airlines" na literatura internacional.

A Tabela 3 resume os achados em todas as bases científicas para sua inclusão no estudo, segundo os critérios estabelecidos.

Tabela 3 - Número de publicações derivadas da busca sistemática consideradas para a pesquisa

\begin{tabular}{|l|c|}
\hline \multicolumn{1}{|c|}{ Descrição } & $\begin{array}{c}\text { No. de publicações } \\
\text { escolhidas }\end{array}$ \\
\hline $\begin{array}{l}\text { Publicações indexadas entre as 100 primeiras publicações mais citadas em cada } \\
\text { base (Web of Science e Scopus) }\end{array}$ & 24 \\
\hline $\begin{array}{l}\text { Publicações indexadas entre as } 101^{\circ} \text { e } 2000^{\circ} \text { publicações mais citadas em cada } \\
\text { base (Web of Science e Scopus) }\end{array}$ & 25 \\
\hline $\begin{array}{l}\text { Publicações indexadas nos 100 primeiros documentos mais relevantes segundo } \\
\text { Google Acadêmico (inclui 1 livro) }\end{array}$ & 3 \\
\hline $\begin{array}{l}\text { Publicações indexadas nos 101 }{ }^{\circ} \text { a 200 }{ }^{\circ} \text { documentos mais relevantes segundo } \\
\text { Google Acadêmico }\end{array}$ & 7 \\
\hline Publicações realizadas no último ano (outubro 2013 - outubro 2014) & $\mathbf{7 6}$ \\
\hline TOTAL (Internacional / Inglês) & 9 \\
\hline Publicações em português indexadas na CAPES & 10 \\
\hline Publicações em português registradas no Google Acadêmico & $\mathbf{2 0}$ \\
\hline Livro registrado no Google Acadêmico (publicação mais citada) & \\
\hline TOTAL (Local / Português) & \\
\hline
\end{tabular}

Uma revisão em profundidade (i.e. leitura e análise) das publicações selecionadas permitiu o desenvolvimento do capítulo teórico da presente dissertação (Capítulo 3).

\subsection{Método para o estudo de casos}

Uma descrição e breve discussão dos principais aspectos desta etapa constituinte da pesquisa são apresentadas a continuação.

\subsubsection{Conceitos básicos}

O método de pesquisa denominado Estudo de Caso pode ser definido segundo palavras de Yin (2015, p. 17) como um estudo empírico “[...] que investiga um fenômeno contemporâneo (o 'caso') em profundidade e em seu contexto de mundo real, especialmente quando os limites 
entre o fenômeno e o contexto puderem não ser claramente evidentes.”. O mesmo autor (YIN, 2015, p. 18) destaca como características relevantes do método que:

a investigação enfrenta a situação tecnicamente diferenciada em que existem mais variáveis do que pontos de dados;

- $\quad$ Conta-se com múltiplas fontes de evidencia;

- Beneficia-se do desenvolvimento anterior das proposições teóricas para orientar a coleta e a análise de dados.

\subsubsection{Abordagem da pesquisa}

O método utilizado na verificação empírica do problema de pesquisa se enquadra essencialmente dentro da abordagem qualitativa. Martins e Theóphilo (2007, p. 136) ressaltam que, a diferença da pesquisa preeminentemente quantitativa, no caso da pesquisa qualitativa “[...] coleta e análise ocorrem simultaneamente.” Para os autores (Ibid.) uma das suas características principais é a predominância da descrição, sendo que um pequeno detalhe pode ser essencial para o entendimento da realidade.

Martins e Theóphilo (2007, p. 137) apontam como uma das justificativas para utilizar uma abordagem deste tipo, o estar numa situação em que se disponha de "[...] pouca informação a respeito do assunto a ser pesquisado, sendo necessário explorar o conhecimento que as pessoas têm com base em suas experiências ou senso comum.”.

Dentro desta abordagem, especificamente, optou-se pela condução de um estudo de casos múltiplos segundo a linha metodológica de Yin (2015), por considerar-se um método conveniente quando se tenta estudar alguns aspectos adicionais sobre o tema que não podem ser explorados completamente através de outros métodos, como o empreendido na etapa inicial. 


\subsubsection{Natureza da pesquisa}

Segundo Yin (2015, p. 7-9) qualquer método de pesquisa pode ser usado com três propósitos: exploratório, descritivo e explicativo; sendo três condições as que determinam o método de pesquisa mais adequado:

a) O tipo de questão;

b) A extensão do controle sobre os eventos comportamentais reais, e;

c) O grau de enfoque sobre os eventos (contemporâneos vs. totalmente históricos).

Uma comparação que apresenta diferentes situações ao respeito destas condições em relação a diferentes métodos de pesquisa (YIN, 2015, p. 10), ajuda a entender melhor a adequabilidade de cada método (Quadro 1).

Quadro 1 - Situações relevantes em relação a diferentes métodos de pesquisa

\begin{tabular}{|l|l|l|l|}
\hline Método & $\begin{array}{l}\text { Formato de questão } \\
\text { de pesquisa }\end{array}$ & $\begin{array}{l}\text { Exige controle dos eventos } \\
\text { comportamentais? }\end{array}$ & $\begin{array}{l}\text { Enfoca } \\
\text { contemporâneos? }\end{array}$ \\
\hline Experimento & Como, por quê? & Sim & Sim \\
\hline $\begin{array}{l}\text { Levantamento } \\
\text { (Survey) }\end{array}$ & $\begin{array}{l}\text { Quem, o quê, onde, } \\
\text { quantos, quanto? }\end{array}$ & Não & Sim \\
\hline Análise de arquivos & $\begin{array}{l}\text { Quem, o quê, onde, } \\
\text { quantos, quanto? }\end{array}$ & Não & Sim/Não \\
\hline Pesquisa histórica & Como, por quê? & Não & Não \\
\hline Estudo de caso & Como, por quê? & Não & Sim \\
\hline
\end{tabular}

FONTE: YIN, 2015, p. 10.

Yin (2015, p. 9-12) esclarece que as questões do tipo "o quê" podem se desdobrar em duas possibilidades. Numa delas, o "o quê" remete a linhas de investigação de "quantos" ou "quanto", as quais favorecem métodos quantitativos como pode ser um levantamento e outros. Porém, na segunda possibilidade, o "o quê" tem caráter exploratório, justificando a condução de um estudo desse tipo, no qual qualquer um dos cinco métodos pode ser utilizado, entre eles o estudo de caso exploratório. Nessa situação a "[...] meta seria desenvolver hipóteses e proposições pertinentes para investigação posterior.” (YIN, 2015, p. 10). 
Sobre as segunda e terceira condições, o autor (YIN, 2015, p. 12-13) indica que o estudo de caso será o método preferido "[...] durante o exame dos eventos contemporâneos, mas quando os comportamentos relevantes não podem ser manipulados.".

Para Bonoma (1985) o propósito de um estudo de caso “[...] não é a quantificação ou ainda a enumeração, [...] Em uma palavra, o objetivo é a compreensão."3 (Ibid., p.206, tradução nossa). Ele (BONOMA, 1985) advoga pelo seu uso quando a teoria não esteja consolidada, quando se trate de situações complexas, quando o fenômeno deva ser estudado no seu contexto e quando se precise aprofundar no conhecimento.

Considerando que um dos propósitos deste trabalho de investigação é o de estudar elementos do conceito modelo de negócios que existem em organizações que se desempenham em mercados competitivos, para posteriormente poder discutir sobre sua correspondência com o identificado na teoria, a condução de um estudo de casos exploratório surgiu como uma alternativa interessante para complementar a pesquisa inicial sobre o tema.

\subsubsection{Tipo de pesquisa}

Nesta etapa definiu-se a condução de um estudo de casos múltiplos (YIN, 2015, p.59-66) exploratórios. Mais especificamente, o desenho da pesquisa estabeleceu um projeto de casos múltiplos do tipo holístico (YIN, 2015, p. 66-67).

Yin (2015) defende uma lógica diferente na abordagem dos estudos de casos múltiplos, em relação a outro tipo de pesquisa. Para Yin (2015, p. 60-65) uma melhor analogia para a condução de casos múltiplos é a da condução de experimentos múltiplos.

A eleição desta abordagem abre a possibilidade de seguir duas vias: selecionar os casos para produzir resultados similares ou seleciona-los para produzir resultados contrastantes, mas para razões previsíveis (YIN, 2015, p. 60). A primeira das opções supõe que cada caso seja utilizado para realizar uma réplica, chamada de replicação literal, (Ibidem) e foi tal opção a preferida para esta pesquisa de caráter inicial.

\footnotetext{
3 "[...] is not quantification or even enumeration, [...]. In a word, the goal is understanding."
} 
Fazendo a distinção na lógica deste tipo de pesquisa com a lógica existente em outro tipo de pesquisa, como ser, por exemplo, um levantamento (survey), contestam-se algumas das objeções que pode enfrentar o método se não é entendido sob esta perspectiva.

Na lógica dos estudos de casos múltiplos, procura-se conseguir uma generalização de tipo analítica (YIN, 2015, p. 43-47), onde os resultados devieram tomar a forma de lições aprendidas, hipóteses ou outros princípios aplicáveis a outras situações (YIN, 2015, p. 72).

Sobre a variação no tipo escolhido, estudos de casos múltiplos holísticos, deve-se dizer que esta supõe unidades únicas de análise no desenho do projeto e, como indica Yin (2015, p. 66), obedece ao fenômeno estudado e às questões de pesquisa.

Uma observação à figura 1, que apresenta diferentes tipos de projetos de estudo de casos cruzando as dimensões número de casos e número de unidades de análise, permite distinguir onde se situa a variação escolhida para a presente pesquisa entre as alternativas existentes.

\subsubsection{Procedimentos metodológicos}

Nesta subseção se detalha os aspectos relativos aos procedimentos seguidos na verificação empírica das questões abordadas na pesquisa mediante a condução do estudo de casos. 


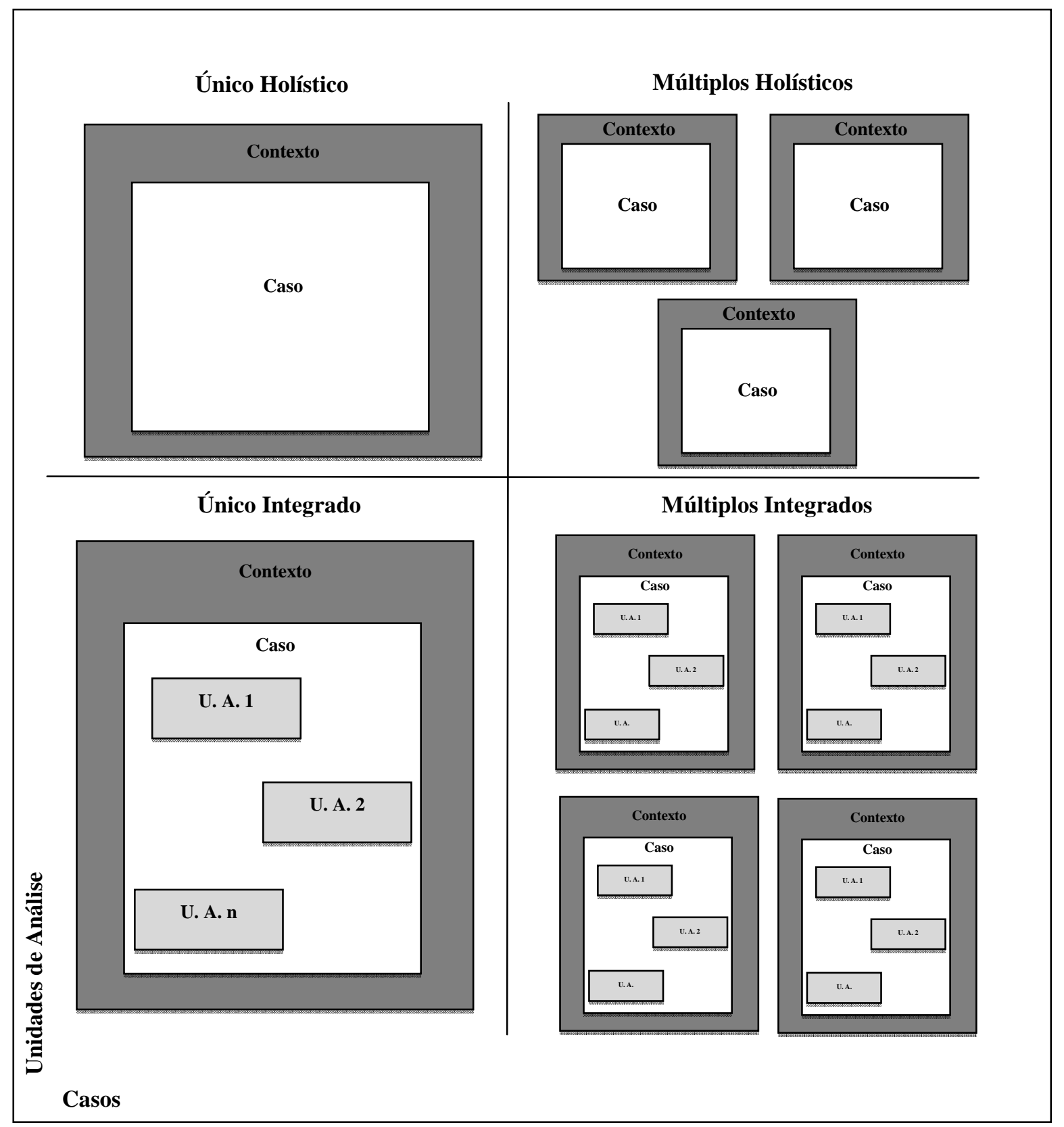

Figura 1 - Tipos de projeto de estudo de casos

FONTE: Extraído e adaptado de YIN (2015, p. 53)

\subsubsection{Etapas da pesquisa empírica}

Posteriormente à fase da pesquisa que permitiu desenvolver uma base teórica respectiva à temática de modelo de negócios, a fase de verificação empírica estabeleceu diferentes etapas com o objetivo de sistematizar a mesma. A figura 2 representa e resume visualmente toda a fase e suas ligações. 

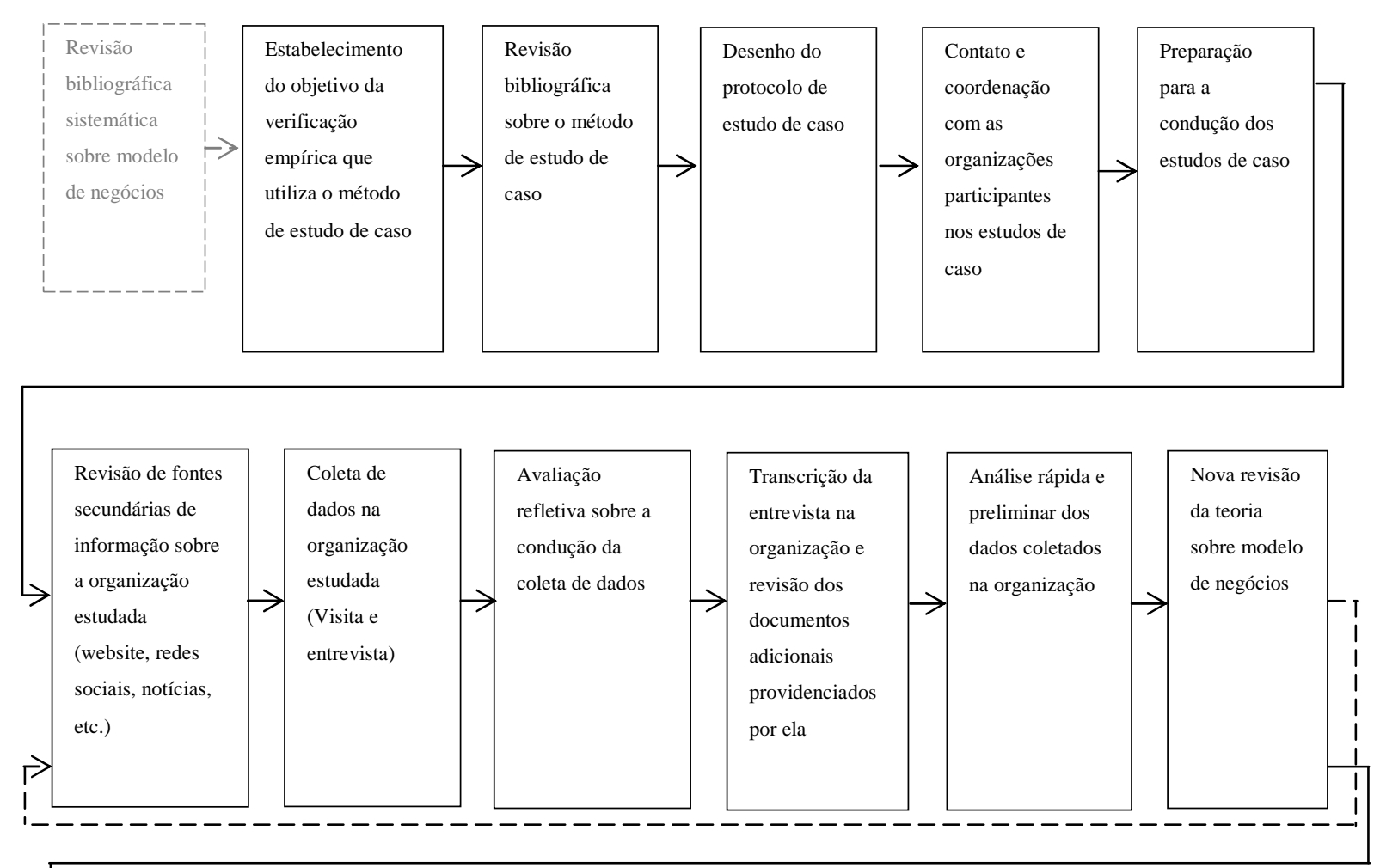

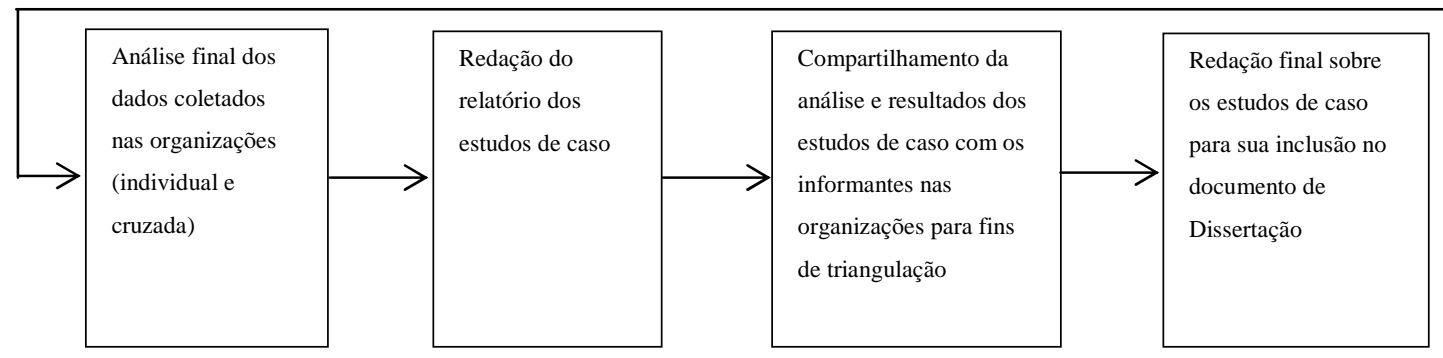

Figura 2 - Etapas da pesquisa empírica com estudo de casos

Da representação gráfica do processo de pesquisa em campo, apresentada na figura 2, pode-se dizer que, embora esta seja uma fase independente e com várias etapas próprias, ela teve como antecedência na sequência, à fase da pesquisa onde se estabeleceu a fundamentação teórica sobre o tema "modelo de negócios". Além disso, deve-se salientar que esta etapa também precisou estabelecer claramente os objetivos, as questões e o protocolo da pesquisa de forma prévia a sua realização e requereu uma revisão e estudo do método específico como é o estudo de casos.

Assim mesmo, pode-se observar que, nas etapas da pesquisa, convivem atividades de caráter mais teórico, como podem ser as revisões da teoria e as análises, com atividades altamente operativas como são os contatos com as organizações ou as transcrições da informação 
coletada. Em muitas das etapas, como a preparação para a condução do estudo de casos ou a coleta mesma, teoria e prática se fazem presentes de forma constante.

Na parte intermedia da figura 2 se observa um padrão das etapas repetidas para cada caso estudado na pesquisa, sendo que a repetição é representada pela seta em linha ponteada e que essa sequência continua até concluir com o último dos casos individuais estudados, para recém passar às etapas finais da pesquisa empírica.

\subsubsection{Definições sobre os casos}

Yin (2015, p. 33-37) inclui como um dos componentes essenciais num projeto de pesquisa que utiliza o estudo de casos como método, às unidades de análise, pelo que inicialmente se tomaram decisões sobre sua definição e delimitação.

Devido a que o fenômeno estudado, "modelo de negócios", é inerente à existência das organizações, decidiu-se escolher empresas nas quais se possam estudar alguns dos elementos e proposições encontradas na teoria, sem descartar a expectativa de obter qualquer nova descoberta que possa contribuir à investigação do tema, decorrente da valiosa experiência que possuem organizações que desenvolvem negócios no dia a dia.

Especificamente, definiu-se como unidade de análise do estudo de casos à organização e como unidade de coleta de dados a indivíduos pertencentes à organização, neste caso um executivo vinculado à área de Estratégia na empresa. A figura 3 mostra o posicionamento desta definição.

\begin{tabular}{|c|c|c|c|}
\cline { 3 - 4 } \multicolumn{2}{c|}{} & \multicolumn{2}{c|}{ Fonte da coleta de dados } \\
\cline { 3 - 4 } \multicolumn{2}{c|}{} & De um individuo & De uma organização \\
\hline \multirow{2}{*}{$\frac{0}{\overparen{D}}$} & Sobre um individuo & & \\
\cline { 2 - 4 } & Sobre uma organização & $\mathbf{X}$ & \\
\hline
\end{tabular}

Figura 3 - Posição na escolha de unidade de análise e de coleta de dados para os estudos de casos. FONTE: Elaboração com base em YIN, 2015, p. 97 
Além disso, Benbasat, Goldstein e Mead (1987, p. 370, tradução nossa) acreditam que uma pesquisa de estudo de caso "[...] está bem-adequada para capturar o conhecimento dos praticantes e desenvolver teorias a partir dele."4

Sobre a delimitação dos casos pode se dizer que nesta pesquisa exploratória da temática decidiu-se escolher organizações similares em quanto ao setor competitivo onde elas se desenvolvem e as suas principais características: tamanho, antiguidade e faturação.

\subsubsection{Seleção dos estudos de casos}

Na seleção das organizações que formam parte da pesquisa de estudos de casos múltiplos se consideraram diferentes critérios teóricos e práticos. Por um lado, Yin (2015, p. 99) recomenda que se selecionem os casos "[...] que se adaptem melhor ao seu projeto de replicação (literal ou teórica).”. Por outra parte, o mesmo autor (Ibid.) aponta que em algumas oportunidades o caso se selecionará devido a um arranjo ou acesso especial que se possua.

Embora ainda chamando de "amostragem" à seleção em pesquisa qualitativa"; Sampieri, Collado e Lucio (2010, p. 393) descrevem esta como uma "amostragem" que não procura generalizar resultados, não é probabilística, se determina durante ou depois da imersão inicial e se pode ajustar em qualquer momento do estudo.

Small (2009) também defende a lógica diferente à tradicional quantitativa para a seleção e condução de estudo de casos, advogando por que estudos baseados em entrevistas não sejam concebidos e julgados por externos como estudos com amostras pequenas, senão como estudos de casos múltiplos que muito provavelmente providenciarão as respostas mais frutíferas e efetivas às questões colocadas neste tipo de pesquisa (Ibid., p. 24).

Em cada uma das situações anteriormente mencionadas, deve-se refletir sobre as implicações de cada uma com o tema de generalização de resultados, que dito seja de passo não sempre é objetivo de um estudo sob o paradigma qualitativo.

\footnotetext{
4 "[...] is well-suited to capturing the knowledge of practitioners and developing theories from it.".

${ }^{5}$ Yin (2015) faz ênfase em diferenciar a lógica da replicação da lógica da amostragem na condução de pesquisa com o método de estudo de caso e chama de "erro" qualquer analogia ao respeito (Ibid., p. 51), porém vários autores na tradição qualitativa (c.f. Flick, 2009) utilizam o termo fora de sua concepção mais comum que é a da tradição estritamente quantitativa.
} 
Uma vez feitas as definições e delimitações expostas na subseção anterior, discutiram-se e analisaram-se quais organizações poderiam formar parte da pesquisa e contribuir para responder as principais questões colocadas. Por sugestão do professor orientador, escolheu-se uma primeira empresa pelas suas características, o seu setor (tecnologia) e pelas maiores possibilidades de acesso devido a um dos seus altos executivos ser conhecido por ambas pessoas. Paralelamente, iniciaram-se gestões para conseguir uma empresa similar para conduzir outro dos estudos de caso.

Uma vez realizada a coleta na primeira organização, pôde-se fechar o acesso à segunda empresa e uma vez realizada a coleta nesta, pôde se negociar o acesso a uma terceira e última empresa com similares características, sendo que esta última foi uma sugestão do executivo da primeira organização estudada.

Para Small (2009, p. 24-25) o processo de realização de entrevistas deve ser sequencial, objetivando uma saturação, isto é, que o último caso selecionado providencie muito pouca informação nova ou surpreendente.

As três organizações estudadas compartem as seguintes características:

a) São empresas com 18 ou mais anos no mercado;

b) Pertencem a um setor no qual existe concorrência e possibilitam adequadamente estudar as proposições da pesquisa;

c) Consentiram acesso as suas informações para a realização da pesquisa.

No concernente ao número de casos, Sampieri, Collado e Lucio (2010, p. 394) consideram como fatores que intervêm para estabelecê-lo: a capacidade operativa de coleta e análise, o entendimento do fenômeno, e a natureza do fenômeno sob análise.

Outra das definições chaves na seleção dos casos teve a ver com as unidades de coleta de dados. Flick (2009) não somente cita o acesso às instituições como um dos problemas a serem resolvidos no trabalho em campo, mas o acesso aos indivíduos (Ibid., p. 109) aparece como questão desafiadora na condução de uma pesquisa. Temas ligados à disposição ou falta de familiaridade são questões que devem ser consideradas no desenho e condução da pesquisa. 
Sob a concepção de um "bom informante" de $\operatorname{Morse}^{6}$ (1998 apud FLICK, 2009, p. 123), o autor sugere como critérios para selecionar sujeitos relevantes, especialmente entrevistados, aos seguintes:

- $\quad$ Eles devem ter conhecimento necessário e experiência no assunto para responder às questões;

- $\quad$ Eles devem ter a capacidade de articular;

- $\quad$ Eles devem ter o tempo para serem consultados, e;

- $\quad$ Eles devem estar dispostos a participar no estudo.

Morse refere-se à inclusão destes casos como uma seleção primária, à qual deveriam se concentrar os esforços de pesquisa, porém sem descartar a existência de uma seleção secundária, constituída por pessoas dispostas a darem seu tempo para a investigação, mas que não cumprem com os critérios particulares de conhecimento e experiência, e podem ser apenas considerados ante uma clara situação na qual não existam suficientes casos na seleção primária.

Numa primeira instância do desenho da pesquisa, pensou-se em entrevistar a mais de uma pessoa na organização, mas novamente uma revisão de critérios teóricos e práticos fez que se decidisse coletar a informação da pessoa mais idônea na organização para responder, discutir e avaliar questões relativas a temas de estratégia e negócios.

Um resumo do perfil dos indivíduos que contribuíram com a coleta de dados nas organizações selecionadas, se apresenta no quadro 2 :

\footnotetext{
${ }^{6}$ MORSE, Janice M. Designing Funded Qualitative Research. In: N. Denzin and Y.S. Lincoln (eds.), Strategies of Qualitative Research. London: SAGE, 1998.
} 
Quadro 2 - Perfil dos indivíduos participantes na coleta de dados nas suas organizações no estudo de casos

\begin{tabular}{|l|l|l|l|l|l|}
\hline $\begin{array}{l}\text { Empresa / } \\
\text { Departamento }\end{array}$ & Nome & Gênero & Posição & $\begin{array}{l}\text { Anos na } \\
\text { empresa }\end{array}$ \\
\hline $\begin{array}{l}\text { Empresa "X" / Área de } \\
\text { Operações }\end{array}$ & Entrevistado 1 & 40 anos & Masculino & $\begin{array}{l}\text { - Executivo na área } \\
\text { de operações (Diretor } \\
\text { Operativo) }\end{array}$ & 12 anos \\
\hline $\begin{array}{l}\text { RTM - Empresa 2 / } \\
\text { Área Comercial }\end{array}$ & $\begin{array}{l}\text { Adriane Rego } \\
\text { (Entrevistada 2) }\end{array}$ & 51 anos & Feminino & $\begin{array}{l}\text { - Executiva na área } \\
\text { comercial } \\
\text { (Diretora Comercial e } \\
\text { de Novos Produtos) }\end{array}$ & 18 anos \\
\hline $\begin{array}{l}\text { INW Group - Empresa } \\
\text { Software }\end{array}$ & $\begin{array}{l}\text { Alexandre Leitão } \\
\text { (Entrevistado 3) }\end{array}$ & 38 anos & Masculino & $\begin{array}{l}\text { - Diretor / Sócio } \\
\text { (CEO) }\end{array}$ & 6 anos \\
\hline
\end{tabular}

\subsubsection{Método na coleta de dados}

Para a coleta de dados, decidimos pela aplicação de entrevistas do tipo semi-estruturadas (SAMPIERI; COLLADO; LUCIO, 2010), fazendo uso de um questionário construído em função a alguns dos tópicos identificados na revisão bibliográfica sobre o tema. Seguindo as orientações de Yin (2015, p. 109-127) a coleta também incluiu a utilização de outras fontes de evidência como são a informação derivada de documentos providenciados pelas organizações e a obtida mediante a revisão dos dados existentes em matérias jornalísticas, redes sociais e sítios institucionais da "web".

\subsubsection{Operacionalização da coleta}

$\mathrm{Na}$ coleta de dados nos estudos de casos múltiplos se cumpriram etapas definidas como a elaboração e estudo do protocolo do estudo de casos; a preparação para as entrevistas; a coordenação com as organizações participantes; a revisão de informação secundária das organizações; e; a visita às organizações e a realização das entrevistas, junto à sua posterior transcrição. 
Previamente à coleta de dados, elaborou-se um protocolo segundo as indicações contidas em Yin (2015, p. 87-97). O mesmo é tratado no seguinte apartado (2.2.4.2) e pode ser consultado na sua integridade no Apêndice A, tal qual foi desenhado originalmente.

A preparação para as entrevistas consistiu na revisão de recomendações e dicas para sua condução, contidas em bibliografia dedicada ao tema e a discussão das perguntas com o professor orientador.

A coordenação com as organizações participantes nesta etapa implicou atividades como ser o contato inicial; diversas ligações telefônicas, agendamentos e reagendamentos para realizar as visitas; a troca de informação por correio eletrônico; o envio do roteiro de entrevista a cada informante com pelo menos 24 horas de antecedência ${ }^{7}$; e a combinação de aspectos relativos à confidencialidade da participação e informações coletadas.

Previamente à realização da visita e entrevista em cada um dos casos, realizou-se uma exploração da informação existente sobre a empresa no seu sitio "web", suas redes sociais e qualquer outra fonte encontrada na sua busca. Este passo teve o propósito de familiarizar-se o mais possível com a informação da organização, conseguir dados gerais procurados no instrumento de coleta, e identificar quais dados deveriam ser obtidos ou conferidos diretamente dos informantes na empresa.

O dia prévio à visita de cada empresa para a entrevista se fez um repasso do protocolo do estudo de casos, o teste dos equipamentos e software para a gravação dos depoimentos, e a preparação do material a ser usado na visita como ser material para notas, roteiro e formulários de autorização.

No dia da visita, em todos os casos, conversou-se informalmente antes e depois da entrevista. Antes, para deixar o entrevistado a par da pesquisa e receber uma contextualização da organização por parte dele. Depois, para aproveitar e conhecer as impressões da realização da entrevista e apreciar mais a empresa in situ nos casos em que foi possível.

\footnotetext{
${ }^{7}$ Devido a razões relativas às circunstâncias de cada visita, o menor tempo de antecedência com que um dos entrevistados contou com o roteiro de entrevista foi de 1 dia. Sendo que o maior tempo que um entrevistado teve o roteiro no seu poder foi de 16 dias.
} 
Yin $(2015$, p. 114) assinala que "O áudio registrado certamente fornece uma interpretação mais precisa de qualquer entrevista do que fazer suas próprias anotações.". Todas as entrevistas formais na pesquisa puderam ser gravadas com o consentimento dos informantes e ao mesmo tempo, breves notas com os aspectos mais salientes das respostas foram tomadas, por razões de segurança.

A confidencialidade na pesquisa qualitativa é uma das questões éticas apontadas por Flick (2009, p. 42), pelo que se tomaram providências na pesquisa com a intenção de assegurar que informação sensível e/ou anonimato desejados não sejam vulnerados, de acordo com a preferência dos entrevistados. Na conclusão de toda visita se obteve um compromisso assinado de autorização para o uso da informação por parte dos informantes, conjuntamente ao compromisso de confidencialidade por parte do pesquisador.

Dentro das horas posteriores à realização de cada entrevista, o mesmo pesquisador efetuou a transcrição literal da entrevista na sua integridade a um documento Word utilizando software de ajuda para transcrições.

\subsubsection{Protocolo do estudo de casos}

Para Yin $(2015$, p. 88) o protocolo de um estudo de casos “[...] é mais do que um questionário ou um instrumento." porque além de conter este, também contém os procedimentos e regras gerais a serem seguidas.

A confecção do protocolo da presente pesquisa foi um dos passos iniciais e fundamentais para o andamento da verificação empírica, pois como Yin (2015, p. 88) indica este "[...] é essencial [...]" quando se realiza um estudo de casos múltiplos. Sua existência contribui para aumentar a confiabilidade da pesquisa, critério considerado na avaliação da qualidade de uma pesquisa que se utiliza do método estudo de casos.

O protocolo do estudo de casos da pesquisa (Apêndice A) foi construído seguindo a estrutura e conteúdo propostos por Yin (2015, p. 87-97). 


\subsubsection{Entrevista semiestruturada}

Bauer (2002, p. 189) afirma que as entrevistas, estruturadas ou não, são mecanismos convenientes e estabelecidos na pesquisa social. Martins e Theóphilo (2007, p. 86) explicam que a entrevista é uma técnica de pesquisa para a coleta de evidências que tem o propósito de entender e compreender o significado que os entrevistados atribuem a questões e situações específicas. Yin (2015, p. 114) por sua parte afirma que as entrevistas são uma "[...das fontes mais importantes para o estudo de caso [...]”.

Segundo Martins e Theóphilo (2007, p. 86), na ocorrência de uma entrevista semi-estruturada, o encontro é conduzido com o uso de um roteiro, “[...] mas com liberdade de serem acrescentadas novas questões pelo entrevistador.”. Este tipo de conferência, chamada também como entrevista semi-estandardizada (semi-standardized interview) por Flick (2009, p. 156), tem, segundo o autor, suas bases na teoria subjetiva (subjective theory) que postula que " [...] os entrevistados têm um estoque complexo de conhecimento acerca do tópico sob estudo.", (Ibid., tradução nossa). Este conhecimento inclui supostos que são explícitos e imediatos, os quais podem ser expressos espontaneamente na resposta a questões abertas. Por sua vez, estes são complementados por suposições implícitas.

O autor (FLICK, 2009, p. 156) acredita que auxílios metodológicos têm que ser utilizados para apoiar a integração destes supostos por parte dos entrevistados, implicando isto o emprego de questões abertas, questões guiadas pela teoria (theory-driven), questões dirigidas pelas hipóteses (hypotheses-directed) e questões confrontantes.

Flick (2009, p.158-161) sugere um estágio adicional que envolve a aplicação da técnica de structure laying na pesquisa, mas sendo consciente que na maioria dos projetos, uma versão reduzida do método é aplicada na prática e adequações em base à pergunta-pesquisa são necessárias.

Para Martins e Theóphilo (2007, p. 86) o roteiro e orientações da entrevista têm que estar ancorados no referencial teórico e em acordo com os objetivos da pesquisa. No desenho das questões, roteiro de entrevista e sua condução mesma, diretrizes propostas por Flick (2009,

\footnotetext{
8 "[...] the interviewees have a complex stock of knowledge about the topic under study."
} 
170-173), Kvale e Brinkmann (2009), e Sampieri, Collado e Lucio (2010, p. 420-422) foram consideradas para a realização da pesquisa em campo.

Yin (2015, p. 115-117) postula que as entrevistas em um estudo de casos podem ser de três tipos: entrevistas prolongadas, entrevistas curtas e entrevistas de levantamento. Sobre o segundo tipo, que é o das entrevistas curtas de caso, o autor (YIN, 2015, p. 115) as descreve como "[...] mais focadas [...]", que podem "[...] tomar apenas cerca de uma hora [...]" e cuja finalidade "[...] pode ser simplesmente a de corroborar determinadas descobertas [...]".

Porém, Yin (Ibid., p. 116) também adverte que neste tipo de entrevista, o pesquisador ainda deve parecer "[...] genuinamente ingênuo sobre o tópico, permitindo que o entrevistado faça um comentário inédito sobre ele [...]”, e também que deve tentar evitar uma ameaça metodológica na qual se apresenta uma influência mútua e sútil entre o entrevistado e o pesquisador, a qual ele chama de reflexividade e a qual pode estar presente neste tipo, inclusive quando a exposição não é tão prolongada como no caso das entrevistas do primeiro tipo.

Um detalhe dos dados das visitas e entrevistas realizadas para a pesquisa é apresentado no Quadro 3.

Quadro 3 - Dados das visitas e entrevistas realizadas na pesquisa de estudo de casos múltiplos

\begin{tabular}{|l|l|l|l|l|}
\hline Organização & Localização & Entrevistado & $\begin{array}{l}\text { Pessoas } \\
\text { entrevistadas }\end{array}$ & $\begin{array}{l}\text { Data, hora e tempo } \\
\text { brindado }\end{array}$ \\
\hline Empresa "X" & $\begin{array}{l}\text { Santo Amaro, } \\
\text { São Paulo }\end{array}$ & $\begin{array}{l}\text { MP } \\
\text { Diretor Operacional }\end{array}$ & $\begin{array}{l}\text { - Executivo na } \\
\text { área de operações } \\
\text { (Entrevistado 1) }\end{array}$ & $\begin{array}{l}\text { 30-abr-2015, 08:00 am } \\
\text { (2 horas e 20 min. de } \\
\text { visita / 1 hora e 5 min. de } \\
\text { entrevista ) }\end{array}$ \\
\hline $\begin{array}{l}\text { RTM - Empresa } \\
2\end{array}$ & Sé, São Paulo & $\begin{array}{l}\text { Adriane Rego } \\
\text { Diretora Comercial e } \\
\text { de Novos Produtos }\end{array}$ & $\begin{array}{l}\text { área comercial } \\
\text { (Entrevistada 2) }\end{array}$ & $\begin{array}{l}\text { (1 hora de visita / } 43 \\
\text { min. de entrevista) }\end{array}$ \\
\hline Empresa 3 & $\begin{array}{l}\text { Butantã, São } \\
\text { Paulo }\end{array}$ & $\begin{array}{l}\text { Alexandre Leitão } \\
\text { CEO }\end{array}$ & $\begin{array}{l}\text { - Diretor / Sócio } \\
\text { (Entrevistado 3) }\end{array}$ & $\begin{array}{l}\text { 18-junho-2015, 12:00 pm } \\
\text { (0 min. de visita*, } 12 \\
\text { min. conversa / } 48 \text { min. }\end{array}$ \\
\hline
\end{tabular}

Notas: (*) A empresa 3 estava realizando uma mudança durante vários dias nos quais a entrevista podia ser concedida pelo que a mesma teve que ser feita finalmente num local diferente a onde está sediada a empresa. 
Questões relativas à confiabilidade e validade na coleta de dados mediante as entrevistas são discutidas nos apartados 2.2.6.1 e 2.2.6.2. De similar forma, a preocupação com a qualidade na coleta de informações contemplou a avaliação posterior de cada entrevista segundo as 13 questões propostas por Sampieri, Collado e Lucio (2010, p. 425) (Ver anexo A) nas horas seguintes à sua conclusão.

O instrumento de coleta específico utilizado nas entrevistas é discutido na seguinte seção.

\subsubsection{Questionário para a entrevista}

A construção do instrumento de coleta esteve baseada na identificação de temas relativos ao conceito como resultado da revisão de literatura sobre o tema. As perguntas têm um caráter exploratório e foram agrupadas em grandes tópicos. As questões incluídas têm a ver com:

a) a definição e elementos do modelo de negócios;

b) as funções dos modelos de negócio;

c) as propriedades dos modelos de negócio;

d) a relação entre estratégia e modelo de negócios.

O detalhe do roteiro de entrevista; que inclui as instruções de protocolo, a ordem exata das questões, as questões acessórias, e o layout do questionário; pode ser consultado no apêndice B.

\subsubsection{Outras fontes de evidência}

Yin (2015, p. 117-118) ressalva que, quando as entrevistas se focam em eventos comportamentais, é uma abordagem razoável “[...] corroborar os dados da entrevista com informações de outras fontes.", mas anota que quando se está interessado nas visões pessoais de um entrevistado - opiniões, atitudes e significados - essa corroboração não seria tão relevante como no primeiro caso. 
No método de estudo de casos, existem diferentes possibilidades de fontes de informação. As fontes de evidência citadas por Yin (2015, p. 109-122), ademais da entrevista, são: a documentação, os registros em arquivo, as observações diretas, a observação participante e os artefatos físicos.

Devido a natureza do problema estudado na pesquisa e limitações habituais no acesso a determinada informação nas organizações, optou-se por utilizar as fontes de documentação na forma de material promocional das empresas, arquivos de apresentação institucional, apresentações de projetos a nível interno, e registro de notícias.

A recorrência a este tipo de fontes num primeiro momento teve o propósito de gerar insights e conhecimento prévio a ser utilizado e discutido durante a realização da coleta de dados mediante as entrevistas pessoais. Numa etapa posterior, a utilização destas fontes documentais teve o propósito de complementar, corroborar ou contestar a informação proveniente da fonte com maior peso no estudo de caso como foi a das entrevistas.

Duas precauções sobre este tipo de fonte foram levadas em conta seguindo as recomendações de Yin (2015, p. 112-113). Primeiramente, o cuidado de evitar considerar este tipo de informação como uma “[...] verdade indubitável [...]” como explica Yin (Ibid., p. 112, 134), e, adicionalmente, a necessidade do bom senso para se focar na informação mais pertinente, (YIN, p. 113, 133-134).

\subsubsection{Método na análise de dados}

Para Flick (2009, p. 306, tradução nossa): “A interpretação dos dados está no âmago da pesquisa qualitativa." ${ }^{9}$. O cientista da era vigente possui um variado arsenal de instrumentos para afrontar esta fase do processo de pesquisa. Seguidamente se apresenta uma introdução ao método, os elementos na sua abordagem, assim como suas limitações.

\footnotetext{
9 "The interpretation of data is at the core of qualitative research,"
} 


\subsubsection{Análise dos dados nos estudos de casos múltiplos}

Ao falar da estratégia analítica para tratar a evidência coletada (YIN, 2015, p. 137-147), Yin indica que a estratégia “[...] deve seguir um ciclo (ou ciclos repetidos) envolvendo suas questões de pesquisa originais, os dados, seu manuseio e sua interpretação justificáveis dos dados e sua capacidade de expor algumas descobertas e tirar algumas conclusões.”.

Na pesquisa utiliza-se na análise uma combinação entre a estratégia baseada em proposições teóricas (Ibid., p. 140-141) e as explanações rivais (Ibid., p. 144-145). A primeira destas estratégias gerais implica seguir as proposições teóricas que levaram ao estudo de casos. Especificamente se intenta observar se o construto armado com a revisão teórica corresponde com as respostas brindadas na coleta em campo. Já no caso da segunda estratégia, o intuito é considerar, a toda hora, diferentes explanações à informação providenciada pelos respondentes.

No que se refere às técnicas analíticas específicas, faz-se recorrência às alternativas de combinação de padrão (Ibid., p. 147-151) e síntese cruzada de casos (Ibid., p. 168-172). Na combinação de padrão se compara um padrão baseado nas descobertas com um padrão previsto antes da coleta. A técnica é chamada por Yin (2015, p. 147) como uma “[...] das mais desejáveis [...]" para a análise de estudos de caso. Por sua parte, a técnica de síntese cruzada de casos é uma técnica exclusiva de estudos de casos múltiplos. A mesma, pelo geral, utiliza tabelas onde se inserem os dados dos casos individuais de acordo a uma estrutura estabelecida. Este tipo de organização permite ver se os casos "[...] replicaram ou contrastaram uns em relação a outros." (YIN, 2015, p. 170-171).

\subsubsection{Qualidade da pesquisa com estudo de casos}

Yin (2015, p. 47-52) discorre sobre os critérios para julgar a qualidade de uma pesquisa. São quatro testes os estabelecidos pelo autor para este julgamento: validade do constructo, validade interna, validade externa, e confiabilidade.

No que se refere à confiabilidade e a validade na pesquisa qualitativa, Flick $(2009$, p. 385398) apresenta uma discussão que abrange tópicos como as formas de confiabilidade, a confiabilidade do procedimento, tipos de validade, validade do procedimento e critérios 
alternativos. Como conclusão, pode se conjecturar, como sugere o autor (Ibid., p. 398), que a aplicação de critérios tradicionais pode descrever superficialmente algumas especificidades da pesquisa do tipo qualitativo, sem significar que abordagens alternativas resolveriam adequadamente tal problema.

Sobre a confiabilidade específica na interpretação dos dados, o autor (FLICK, 2009, p. 386) anota que o treinamento e as trocas reflexivas sobre os procedimentos interpretativos podem contribuir com o seu aprimoramento.

\subsubsection{Confiabilidade no estudo de casos}

O critério pode ser explicado, utilizando palavras de Yin (2015, p. 51), como a possibilidade de um pesquisador obter os mesmos resultados e conclusões, se seguir o mesmo procedimento ao conduzir o mesmo estudo de caso. Sua meta é a minimização de erros e parcialidades.

Para Flick (2009, p. 386), a confiabilidade sobre os dados da entrevista pode ser melhorada mediante treinamento para $\mathrm{o}(\mathrm{s})$ entrevistador(es) e a verificação das guias de entrevista ou questões, em entrevistas piloto ou depois da realização da primeira delas.

No caso do desenho da presente pesquisa, o treinamento proveio da revisão de bibliografia especializada na técnica, e ante a impossibilidade de realizar uma entrevista ou caso-piloto por limitações no acesso a respondentes, optou-se pela última sugestão, avaliando-se o conteúdo após a primeira entrevista realizada. A avaliação dela sugeriu que nenhuma mudança essencial no conteúdo seria necessária.

Yin (2015, p. 122-134) estabelece quatro princípios que contribuem à confiabilidade de uma pesquisa que se utiliza do método de estudo de casos. Estes são:

a) Usar múltiplas fontes de evidência;

b) Criar uma base de dados do estudo de caso;

c) Manter o encadeamento de evidências;

d) Ter cuidado no uso de dados de fontes eletrônicas. 
Sobre o primeiro deles, se pode dizer que na pesquisa utilizou-se mais de uma fonte: Entrevistas e diferentes documentos. No caso do segundo, durante a pesquisa construiu-se uma base de dados que inclui as anotações tomadas em campo, os arquivos de áudio das entrevistas realizadas, as transcrições literais dos depoimentos na sua versão de texto Word, os formulários de autorização de uso da informação, os formulários da avaliação pessoal do pesquisador sobre cada entrevista, cópias eletrônicas da informação trocada, e, os arquivos físicos e eletrônicos da informação obtida.

Sobre o encadeamento de evidências (YIN, 2015, p. 132), acredita-se que a exposição com a citação de fontes no presente relatório, a descrição detalhada de como foi coletada a informação tal como se apresenta neste mesmo capítulo sobre o método, e por fim, a vinculação das questões do protocolo do caso com as questões da pesquisa; contribuem para o cumprimento deste princípio.

No caso do último princípio, relativo às fontes eletrônicas, se tomaram os devidos cuidados no referente ao estabelecimento de limites e ao ter consciência sobre a existência de possíveis vieses e imprecisões na informação disponível.

Como ponto final do apartado, deve se mencionar a importância da existência e aderência a um protocolo de estudo de caso para aumentar a confiabilidade da pesquisa. No mesmo sentido, tomaram-se todas as previdências para documentar os procedimentos seguidos e para manter um arquivo dos dados obtidos e utilizados na pesquisa.

\subsubsection{Validade no estudo de casos}

No caso da especificação da validade sobre a informação das entrevistas, o autor (FLICK, 2009, p. 388) afirma que uma opção é conferir formalmente se foi possível assegurar o grau de autenticidade dirigida durante o encontro. Assim mesmo, sugere estar ciente ante qualquer sinal de deformação resultante da situação de entrevista, que possa estar ocasionando a construção de versões específicas das experiências dos entrevistados. Alternativas como a validação comunicativa: encontro posterior à entrevista e a sua transcrição, são apresentadas como opções na pesquisa qualitativa. 
Falando em termos mais gerais sobre a qualidade de uma pesquisa que utiliza o método de estudo de casos, Yin (2015, p. 48-51) explica três tipos de validade:

a) Validade do construto;

b) Validade interna;

c) Validade externa.

A primeira delas, constructo, tem a ver com a identificação de medidas operacionais corretas para os conceitos. A segunda, a interna, tem a ver com a busca do estabelecimento de relação causal, diferenciando relações espúrias. Por fim, a validade externa procura a definição do domínio em que as descobertas podem ser generalizadas.

Considerando que o segundo teste da qualidade de pesquisa, a validade interna, é apontado por Yin $(2015$, p. 48) como exclusivo para estudos de caso explicativos ou causais, não foi considerado na presente pesquisa exploratória, tendo se abocado aos outros dois tipos de validade.

O quadro 4 exibe os critérios de qualidade sugeridos na literatura junto às ações empreendidas na presente pesquisa empírica para cumprir com eles.

\section{Quadro 4 - Critérios de qualidade em pesquisa de estudo de casos em relação às táticas usadas na pesquisa}

\begin{tabular}{|l|l|}
\hline Teste & Táticas usadas no estudo de casos \\
\hline Confiabilidade & - Uso de um protocolo de estudo de casos \\
& - Desenvolvimento de uma base de dados do estudo de \\
& casos \\
\hline Validade de constructo & - Uso de múltiplas fontes de evidência \\
& - Estabelecimento de um encadeamento de evidências \\
& - Revisão do relatório do estudo de casos por parte dos \\
& informantes-chave \\
\hline Validade externa & - Uso da lógica da replicação no estudo de casos \\
& múltiplos \\
\hline
\end{tabular}

FONTE: Elaboração em função a YIN, 2015, p. 48

Além dos critérios sobre confiabilidade e validade discutidos em cada item desta subseção, Yin (2015, p. 172-173) chama a atenção para quatro princípios presentes em boas pesquisas 
sociais: basear-se em todas as evidências, abordar todas as interpretações rivais plausíveis, abordar o aspecto mais significativo do estudo de casos na análise, e, usar o próprio conhecimento prévio de especialista.

Ao respeito das medidas usadas especificamente na condução dos casos para aumentar a qualidade da pesquisa, pode-se mencionar que se utilizou do protocolo previamente e durante a realização das entrevistas. A base de dados está constituída pelas notas tomadas em campo, as transcrições íntegras e literais dos depoimentos, os arquivos de gravação das entrevistas, e a documentação acessória, impressa e eletrônica, utilizada como fonte adicional. O relatório inicial dos estudos de casos foi compartilhado com todos os entrevistados (YIN, 2015, p. 202203), sendo que só dois deles responderam com observações menores. A lógica da replicação se utilizou no momento de selecionar sequencialmente os casos e para fins de realizar réplicas literais dos casos, segundo o método.

\subsubsection{Limitações no estudo de casos}

Yin (2015, p. 51) postula que no caso de pesquisas deste tipo onde não se abordam perguntas do tipo "como" ou "por que", "[...] chegar a alguma generalização analítica pode ser mais difícil.".

Para Eisenhardt (1989, p. 547) as características da pesquisa com estudo de casos podem levar a duas fraquezas quando se construí teoria com este método: ter uma teoria resultante muito rica em detalhe, mas carente da simplicidade da perspectiva geral; ou ter uma teoria resultante limitada e idiossincrática.

Para Scapens (1990, p. 276-277) são três os problemas ou fraquezas do método. Primeiro, a dificuldade em desenhar claramente as fronteiras ao redor do assunto do caso. Segundo, por os estudos de casos representarem interpretações da realidade social, pode surgir um problema de viés por parte do pesquisador. Nas suas palavras "Não existe tal coisa como um estudo de caso 'objetivo" 10 ", (Ibid., p. 277, tradução nossa). Por fim, o autor cita como problema um tema que tem a ver com a ética no relacionamento do pesquisador com seus sujeitos de estudo. Segundo ele (SCAPENS, 1990) quando se precise disfarçar a identidade de uma

\footnotetext{
10 "There can be no such thing as an 'objective' case study."
} 
organização estudada pode se limitar a apreciação do contexto de estudo para garantir acesso à informação confidencial. Da mesma forma, sujeitos podem não estar preparados para revelar as suas visões, opiniões ou dados se sabem que o pesquisador providenciará essa informação a outras pessoas de fora ou mesmo dentro da sua organização, pelo que se pode dificultar a verificação da validade da informação por terceiros. 


\section{REVISÃO DE LITERATURA}

\subsection{Evolução do termo}

Na sua pesquisa sobre as origens do termo, Osterwalder, Pigneur e Tucci (2005), afirmam que apareceu pela primeira vez em um artigo em 1957, porém a sua popularidade é relativamente nova (finais dos anos 1990). Eles (OSTERWALDER, PIGNEUR; TUCCI, 2005) citam a relação dessa popularidade com a expansão dos negócios na Internet. A observação da ligação entre o boom do conceito com o também boom dos negócios pela internet é documentada também por Magretta (2002); Sako (2012) e Zott, Amit e Massa (2011).

Segundo o ponto de vista de Morris, Shirokova e Shatalov (2013, p. 47) existem 4 estágios gerais na evolução do conceito de modelo de negócios: o estágio de aparição, o estágio de uso popular, o estágio descritivo e o estágio analítico.

Dasilva e Trkman (2013, p. 2) presumem que na sua primeira utilização em 1957 por Bellman e outros, embora o termo tiver sido utilizado só uma vez no texto, ele estava intrinsecamente conectado com uma representação da realidade, uma simulação do mundo real mediante o modelo. Os autores observam que na sua primeira utilização num título de "paper" acadêmico: "Educators, electrons, and business models: a problem in synthesis" de Gardner Jones em 1960, o termo não é mais utilizado no conteúdo do texto, apenas sugerindo uma simplificação da realidade.

Segundo Teece (2010, p. 174) o modelo de negócios tem a sua linhagem desde os tempos da troca, mas foi "catapultado" na consciência pública desde os anos 2000 com a economia do conhecimento, a Internet, o outsourcing, o offshoring e a reestruturação de serviços financeiros ao redor do mundo, entre outros. Casadesus-Masanell e Ricart (2010), por sua parte, aludem às origens do termo fazendo referência aos escritos de Peter Drucker. Segundo Ghaziani e Ventresca (2005, p. 531) a conversa pública sobre modelos de negócios começa no princípio da década de 70, exibindo uma forte presença no marco da modelização de sistemas e computação. 
Pesquisas realizadas por Ghaziani e Ventresca (2005), e Zott, Amit e Massa (2011) evidenciaram que a presença do termo em publicações indexadas em bases de dados especializadas tem um comportamento claramente distinguível em dois períodos. Um deles que abrange desde meados da década de 70 até meados da década de 90 , onde a publicação era relativamente menor, e ao período partir de meados da década de 90 até finais da década de 2000s quando a publicação sobre o tema em jornais acadêmicos e não acadêmicos “explode" (ZOTT; AMIT; MASSA, 2011, p. 1022; GHAZIANI; VENTRESCA, 2005, p. 543), observando-se também uma predominância do segundo tipo.

Embora a auge dos negócios "ponto com" tenha acabado com a explosão da bolha, para Dasilva e Trkman (2013, p. 3) o termo "modelo de negócios" sobreviveu a essa crise, sendo prova disso o grande número de papers publicados na década posterior. Os autores identificam uma mudança no foco da análise de companhias online a companhias em geral, e explicam a mesma, sugerindo que a Internet permeou e revolucionou as empresas em praticamente todas as indústrias, espalhando o termo para as companhias tradicionais (brickand-mortar). $\mathrm{O}$ crescimento da literatura é explicado também pelos autores por seu uso em outras esferas além da dos negócios.

Uma possível relação na evolução do conceito segundo Osterwalder, Pigneur e Tucci (2005) e a evolução segundo Morris, Shirokova e Shatalov (2013) é proposta e pode ser visualizada graficamente na figura 4.

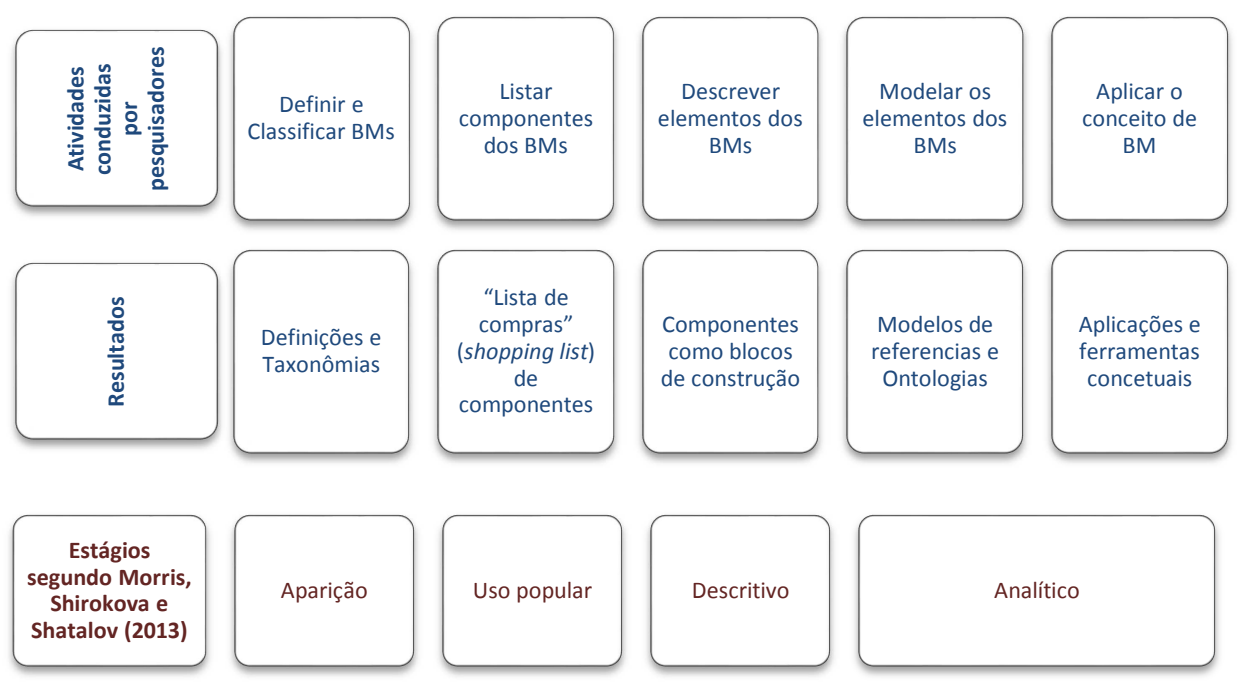

Figura 4 - Evolução do conceito modelo de negócios segundo alguns autores FONTE: Elaboração com base em OSTERWALDER; PIGNEUR; TUCCI. 2005, e, MORRIS; SHIROKOVA; SHATALOV. 2013 


\subsection{Abordagens e definição}

Existem múltiplas abordagens quando se trata do conceito de modelo de negócios. Por exemplo, Osterwalder, Pigneur e Tucci (2005) consideram que existem diferentes tipos de autores que têm escrito sobre BM. Entre eles estão os autores que trataram o BM como um conceito abstrato abrangente, aqueles que descreveram diferentes tipos abstratos, e aqueles que apresentam aspectos de um BM particular no mundo real. Sumarizando, os autores têm tratado o tema no que eles chamam de níveis conceituais e de exemplo (instance levels).

Um exemplo do primeiro tipo de visão chegaria a ser a publicação de Baden-Fuller e Mangematin (2013), os quais postulam que a sua perspectiva sobre modelo de negócios vê estes não só como fenômenos reais, mas como instrumentos cognitivos que encarnam conhecimento acerca das conexões entre elementos tradicionais dentro da firma e os de fora. Tikkanen et al. (2005) corroboram a afirmação indicando que modelo de negócios é tanto um fenômeno cognitivo, quanto é construído sobre aspectos materiais da empresa.

Doganova e Eyquem-Renault (2009) consideram que a abordagem dos modelos de negócios transita por visões essencialistas, funcionalistas, e pragmáticas. Nas essencialistas os acadêmicos têm se ocupado pela descrição/representação de uma realidade; nas funcionalistas, a questão abordada é “o que os modelos de negócio fazem?”; nas pragmáticas, a preocupação é a utilidade, associada a um poder explicativo e preditivo, conceituando-se os modelos de negócios como ferramentas de gestão interna ou instrumentos para relacionamento externo. $\mathrm{Na}$ sua abordagem pragmática, as autoras (DOGANOVA; EYQUEM-RENAULT, 2009) entendem que os modelos não são apenas puras abstrações, considerando-os objetos "materiais" a escala que permitem manipulação e experimentação (Ibid., p.1568).

No entendimento de Zott, Amit e Massa (2011), a literatura sobre modelo de negócios se desenvolveu em silos dependendo do interesse dos respectivos pesquisadores, os quais muitas vezes adotam definições idiossincráticas que se ajustem aos seus propósitos. George e Bock (2011, p. 85) evidenciaram a mesma tendência na sua revisão. Como exemplo, um estudo recente de Coombes e Nicholson (2013) evidenciou que o corpo crescente de literatura sobre 
modelos de negócios tem sido dominado por disciplinas não relacionadas ao Marketing até tempos recentes.

Para Teece (2010, p. 175-176) existe carência na fundamentação teórica (theoretical grounding) na área de estudos econômicos, onde simplesmente não tem lugar estabelecido para os BMs na teoria econômica, provavelmente pela "[...] ubiquidade de constructos teóricos que têm aos mercados resolvendo problemas [...]." (Ibid., p. 175, tradução nossa); e na área de negócios, o conceito carece de um lugar "aceitável” em estudos organizacionais, estratégicos e de marketing. O autor (Ibid., p. 176) entende que o estudo de modelo de negócios é um tópico interdisciplinar que tem sido negligenciado.

George e Bock (2011, p. 85) consideram que a construção de teoria e pesquisa empírica sobre modelo de negócios têm se germinado de alguns temas estabelecidos na teoria organizacional. Eles identificam 6 temas gerais, a saber: Desenho Organizacional, Visão baseada em Recursos, Narrativa e Construção de Sentidos (Sensemaking), Natureza da Inovação, Natureza da Oportunidade, e Estruturas Transacionais.

Para Klang, Wallnöfer e Hacklin (2014, p. 473), o âmago que reflete a fundação sobre a qual, acadêmicos e profissionais têm construído seu significado específico do rótulo "modelo de negócios" é construído a partir de três dimensões: Classificação, Constituição e Configuração. Classificação descreve a relação sintática entre o conceito de modelo de negócios e outros conceitos em Administração. Constituição se refere à identificação/especificação da relação entre o conceito de modelo de negócios e seus elementos constitutivos. Por fim, Configuração denota o complexo sistema de interdependência entre os elementos do conceito de modelo de negócios.

Segundo Klang, Wallnöfer e Hacklin (2014, p. 470-473), resultantes das tensões paradoxais na pesquisa sobre modelos de negócios surgem três pedras angulares (cornerstones) identificáveis mediante a análise de duas dimensões: desenho de pesquisa e audiência alvo. Para os autores estas três pedras angulares têm a ver com: o aparente viés da comunidade cientifica para estudar o modelo de negócio a partir do que este não é, o constante crescimento do montante de elementos que constituiriam um BM, crescimento este não necessariamente estruturado ou sustentado em observações empíricas, e a existência de uma corrente inspirada 
na busca de nova evidência empírica, a qual não necessariamente se apoia na pesquisa cumulativa existente. O Quadro 5 caracteriza estas tensões identificadas:

Quadro 5 - Tensões paradoxais na pesquisa sobre modelo de negócios e características

\begin{tabular}{|c|c|c|c|c|c|}
\hline $\begin{array}{l}\text { Pedras } \\
\text { angulares } \\
\text { das tensões } \\
\text { paradoxais }\end{array}$ & $\begin{array}{ll}\text { Dimensões } & \\
\text { sintáticas } & \text { do } \\
\text { modelo } & \text { de } \\
\text { negócios } & \end{array}$ & $\begin{array}{l}\text { Questões subjacentes chaves } \\
\text { definindo o rótulo modelo de } \\
\text { negócios }\end{array}$ & $\begin{array}{l}\text { Audiência } \\
\text { alvo } \\
\text { dominante }\end{array}$ & $\begin{array}{l}\text { Desenho de } \\
\text { pesquisa } \\
\text { prevalecente }\end{array}$ & $\begin{array}{l}\text { Relação } \\
\text { acadêmica } \\
\text { com a } \\
\text { pesquisa } \\
\text { prévia }\end{array}$ \\
\hline $\begin{array}{l}\text { "Orgulho da } \\
\text { observação" }\end{array}$ & Configuração & $\begin{array}{l}\text { Como se vê um modelo desde } \\
\text { dentro? }\end{array}$ & Mista & $\begin{array}{l}\text { Empírico, } \\
\text { dirigido } \\
\text { pelos dados }\end{array}$ & Baixa \\
\hline $\begin{array}{l}\text { "Miopia da } \\
\text { eliminação" }\end{array}$ & Classificação & $\begin{array}{l}\text { O que é modelo de negócios } e \\
\text { o que não é? }\end{array}$ & $\begin{array}{l}\text { Acadêmica, } \\
\text { erudita }\end{array}$ & Misto & Alta \\
\hline $\begin{array}{l}\text { "Tentação de } \\
\text { não deixar a } \\
\text { mesa de } \\
\text { desenho" }\end{array}$ & Constituição & $\begin{array}{l}\text { Do que está construído um } \\
\text { modelo de negócios? }\end{array}$ & $\begin{array}{l}\text { Praticante, } \\
\text { gerencial }\end{array}$ & $\begin{array}{l}\text { Conceitual, } \\
\text { dirigido pela } \\
\text { teoria }\end{array}$ & Média \\
\hline
\end{tabular}

FONTE: TRADUZIDO DE KLANG; WALLNOFER; HACKLIN; 2014, p. 472.

Tem se debatido bastante sobre as abordagens e perspectivas que participam na discussão sobre os modelos de negócios. Makinen e Seppanen (2007) ao fazer um contraste com critérios taxonômicos acharam que as conceitualizações sobre negócios existentes na sua época obedeciam fracamente a tais critérios, chegando a serem estas concepções desde incomensuráveis até quase enganosas. Porém os autores reconheciam indícios de convergência em certas definições básicas e funções (Ibid., p. 744) e realçavam que a confusão resultante da existência de múltiplas perspectivas na busca por definições unificadas era sinal de que o campo estava avançando no seu inquérito científico.

Christoph Zott e Raphael Amit, pesquisadores reconhecidos pela sua dedicação ao estudo do termo, na sua publicação mais recente até a data (ZOTT; AMIT, 2013), apresentam sua posição sobre o modelo de negócios como um constructo robusto, teoricamente falando. Para Priem, Butler e Li (2013, p. 480) o conceito de BM adiciona uma visão mais holística e baseada em alinhamento (fit-based) da administração estratégica, razão pela qual os autores chamam a atenção na sua direção. Enquanto que para Keen e Qureshi (2006, p. 1) é um constructo intelectual necessário.

As preocupações teóricas acerca de uma sobreposição com outros conceitos estabelecidos, uma falta de independência, uma falta de unicidade, uma falta de definição consistente e uma 
falta de suporte empírico na abordagem de modelos de negócios proclamadas por Arend (2013) são rebatidas por Zott e Amit (2013, p. 404-406).

Os pesquisadores Zott, Amit e Massa (2011) identificaram uma utilização do termo para explicar principalmente três fenômenos: e-business, questões estratégicas e gestão de inovação e tecnologia. Contudo, eles acharam os seguintes pontos comuns pregoando que podem ser ponto de partida para o avanço da pesquisa na área:

a) BM emergindo como uma nova unidade de análise;

b) BM enfatiza abordagem ao nível de sistema, holístico;

c) Atividades organizacionais jogam um papel importante;

d) BM busca explicar como o valor é criado e capturado, não só o último.

Segundo Nenonen e Storbacka (2010, p. 45) as similitudes que podem ser identificadas entre as numerosas e diversas definições achadas na sua revisão são:

a) a maioria das definições inclui a criação de valor para o cliente como elemento essencial;

b) a lógica dos ganhos (receita/lucro) é também mencionada;

c) muitas das definições discutem a rede de valor da firma, sugerindo que o conceito deve ser orientado para fora e iluminar sobre as relações com os vários atores;

d) muitas definições discutem os recursos e capacidades que a firma tem;

e) a maioria das definições analisadas discute algum tipo de decisões estratégicas, escolhas ou princípios.

Para Baden-Fuller e Mangematin (2013, p. 419) sim existe consenso entre os acadêmicos nos seguintes aspectos: o modelo tem que ligar empregados dentro da firma com elementos externos, incluindo o lado do cliente e como o valor é capturado.

Morris, Schindehutte e Allen (2005, p. 726), como resultado da aplicação de uma análise de conteúdo a 30 definições sobre modelos de negócio, identificaram três categorias gerais de definições ordenadas hierarquicamente: econômicas, operacionais e estratégicas. No nível mais básico (econômico) a preocupação é com a lógica de geração de lucro. No seguinte nível, operacional, o modelo representa uma configuração arquitetural, com um foco em 
processos e desenhos estruturais. Já no nível estratégico, as definições enfatizam direção global na posição da firma, interações através de fronteiras organizacionais e oportunidades de crescimento. Os autores evidenciaram que estas últimas foram as mais proeminentes (Ibid., p 727).

Também como resultado da aplicação da técnica de análise de conteúdo em definições existentes na literatura acadêmica internacional de primeira linha, Al-Debei e Avison (2010) encontraram 13 classes individuais mutuamente excludentes relacionadas a diferentes aspectos do conceito. Os autores conseguiram classificar estas em quatro classes superiores, a saber: as dimensões V4BM (quatro classes ligadas ao valor), os princípios de modelagem, o alcance do BM e as funções do BM (Ibid., p. 365).

Parece evidente que na exploração da literatura que discutiu algo sobre o conceito de modelo de negócios, existe uma recorrência a estabelecer os seus elementos componentes (Ver RICHARDSON, 2008 para uma comparativa dos componentes apresentados por diferentes autores), como auxílio na busca da compreensão e de sua explicação. Esta observação também e mencionada em Zott, Amit e Massa (2011). Para Klang, Wallnöfer e Hacklin (2014, p. 471) há, em geral, pouco consenso em como os componentes sugeridos dão forma ao conceito. Shafer, Smith e Linder (2005, p. 200-201) apresentam um detalhe do grande número de componentes diferentes identificados na literatura até sua época. Onetti et al. (2012) atualizam esse trabalho e concluem que uma escassa correlação e outras características indicam que ainda existe ambiguidade e falta de consenso na definição dos componentes de um BM.

Outra corrente aparentemente evidente tem a ver com as publicações que tentam se aproximar ao conceito apresentando taxonomias sobre os diferentes modelos existentes. Nesta linha se encontram publicações como as de Tsalgatidou e Pitoura (2001), Mahadevan (2000), Lechner e Hummel (2002), e Rappa (2004) por citar só alguns exemplos. As pesquisas de Pateli e Giaglis (2004), e de Zott, Amit e Massa (2011, p. 1025) observam este fenômeno no caso de literatura sobre e-business. Baden-Fuller e Mangematin (2013, p. 420) entendem que na sua maioria, as tentativas para descrever os modelos de negócios na literatura acadêmica e praticante são taxonômicas (exemplos), existindo carência de tipologias (conceituais) robustas. 
Outro grupo de autores dentro da pesquisa da temática se distingue pelo seu interesse por criar uma ontologia ao redor do conceito, o que implica uma conceitualização e formalização de elementos, relações, vocabulário e semânticas, segundo Zott, Amit e Massa (2011, p. 1026). Neste grupo se podem incluir pesquisas do tipo Osterwalder (2004), Osterwalder e Pigneur (2004), e, Al-Debei e Avison (2010).

Outra das linhas que tem impulsionado a abordagem do conceito de modelo de negócios tem a ver com o estudo da inovação em modelos de negócios. Zott, Amit e Massa (2011, p. 10331034) documentam a pesquisa existente sobre modelo de negócios sob este domínio. Em resumo, esta se caracteriza por dois temas principais: comercialização de inovações através de BMs e a inovação de BMs como um tipo adicional de inovação (TEECE, 2010, p. 186-187) além dos tipos tradicionais. Como resultado da sua revisão nessa área, George e Bock (2011, p. 88) assinalam que se sugere que o modelo de negócios pode ser um vínculo importante entre inovação e estrutura organizacional.

Alguns exemplos de publicações representativas desta linha preocupada com o tema de inovação e modelo de negócios são as publicações de Chesbrough (2007, 2010); Schneider e Spieth (2013); e Sorescu et al. (2011). Exemplos de publicações sobre modelos de negócios ligados à temática de tecnologia são Chesbrough e Rosenbloom (2002) e Baden-Fuller e Haefliger (2013).

Resulta merecedora de menção e possível futuro aprofundamento na análise, a utilização do conceito na abordagem em casos não comumente encontrados na literatura principal sobre o assunto, a qual faz referência a aspectos ligados a transações e resultados monetários ou de competitividade. São exemplos Seelos e Mair (2007), os quais usando o conceito de BM abordaram temas ligados à criação de mercados em contextos de pobreza, e Yunus, Moingeon e Lehmann-Ortega (2010), os quais propõem a construção de modelos de negócios sociais. Outros exemplos de uso não tradicional do termo são encontrados em Dahan et al. (2010); Eyring, Johnson, Nair (2011); e; Boons e Ludeke-Freund (2013).

Baden-Fuller e Mangematin (2013, p. 423) assinalam que a pesquisa emergente nestas áreas está revelando (unpacking) diferenças nas capacidades cognitivas requeridas sob estes casos. Arend (2013, p. 395-398) também as considera áreas de possível exploração (no sentido exploit). 
Sobre a utilização do constructo como variável que intervém em pesquisas empíricas, Zott, Amit e Massa (2011, p. 1030) documentam diferentes casos nos quais "modelo de negócios" foi utilizado como variável em modelos como variável independente, variável moderadora. Ao respeito, a pesquisa de Zott, Amit e Massa (2011, p. 1032-1034) sobre a relação inovação tecnológica-modelo de negócios insinua um relacionamento da variável modelo de negócios com a outra, como antecedente, algumas vezes e como consequência, noutras.

O estudo sobre os antecedentes dos modelos de negócio aparenta estar pouco investigado na pesquisa acadêmica, existindo alguma referência a explorações em andamento como, por exemplo, mencionam Zott e Amit (2013, p. 404), os quais derivaram quatro antecedentes para o desenho de modelo de negócios como são as metas, os padrões (templates), as atividades dos stakeholders, e as restrições do ambiente.

A contribuição, as limitações e as principais características da pesquisa empírica sobre modelo de negócios, entre 1996 e 2010, são apresentadas em Lambert e Davidson (2013).

A seguir, descrevemos alguns dos enfoques distintivos sobre modelos de negócios identificados na revisão bibliográfica.

\subsubsection{O modelo de negócios e sua relação com o conceito de valor}

Ghaziani e Ventresca (2005) mostram que Criação de Valor resulta um dos frames (princípios) importantes na sua análise sobre o uso de modelo de negócios como palavrachave na conversa pública. Como resultado importante, Zott, Amit e Massa (2011, p. 1037) destacam que o componente mais prevalente e comum nas suas três áreas identificadas na abordagem do modelo de negócios é o conceito de valor. Assim mesmo, Zott e Amit (2013, p. 403) chamam a integrar teorias sob a perspectiva dos modelos de negócios na criação de valor.

Teece (2010, p. 172, tradução nossa) postula que “A essência de um modelo de negócios está em definir a maneira pela qual a empresa entrega valor aos clientes, incita os clientes a pagar 
pelo valor e converte esses pagamentos em lucro."11. Assim mesmo, para o autor (Ibid., p. 184) enxergar como entregar valor e capturá-lo são questões chave no desenho do modelo de negócios, não sendo suficiente executar o primeiro sem a premissa do segundo.

Para Al-Debei e Avison (2010) as quatro classes constitutivas do que eles chamam como as dimensões V4BM, estão ligadas ao conceito de valor e “[...] representam os constructos primários e dimensões do conceito de BM."12 (Ibid., p. 365, tradução nossa).

Entre os autores que falam da importância do valor para o conceito de modelo de negócios, pode-se incluir Johnson, Christensen e Kagermann (2008) para os quais os quatro elementos que constituem um modelo de negócios são: a Proposição de valor para o cliente; a Fórmula de lucro; os Recursos chave; e os Processos chave, sendo o primeiro elemento o mais importante para eles. Dentro da fórmula de lucro os autores inserem o modelo de receita, a estrutura de custos, o modelo de margem, e a velocidade de recursos. Na concepção dos autores (JOHNSON, CHRISTENSEN E KAGERMANN, 2008, p. 53) os quatro elementos estão interligados e mudanças em qualquer um dos quatro, afetam aos outros e ao tudo. De maneira muito similar, para Demil e Lecocq (2010) os três componentes essenciais que descrevem um BM são: Recursos e Competências, Estrutura Organizacional, e Propostas para entrega de valor.

Nas pesquisas de Voelpel et al. (2005) e Voelpel, Leibold e Tekie (2004), a abordagem sobre modelo de negócios tem a ver exclusivamente com aspectos relacionados ao valor: proposta de valor para o cliente, configuração da rede de valor para sua criação, e retorno para os stakeholders.

Os autores (MORRIS; SCHINDEHUTTE; ALLEN, 2005, p. 729-730) determinam os chamados componentes, mas descritos como fatores, que constituem um modelo de negócio em função a seis perguntas derivadas das perspectivas encontradas na sua revisão de literatura. Estes componentes e suas perguntas são correspondentemente:

a) Fatores relacionados à proposta: Como se cria valor?;

11 "The essence of a business model is in defining the manner by which the enterprise delivers value to customers, entices customers to pay for value, and converts those payments to profit."

12 "[...] represent the primary constructs and dimensions of the BM concept." 
b) Fatores de mercado: Para quem se cria valor?;

c) Fatores de capacidade interna: Qual a fonte de competência?;

d) Fatores estratégicos competitivos: Como nos posicionamos competitivamente?;

e) Fatores econômicos: Como fazer dinheiro?;

f) Fatores pessoais/investidor: Qual o tempo, escopo e ambições de tamanho?.

Para Amit e Zott (2001) a criação de valor perpassa os limites (boundaries) de empresas e indústrias, sendo o modelo de negócios uma unidade de análise mais apropriada como conceito nesse caso. Os autores (AMIT; ZOTT, 2001, p. 511, tradução nossa) definiram o modelo de negócios indicando que “[...] representa o conteúdo, a estrutura e a governança das transações designadas de modo a criar valor através da exploração de oportunidades de negócio."13.

Zott e Amit (2013, p. 403) recapitulam a argumentação desenvolvida nas suas pesquisas de mais de uma década (cf. Amit e Zott, 2001) indicando que os modelos de negócios podem criar valor através da eficiência (Teoria dos Custos de Transação); da novidade (Schumpeter), das complementaridades (VBR); e do lock-in (Redes estratégicas). Morris, Schindehutte e Allen (2005, p. 727-729) também postulam que a construção do conceito de modelo de negócios se ancora em muitas dessas tradições teóricas.

Na compreensão de Zott e Amit (2013, p. 404 , tradução nossa) os modelos de negócios, embora ancorados na firma, são "[...] mercado centristas e desenhados de forma a permitir à firma focal, não só aumentar o valor total para todos os participantes do modelo de negócios, mas também apropriar uma parte do valor criado."14

Deve-se mencionar que os autores (AMIT; ZOTT, 2001) posicionaram sua conceitualização sob esta linha originalmente, adicionando as atividades posteriormente devido a sua importância para o conceito na sua consideração, como se discutirá no item 3.2.2 desta dissertação.

\footnotetext{
13 "A business model depicts the content, structure, and governance of transactions designed so as to create value through the exploitation of business opportunities."

14 "[...] market centric and designed so as to enable the focal firm not only to enhance total value for all business model participants but also to appropriate a share of the value created."
} 
Embora fortemente posicionados sob um enfoque estratégico dos modelos de negócios, Casadesus-Masanell e Ricart (2010) sugerem que sua concepção do termo se enquadra nessa categoria ao assegurar que as firmas escolhem a lógica de criação de valor e de captura de valor, escolhendo seus modelos de negócios (Ibid., p. 196).

Dasilva e Trkman (2013, p. 4, tradução nossa), apoiando-se sobre as teorias da Visão Baseada em Recursos e da Economia dos Custos de Transação, entendem modelo de negócios como uma representação de uma “[...] combinação específica de recursos, a qual mediante transações, gera valor tanto para clientes como a organização."15

Na conclusão de Zott, Amit e Massa (2011, p. 1031) o modelo de negócios não envolve um mecanismo linear de criação de valor, porque envolve um complexo conjunto de interrelações de troca e atividades entre múltiplos atores. Outra das conclusões sustentadas pela pesquisa dos autores (ZOTT; AMIT, 2010; ZOTT; AMIT; MASSA, 2011) é que o modelo de negócios não pode ser reduzido às questões relativas à organização interna, porque perpassa esses limites.

Na sua discussão da relação estratégia-modelo de negócios, Zott, Amit e Massa (2011, p. 1031) apontam que um dos dois principais fatores diferenciadores que têm chamado a atenção dos acadêmicos na área é o foco do conceito de $\mathrm{BM}$ com os aspectos de proposta de valor e a ênfase no papel do cliente. Sendo a criação de valor centrada no cliente (customer-focused value creation) um dos elementos de forte consenso revelado na revisão dos autores (Ibid.). Adicionalmente, os autores (ZOTT; AMIT; MASSA, 2011, p. 1037) chamam a atenção ao fato de que a ênfase no estudo acadêmico do conceito tem se movimentado da captura de valor para a criação de valor, mas ressaltando a segunda, não ignorando a primeira, algo que eles chamam de foco dual.

Na visão de Chesbrough (2007) as duas funções centrais dos BM são: criar valor e capturar valor, e existe tensão entre as duas. O autor (CHESBROUGH, 2007) apresenta sua definição de modelo de negócios fazendo uso de seis parâmetros, associados a umas respectivas funções: Proposta de Valor; Segmento de Mercado; (Estrutura da) Cadeia de Valor;

\footnotetext{
15 “[...] a specific combination of resources which through transactions generate value for both customers and the organization."
} 
Mecanismo de Geração de Ingresso (e Estrutura de Custos); Posição na Rede de Valor ou Ecossistema; Estratégia Competitiva.

Duas observações surgem da apresentação dos parâmetros prévios, que são a inclusão de Estratégia como elemento do modelo, ingressando na discussão sobre Estratégia e Modelo de Negócios, e a consideração do elemento Cadeia de Valor.

Betz (2002) diretamente realiza uma equivalência entre cadeia de valor e modelo de negócios. Para o autor: "Modelos de negócios são abstratos sobre como os insumos para uma organização são transformados em produtos de valor agregado."16 (Ibid., p. 21). Betz (2002) continua afirmando que "[...] uma versão importante destes [modelos de organização] é o agora famoso modelo de 'valor agregado' de Michael Porter [...]”, e, “[...] O modelo de Porter é somente um de vários tipos de modelos de negócios que um pode usar em planejamento estratégico."17 (Ibid., tradução nossa).

Embora definindo os modelos de negócios como narrativas, como se citou previamente, Magretta (2002) considera que os BMs são variações na cadeia de valor genérica subjacente em todos os negócios. Para a autora estas cadeias têm duas partes: atividades associadas com fazer algo e atividades associadas com vender algo. Baden-Fuller e Mangematin (2013, p. 420) na sua própria tipologia, também propõem dentro dos seus elementos: a cadeia de valor e as ligações (linkages).

A visão dos modelos de negócio como cadeia de valor é contestada por Teece (2010, p. 191) quando afirma que um modelo de negócios aborda apenas parcialmente como organizar a cadeia de valor, posto que se trata também sobre enxergar tanto a proposição de valor quanto os mecanismos de captura de valor.

Zott e Amit (2013, p. 408) entendem que o enfoque de valor se centra na criação de valor no nível da empresa e consideram esse como influente na representação e análise nesse nível de criação de valor, mas sugerindo ser inadequado ante o nascimento de novas formas organizacionais em rede. Particularmente, para os autores (ZOTT; AMIT, 2013) a noção de

\footnotetext{
16 "Business models are abstracts about how inputs to an organization are transformed to value-adding outputs."

17 "[...] one important version of this is the now famous "value-added" model of Michael Porter [...] The Porter model is only one of several kinds of business models one can use in strategic planning."
} 
modelo de negócios perpassa a ideia de cadeia de valor, a qual permanece centrada na firma, representando uma extensão. Segundo Zott e Amit (2013, p. 408), o conceito de modelo de negócios estende aos argumentos do framework de cadeia de valor por ser focado na criação de valor total, enfatizar as dinâmicas da criação e entrega de valor, e por permitir um sequenciamento não linear de atividades interdependentes.

Timmers (1998, p. 4) indica que uma abordagem sistemática para identificar arquiteturas para os modelos de negócios pode ser baseada na "de-construção" e "re-construção" da cadeia de valor. A relação conceitual entre modelos de negócios e "desconstrução" (i.e. desconstruir cadeias de valor integradas verticalmente) é importante de acordo com a visão de Schweizer (2005). O autor entende que definir modelos de negócios pode significar enfocar passos específicos na cadeia de valor (Ibid., p. 37). Com tal ação os novos modelos de negócio poderiam minar ou acabar com a vantagem competitiva de empresas com cadeias de valor completamente integradas.

Para Schweizer (2005, p. 39) "[...] cada parte da cadeia de valor pode servir como fonte de criação de valor e novos modelos de negócios." 18 O autor aponta como diferença entre os conceitos que a cadeia de valor se centra no fluxo de produtos através de uma organização, enquanto que o modelo de negócios, nos diferentes passos executados para completar uma determinada tarefa (Ibid., p. 41) e coloca ênfase nos relacionamentos. Por tanto, a abordagem de modelo de negócios como unidade de análise tem um escopo mais amplo segundo o autor.

Uma das três dimensões constituintes de um modelo de negócios para Schweizer (2005) é a “constelação de cadeia de valor", a qual define como a companhia está posicionada na sua indústria e como assinala criar valor agregado, sendo uma das perguntas-chave para entender o modelo de negócios de uma empresa: "Como está configurada a cadeia de valor de uma companhia condizente com a cadeia de valor da indústria considerada?"19 (Ibid., p. 43, tradução nossa).

As cadeias de valor junto as suas ligações são uma das quatro dimensões apontadas por Baden-Fuller e Mangematin (2013, p. 421-422) na sua tipologia de modelos de negócios.

\footnotetext{
18 "[...] each part of the value chain, can serve as the source of value creation and new business models."

19 "How is the value chain of the company configured with respect to the considered industry value chain?"
} 
Dada a importância do elemento para o conceito "modelo de negócios", como sugere a literatura, se incorpora Valor como um elemento na constituição do construto. A bibliografia revisada alude a dois temas a serem estudados: a criação de valor e a captura de valor. No construto proposto nesta pesquisa se coloca o tema de Valor como elemento de intercâmbio entre a organização e outros atores que se encontram fora dos seus limites.

\subsubsection{O modelo de negócios relacionado com as atividades}

Zott, Amit e Massa (2011, p. 1037) sugerem que a pesquisa que trata o tema de modelo de negócios em relação a processos, funcionalidades e transações se enquadra nesta subcategoria. Eles (ZOTT; AMIT; MASSA, 2011, p. 1020) apontam que as atividades, tanto da firma quanto dos parceiros, desempenham um papel importante nas conceitualizações, sendo este um dos quatro temas emergentes que identificaram em sua pesquisa.

Atividades são definidas como o comprometimento de recursos humanos, físicos e/ou de capital de qualquer parte do modelo de negócios para servir um propósito específico para o cumprimento do objetivo geral. (ZOTT; AMIT, 2010, p. 217). Algumas dessas atividades são realizadas internamente pela empresa, e outras, fora.

Para George e Bock (2011, p. 88): “As definições do construto, mais rigorosas e atraentes na literatura, centram-se em estruturas transacionais como fluxos de logística e renda." ${ }^{20}$ Sua posterior verificação empírica (Ibid., p. 98), encontrou que essa natureza transacional é recorrente.

No desenvolvimento teórico de McGrath (2010) os dois componentes centrais que constituem um modelo de negócios são as unidades de negócio (entendidas lá como aquilo pelo que os clientes pagam) e as vantagens de processo. Nestas segundas, decisões são tomadas acerca de que conjuntos de atividades são empregados para vender as unidades de negócio. Por sua parte, quando Magretta (2002) diz que os modelos de negócio se relacionam com as cadeias de valor, fazendo referência às atividades que são parte dessa cadeia.

\footnotetext{
20 "The most rigorous and engaging construct definitions in the literature center on transactive structures such as the streams of logistics and revenue."
} 
Em Zott e Amit (2010) se apresenta a conceitualização de modelos de negócios sob uma perspectiva de sistema de atividades, definindo-se este, por sua vez, como o conjunto de atividades organizacionais interdependentes centradas na firma focal (Ibid, p. 217). Para os autores dois grupos de parâmetros para considerar, surgem quando se desenha um sistema de atividades: Elementos de Desenho (Conteúdo, Estrutura e Governança) e Temas de Desenho (Novidade, Lock-in, Complementaridades, e Eficiência).

Baseados na corrente teórica dos sistemas de atividades, Zott e Amit (2013, p. 408) expressam a necessidade de desenvolver entendimento sobre como desenhar modelos de negócios que sejam: internamente consistentes, isto é, que as atividades se reforcem mutuamente; consistentes com outros elementos que caracterizam a firma; e consistentes com os modelos de outras firmas que contribuem desenvolvendo atividades que são parte do modelo de negócios da firma focal.

Mediante uma abordagem diferente, Onetti et al. (2012, p. 360, tradução nossa) definem modelo de negócios como "[...] a forma como uma companhia estrutura suas próprias atividades na determinação do focus, locus e modus do seu negócio." ${ }^{21}$ Os pesquisadores consideram que o centro de sua definição está nas atividades da companhia.

Focus, Locus e Modus são explicados pelos autores (ONETTI et al., 2012) como blocos de construção analítica, onde as decisões de foco têm a ver com a alocação dos recursos às diferentes atividades; as decisões de local, com onde as diferentes atividades das empresas estão locadas; e por fim, as decisões sobre "modus", com a forma na qual uma companhia opera na seleção de métodos de administração para cada atividade.

No estudo da inovação em modelos de negócios varejistas de Sorescu et al. (2011), as atividades desempenham um papel importante. Os autores compreendem essa inovação como mudanças na forma que as atividades são organizadas, no tipo de atividades executadas, e no nível de participação dos atores engajados nessas atividades. Para Sorescu et al. (2011, p. S4): "[...] um modelo de negócios pode esboçar como a firma cria valor para os clientes via

21 "[...] the way a company structures its own activities in determining the focus, locus and modus of its business." 
atividades relacionadas ao desenvolvimento de produto e à precificação flexível."22, e em palavras dos autores, um aspecto central de sua definição de um BM é que "[...] incorpora interdependências que transformam um conjunto de estruturas, atividades, e processos num sistema integrado."23 (Ibid.)

As atividades, entendidas como comprometimento de recursos, são então, um dos elementos presentes na organização que definem o modelo de negócios, pelo que são inclusas no constructo da pesquisa.

\subsubsection{O modelo de negócios como desenho (design)}

Uma das linhas que aparenta ter influência na concepção sobre os modelos de negócios, condiz com uma compreensão com base em seu desenho. Por exemplo, Osterwalder, Pigneur e Tucci (2005, p. 2, tradução nossa) conceituaram o modelo de negócios como uma "cópia heliográfica" ("blueprint”) de como uma companhia faz negócios. ${ }^{24}$

Na sua obra (OSTERWALDER, PIGNEUR; TUCCI, 2005; OSTERWALDER; PIGNEUR, 2004, 2010, 2011) os autores Alexander Osterwalder e Yves Pigneur compõem o modelo de negócios de uma organização mediante nove blocos chamados de construção:

a) Proposta de valor (Value Proposition);

b) Segmentos de Clientes (Target Customer);

c) Canais (Distribution Channel);

d) Relacionamento com clientes (Relationship);

e) Recursos principais (Key Resources);

f) Atividades chave (Key Activities/ Core Competency);

g) Parcerias principais (Partner Network);

h) Estrutura de Custo (Cost Structure);

i) Fontes de Receita (Revenue Model).

\footnotetext{
22 "[...] a business model may outline how the firm creates value for customers via activities related to product development and flexible pricing."

23 "[...] incorporates interdependencies that transform a set of structures, activities, and processes into an integrated system."

24 "[...] as the blueprint of how a company does business."
} 
Para os autores

\begin{abstract}
Um modelo de negócios é uma ferramenta conceitual que contém um conjunto de objetos, conceitos e seus relacionamentos com o objetivo de expressar a lógica de negócios de uma firma específica. Portanto, devemos considerar quais conceitos e relacionamentos permitem uma descrição e representação simplificadas do que valor é providenciado aos consumidores, como isso é feito e com quais consequências financeiras. (OSTERWALDER, PIGNEUR; TUCCI, 2005, p. 3 , tradução nossa).
\end{abstract}

A business model is a conceptual tool containing a set of objects, concepts and their relationships with the objective to express the business logic of a specific firm. Therefore we must consider which concepts and relationships allow a simplified description and representation of what value is provided to customers, how this is done and with which financial consequences. (OSTERWALDER, PIGNEUR; TUCCI, 2005, p. 3).

No contexto de sua pesquisa na área de empreendedorismo e PMEs, George e Bock (2011, p. 99, tradução nossa) conseguem construir um conceito de modelo de negócios como "[...] $o$ desenho de estruturas organizacionais que efetivam uma oportunidade comercial." 25 .

O framework teórico proposto por Nenonen e Storbacka (2010) contém três tipos de componentes: Princípios de Desenho; Recursos e Capacidades. Cada um deles é cruzado com outras quatro dimensões: mercado, proposta, operações e gestão. Destacam os princípios de desenho pelas definições que estabelecem no modelo. Segundo a pesquisa dos autores (NENONEN; STORBACKA, 2010, p. 51), nenhum desenho de modelo de negócios se revela como superior per se, sendo que diferentes configurações podem atingir resultados igualmente sólidos, financeiramente falando. Os pesquisadores propõem que os modelos de negócios "[..] sejam vistos como constelações de elementos de desenho que são orquestrados por um único tema."26 (Ibid., p. 52, tradução nossa).

Embora ressaltando a importância do conceito valor na construção da essência de um modelo de negócios, para Teece (2010, p. 173, tradução nossa) "[..] um modelo de negócios representa nada menos que a 'arquitetura' organizacional e financeira de um negócio." ${ }^{27} \mathrm{De}$ forma similar, para Smith, Binns e Tushman (2010, p. 450, tradução nossa), modelo de negócios significa:

\footnotetext{
25 "[...] the design of organizational structures to enact a commercial opportunity."

26 "[...] be viewed as constellations of design elements that are orchestrated by a single theme."

27 "[...] a business model embodies nothing less than the organizational and financial 'architecture' of a business."
} 
[...] o desenho pelo qual uma organização converte um conjunto dado de escolhas estratégicas [...] em valor, e usa uma arquitetura organizacional particular - de pessoas, competências, processos, cultura e sistemas de mensuração - a fim de criar e capturar esse valor.

[...] the design by which an organization converts a given set of strategic choices [...] into value, and uses a particular organizational architecture - of people, competencies, processes, culture and measurement systems - in order to create and capture this value.

Por sua parte, Timmers (1998, p. 4, tradução nossa) define modelo de negócios como "Uma arquitetura para os fluxos de produto, serviço e informação, incluindo a descrição dos vários atores de negócios e os seus papeis [...]"28.

Mais próximos a esta visão, Baden-Fuller e Mangematin (2013, p. 419) postulam que os modelos de negócios são um exemplo especial de configuração. Para os autores, os modelos não devem ser uma descrição completa do que a firma faz, mas ser uma caracterização desmontada (stripped-down) que capture a essência das relações causa-efeito entre os consumidores, a organização e o dinheiro. Pensando num nível maior de agregação, pode-se mencionar que, para Mason e Spring (2011, p. 1035, tradução nossa): "Quase toda a literatura de modelo de negócios reconhece a arquitetura da rede de negócios." ${ }^{29}$, e por isso incluem esta como um dos três elementos dos modelos de negócios.

\subsubsection{O modelo de negócios como lógica}

Para Keen e Qureshi (2006, p. 2, tradução nossa) um dos temas comuns emergentes nas definições sobre modelo de negócios é que estas enfatizam que BM “[...] é uma declaração da 'lógica' básica do negócio; é uma abstração de proposições, articuladas como reivindicações e intenções." 30 Segundo eles: “'Lógica' e 'valor' são palavras-âmago na literatura sobre modelos de negócios." (Ibid.) $)^{31}$

Segundo Chesbrough e Rosenbloom (2002, p. 529, tradução nossa): "Um modelo de negócios bem sucedido cria uma lógica heurística que conecta o potencial técnico com a realização de

\footnotetext{
28 "An architecture for the product, service and information flows, including a description of the various business actors and their roles [...]"

29 "Almost all of the business model literature recognises the architecture of the business network."

30 "[...] is a statement of the basic "logic" of the business; it is an abstraction of propositions, articulated as claims and intentions."

31 " "Logic" and "value" are core words in the literature on business models."
} 
valor econômico."32, e, "Lógica heurística é requerida para descobrir um modelo de negócios apropriado[...]"33 (Ibid., p. 550). Chesbrough e Rosenbloom (2002) sugerem que a lógica dominante da corporação é derivada do seu modelo de negócios estabelecido.

Casadesus-Masanell e Ricart (2010) observam que a noção de modelo de negócios como lógica da firma, i.e. como opera e cria valor para seus stakeholders, apresenta-se muito similar ao que se entende por estratégia. Casadesus-Masanell e Ricart $(2010,2011)$ se aderem inicialmente a este tipo de abordagem, acrescentando na teorização do conceito ao distinguir que os BM estão conformados por escolhas e consequências.

\subsubsection{O modelo de negócios como narrativa}

Segundo Magretta (2002, p. 87, tradução nossa) os modelos de negócio são “[...] histórias que explicam como as empresas trabalham."34 Para Magretta (2002) os modelos funcionam quando passam dois testes: o da narrativa e o dos números.

Somando-se e aprofundando neste tipo de abordagem se encontram Doganova e EyquemRenault (2009) para as quais modelo de negócios é um artefato (device) narrativo e calculista que permite os empreendedores explorarem o mercado. Para as autoras (Ibid,. p. 1562), os BMs são distintivos por essa mistura de contação de história (story-telling) e cálculo (calculation). Na sua visão, narrativa e cálculo são complementares num modelo de negócios.

Para Doganova e Eyquem-Renault (2009, p. 1567) a coerência dessa narrativa é assegurada pela sua trama, a qual jaz na tensão entre oportunidade e habilidade para explorá-la. Fazendo referência a seu entendimento de modelo em geral, as autoras sugerem que os modelos de negócios mais do que descrição são uma "demonstração" (Ibid., p. 1568).

Segundo Keen e Qureshi (2006, p. 9, tradução nossa): "Modelos de negócios são uma narrativa. Eles devem ser simples na sua declaração e ajudar a mobilizar stakeholders relevantes." 35 .

\footnotetext{
32 "A successful business model creates a heuristic logic that connects technical potential with the realization of economic value."

33 "Heuristic logic is required to discover an appropriate business model [...]"

34 “[...] are stories that explain how enterprises work."
} 
George e Bock (2011, p. 87) consideram que o modelo de negócios como mecanismo narrativo limita o escopo da pesquisa à formação de historias e à catalogação de pontos comuns narrativos.

\subsection{Funções atribuídas aos modelos de negócios}

Para Osterwalder, Pigneur e Tucci (2005) as funções dos modelos de negócios são: Compreensão e compartilhamento, Análise, Administração, Prospecção, e Patenteamento. AlDebei e Avison (2010, p. 359) consideram que os modelos de negócios fornecem formas poderosas para entender, analisar, comunicar e administrar escolhas estrategicamente orientadas.

Para Magretta (2002, p. 90) o grande ponto forte dos modelos de negócio é o de focar a atenção em como todos os elementos do sistema encaixam num todo. Para ela um bom modelo de negócios (que na sua visão equivale a uma boa história) pode servir para alinhar a organização nos seus valores. Da mesma forma, a autora apregoa que o BM poder ser uma poderosa ferramenta para a execução. Por sua parte, Mason e Spring (2011, p. 1038, tradução nossa) asseveram que "Os modelos de negócios podem ser entendidos como um mecanismo de framing para influenciar e moldar a ação coletiva e individual." 36 .

Al-Debei e Avison (2010, p. 369) indicam que o BM providencia uma visão holística de um negócio, a qual não só é útil para entender uma estrutura interna e suas funções, senão também para enxergar como uma organização se conecta e interage com seu ambiente externo.

Chesbrough $(2007,2010)$, em associação com os seis parâmetros que providencia para ajudar a sua definição de modelo de negócios (CHESBROUGH, 2007, p. 13), apresenta seis funções do modelo de negócios as quais são: Articular a proposta de valor; identificar o segmento de

\footnotetext{
35 "Business models are a narrative. They must be simple in their statement and help to mobilize relevant stakeholders."

36 "Business models can be understood as a framing device for influencing and shaping collective and individual action."
} 
mercado; definir a estrutura da cadeia de valor requerida pela firma; especificar o mecanismo geração de renda e estimar a estrutura de custos; descrever a posição da firma na rede de valor (ecossistema); e formular a estratégia competitiva.

Para o autor (CHESBROUGH, 2007, p. 12, tradução nossa): “Um melhor modelo de negócios frequentemente vai derrotar uma melhor ideia ou tecnologia." ${ }^{, 2}$. Na mesma linha, Johnson, Christensen e Kagermann (2008) consideram que uma inovação em produto/tecnologia não é suficiente, e se precisa um BM ótimo para ter sucesso. Para Zott, Amit e Massa (2011, p. 1032) um dos papéis identificados dos modelos de negócios é o de destravar o potencial de novas tecnologias convertendo-o em resultados de mercado.

Teece (2010, p. 172) afirma que sem um modelo de negócios bem desenvolvido, inovadores vão fracassar, quer entregando quer capturando valor das suas inovações. Em suas palavras, eles “[...] precisam sobressair não são na inovação de produtos, mas também no desenho de modelos de negócios."38 (Ibid., p. 173).

Chesbrough (2010) afirma que a mesma ideia ou tecnologia trazida ao mercado através de dois modelos de negócios diferentes vai derivar em dois resultados econômicos diferentes também. Nas suas palavras (Ibid. p. 355) provavelmente “[...] uma tecnologia medíocre seguida dentro de um modelo de negócios grandioso pode ser mais valiosa que uma grandiosa tecnologia explorada via um modelo de negócios medíocre." ${ }^{\text {39. }}$

Segundo Doganova e Eyquem-Renault (2009, p. 1567) e sua concepção dos modelos de negócios na base de narrativa e cálculo, esta combinação (n-c) é particularmente relevante em situações de incerteza.

Para George e Bock (2011, p. 99):

Um modelo de negócio reduz uma ideação empreendedora a uma oportunidade definível, estabelece o conjunto de objetivos relevantes que conduz a ação empreendedora e investidura organizacional, e delimita a implementação das atividades organizacionais que decretam a oportunidade.

\footnotetext{
37 "A better business model often will beat a better idea or technology."

38 "[...] need to excel not only at product innovation but also at business model design."

39 "[...] a mediocre technology pursued within a great business model may be more valuable that a great technology exploited via a mediocre business model.”
} 
A business model narrows entrepreneurial ideation to a definable opportunity, establishes the relevant goal set that drives entrepreneurial action and organizational investiture, and bounds the implementation of organizational activities that enact the opportunity.

Em Baden-Fuller (2010), os autores exploram o conceito de modelo de negócios em relação a três das suas funções. Os autores afirmam sobre um caráter multivalente dos BMs (Ibid., p. 167). Para Baden-Fuller (2010) as funções podem ser:

a) providenciar meios para descrever e classificar negócios (taxonomias e tipologias);

b) operar como áreas para a investigação científica (analogamente a organismos biológicos ou modelos econômicos matemáticos);

c) atuar como receitas [no sentido de receitas de cozinha] para gerentes criativos.

A analogia receita-BM é explorada por Sabatier, Mangematin e Rouselle (2010) na sua própria analogia para abordar o tema de portfólio de modelos de negócios.

\subsection{Propriedades dos modelos de negócios}

A literatura sobre modelo de negócios é tão vasta quanto são as propriedades atribuídas a tal conceito.

Para Teece (2010, p. 172) cada vez que uma empresa de negócios é estabelecida esta utiliza, quer explicitamente quer implicitamente, um modelo de negócios. Também, no entendimento do autor (Ibid., p. 190): “A seleção/desenho de modelos de negócio é uma microfundação chave das capacidades dinâmicas [...]"40. Por fim o autor, (Ibid., p. 191) faz referência à noção de que um modelo de negócios não pode ser avaliado (assessed) em abstrato, posto que sua adequabilidade tem que ser determinada frente a um contexto ou ambiente particulares.

Na construção e discussão do conceito apresentada por Al-Debei e Avison (2010), os princípios modeladores identificados pelos autores fazem referência a algumas representações do modelo de negócios como coerente, no sentido que descreve uma lógica de forma

\footnotetext{
40 "The selection/design of business models is a key microfoundation of dynamic capabilities [...]"
} 
holística; abstrato, por cobrir só os componentes chave e ser uma simplificação que reflete a realidade; granular, desde que seus componentes podem ser separados em dimensões, as quais por sua vez podem ser subdivididas em elementos; versátil no sentido que pode ser utilizado para entender uma lógica em diferentes níveis e ser usado para diferentes propósitos nas organizações; e, dinâmico, a fim de enfrentar mudanças contínuas.

Para Baden-Fuller e Mangematin (2013, p. 419) um modelo de negócios é potencialmente separável do contexto da firma, incluindo a tecnologia que usa. Assim mesmo, os autores (BADEN-FULLER; MANGEMATIN, 2013) sugerem ao longo de sua obra, uma natureza de causalidade [nas relações entre elementos internos e externos] embutida nos modelos de negócios.

A abordagem proposta por McGrath (2010) é a abordagem guiada pela descoberta (discovery driven). A autora (Ibid., p. 248-249) apresenta considerações sobre a contribuição do conceito de modelo de negócios na direção de quatro aspectos: foco outside-in ao invés de inside-out; a ênfase na centralidade da experimentação na sua descoberta e desenvolvimento; a nova apreciação do dinamismo das vantagens competitivas; e uma compreensão em desenvolvimento de que a estratégia, muito frequentemente, é mais guiada pela descoberta do que orientada ao planejamento. Para Sako (2012, p. 23) um dos pontos no qual os estrategistas não concordam é sobre o equilíbrio entre planejamento e experimentação para chegar a um modelo de negócios apropriado.

Baden-Fuller e Mangematin (2013, p. 424, tradução nossa) alegam que os modelos de negócio são “[...] instrumentos manipuláveis [...]”. Acrescentando sobre essa ideia, McGrath (2010, p. 254), num enfoque influenciado pelo conceito de experimentação, afirma que:

- $\quad$ A experimentação com modelos de negócios acontece tanto através quanto dentro das firmas;

- A evolução de modelos de negócios é altamente dependente da trajetória (pathdependent): experimentos precoces vão ter influência nos modelos por vir;

- $\quad$ É quase impossível dizer com antecedência qual desenho de modelo de negócios vai ganhar [dominância]. 
George e Bock (2011) apresentando suas três dimensões principais do conceito: Estrutura de recursos, Estrutura transacional e Estrutura de valor; explicam sobre a dominância dimensional (Ibid., p. 102-105) nos modelos de negócios indicando que esta se apresenta quando mais recursos ou importância, dentro da configuração de atividades e esforços, são outorgados a uma dessas dimensões do BM. De forma contraria, a paridade dimensional aconteceria quando uma firma explora suas oportunidades com um foco equivalente nas dimensões.

Na visão de Doganova e Eyquem-Renault (2009, p. 1562) os modelos de negócios aparecem como "objetos fronteira" ("boundary objects") por habitar vários mundos sociais entrecruzados, satisfazendo requerimentos informacionais em cada um deles. Por tanto, para as autoras (DOGANOVA; EYQUEM-RENAULT, 2009) uma das características mais notáveis dos BMs é sua circulação, entendida como sua direção a diversos públicos, e é a essa audiência pela qual o modelo de negócio é feito para se encaixar (Ibid., p. 1565).

Como apontava Schweizer (2005, p. 40) a perspectiva dinâmica dos modelos de negócios estava ausente na teoria, porém recentemente diversos autores têm escrito sobre o dinamismo dos modelos de negócios (cf. CAVALCANTE; KESTING; ULHOI, 2011, ACHTENHAGEN; MELIN; NALDI, 2013, ou, ASPARA ET AL., 2011). Para Zott e Amit (2013, p. 409) a investigação da dinâmica na evolução dos modelos de negócios é uma linha de pesquisa multidisciplinar que vai solidificar o conceito como nível e unidade de análise no entendimento de criação/captura de valor.

De forma inicial, se pode mencionar que se atribui aos modelos de negócio a propriedade de mudar, porem alguns autores advertem sobre a dificuldade de mudança num BM pela existência de inércia (CHESBROUGH, 2007, TEECE, 2010, p. 181, 187), conforto (CHESBROUGH, 2007) ou barreiras à experimentação (CHESBROUGH, 2010).

Para Demil e Lecocq (2010) existem duas abordagens no uso do termo modelo de negócios: A que eles chamam de abordagem estática, usando o BM como cópia heliográfica (blueprint) dos componentes, e a abordagem transformacional, usando BM como ferramenta para tratar mudança e inovação na organização ou no modelo mesmo. Os autores veem ambas as abordagens como complementarias e reconciliáveis mais do que opostas (Ibid., p. 242). 
Os autores analisam a evolução dos modelos de negócios, olhando a dinâmica crida pela interação dos seus componentes. No seu entendimento (DEMIL; LECOCQ, 2010, p. 240) esta evolução tem que ser vista como as sequências que abrangem mudanças entrelaçadas, determinadas e emergentes, as quais afetam aos componentes essenciais ou aos seus elementos. Estas sequências significariam que o modelo de negócios [...] está permanentemente num estado de desequilíbrio transitório [...]" ${ }^{\text {41 }}$ (Ibid., p. 240).

Para McGrath (2010) os modelos de negócio frequentemente não podem ser completamente antecipados com antecedência e devem ser "aprendidos" (Ibid., p. 248) ao longo do tempo, e os modelos de negócios “evoluem e maduram.” (Ibid., p. 249). Hedman e Kalling (2003, p. 54) coincidem indicando que "O modelo de negócios tem que ser administrado e desenvolvido no tempo." 42

Teece (2010, p. 177, tradução nossa) indica que "Os modelos de negócio devem metamorfosear no tempo enquanto os mercados mutáveis, tecnologias e estruturas legais o ditem e/ou permitam." ${ }^{43}$. Doganova e Eyquem-Renault (2009, p. 1565) assinalam que o modelo de negócios é múltiplo, ele circula em espaço e tempo.

Na perspectiva de Schweizer (2005, p. 48-50), na medida em que o panorama e condições competitivas mudem no tempo, as companhias podem defrontar a imediata necessidade de mudar seus modelos de negócios no intuito de permanecerem competitivas.

Na alusão à circulação, feita previamente pelas autoras Doganova e Eyquem-Renault (2009, p. 1568-1569), aponta-se que os modelos de negócios podem se converter em exemplos ou moldes (templates), sujeitos a comparação e/ou imitação. Teece (2010, p. 179) menciona que os elementos brutos de um BM “[...] são frequentemente bastante transparentes e (em principio [?]) fáceis de imitar [...]." ${ }^{, 44}$ Kallio, Tinnila e Tseng (2006) discorrem sobre a possibilidade de, os modelos de negócios de empresas de um mesmo setor mas em países diferentes, serem comparados e copiados. Uma pesquisa sobre um modelo de negócios desenvolvido com um enfoque global é apresentada em Chung, Yam e Chan (2004).

\footnotetext{
41 "[...] is permanently in a state of transitory disequilibrium [...]"

42 "The business model has to be managed and developed over time."

43 “Business models must morph over time as changing markets, technologies and legal structures dictate and/or allow."

44 "[...] are often quite transparent and (in principal) easy to imitate [...]"
} 
Magretta (2002) chama a atenção ao fato de que os modelos de negócio podem se "copiar" muitas vezes sem os mesmos resultados, citando o exemplo de um modelo de negócio bem sucedido (Disney nos EUA) copiado a outro continente, sem o mesmo sucesso. Por sua parte, Teece (2010, p. 179, tradução nossa) nota que "Um modelo de negócios tendo sido pioneiro por uma companhia em um espaço pode ser adotado por outra companhia em outro espaço." ${ }^{45}$. McGrath (2010, p. 252) acredita que quando um modelo de negócios é copiado, feito irrelevante por acontecimentos do ambiente ou já não é mais apropriado para os clientes, existe a oportunidade para que novos modelos de negócio floresçam.

Para Teece (2010, p. 182) são três os fatores que podem impedir um comportamento de imitação que solape as vantagens de um modelo pioneiro: implementar um BM pode requerer sistemas, processos e ativos difíceis de replicar; pode existir certo nível de opacidade que pode impedir os externos de enxergar com suficiente detalhe como o BM é implementado ou as fontes de aceitabilidade dos clientes; ou, a relutância por parte dos incumbentes por receio a canibalizar suas vendas existentes ou inquietar relações de negócios importantes.

O modelo de negócios como vantagem competitiva é citado por inúmeros autores. Para Magretta (2002, p. 92), quando um novo modelo altera as economias de uma indústria e é difícil de imitar, cria forte vantagem competitiva. Para Teece $(2010$, p. 173, 179) desenvolver um modelo de negócios bem sucedido é insuficiente para assegurar vantagem competitiva, desde que a imitação é frequentemente fácil. Nesse sentido, um modelo diferenciado, difícil de imitar, eficaz e eficiente seria mais provável de providenciar lucro. Contrariando a afirmação, em palavras de Kim e Mauborgne (2000, p. 134, tradução nossa): “[...] um bom modelo de negócios é em si mesmo uma poderosa defensa contra a imitação."

Morris, Schindehutte e Allen (2005, p. 727, tradução nossa), numa concepção integrativa para eles, propõem entender modelo de negócios, no âmbito da pesquisa em empreendedorismo, como:

\footnotetext{
45 "A business model pioneered by one company in one space may be adopted by another company in another space."

46 "[...] a good business model is itself a powerful defense against imitation."
} 
[...] uma representação concisa de como um conjunto interrelacionado de variáveis de decisão, nas áreas de estratégia do empreendimento, arquitetura e economia, são tratadas para criar vantagem competitiva sustentável em mercados definidos.

[...] a concise representation of how an interrelated set of decision variables in the areas of venture strategy, architecture, and economics are addressed to create sustainable competitive advantage in defined markets.

Zott, Amit e Massa (2011, p. 1030) indicam que os modelos de negócios podem jogar um papel central explicando o desempenho da firma. Segundo Teece (2010, p. 191) escolher o modelo de negócio errado equivale praticamente a não ter chance de sucesso nos negócios.

Segundo Teece (2010, p. 187, tradução nossa): “Às vezes, a criação de novos modelos de negócios conduz à criação de novas indústrias." ${ }^{47}$ Contudo, o modelo de negócios certo é raramente aparente cedo nas indústrias emergentes (Ibid.).

Ademais das propriedades dos modelos de negócios discutidas na literatura, alguns autores identificaram alguns problemas quando se utiliza o conceito em organizações que desenvolvem suas atividades no mundo dos negócios.

Entre os problemas apontados por Johnson, Christensen e Kagermann (2008) está que poucas companhias conhecem bem seus modelos de negócios. Al-Debei e Avison (2010, p. 372, tradução nossa) observam que os modelos de negócios das empresas:

[...] raramente estão articulados ou definidos explicitamente. $\mathrm{Na}$ maioria das vezes, eles representam um conhecimento tácito nas mentes de um ou poucos gerentes chave dentro das organizações e raramente são comunicados a outros.

[...] are rarely articulated or defined explicitly. Most often they represent a tacit knowledge in the minds of one or few key managers within organizations and are seldom communicated to others.

Em palavras de Teece (2010, p. 187), um empreendedor "[...] pode ser capaz de intuir um novo modelo, mas não ser capaz de racionaliza-lo e articulá-lo completamente." ${ }^{48}$. A pesquisa empírica de Linder e Cantrell (2001, p. 14) suporta esta ideia.

Olhando os modelos de negócios sob a ótica da representação, Casadesus-Masanell e Ricart (2010, p. 200) notam que os modelos de negócios completos frequentemente são muito

\footnotetext{
47 "Sometimes the creation of new business models leads to the creation of new industries."

48 "[...] may be able to intuit a new model but not be able to rationalize and articulate it fully."
} 
complexos e incômodos de representar como para trabalhar com eles. Os autores propõem duas opções para afrontar estas desvantagens: A Agregação, que implica fazer um zoom-out no modelo e a Decomposição, que supõe analisar alguns dos componentes em isolamento. Similar abordagem analítica é sugerida por Teece (2010, p. 188) quando fala sobre a "desconstrução" e avaliação por elementos na análise.

Na criação e uso de modelos de negócios na prática, Shafer, Smith e Linder (2005, p. 204206) identificam quatro problemas comuns associados:

a) Suposições equivocadas por debaixo da lógica central do modelo;

b) Limitações nas escolhas estratégicas consideradas;

c) Mal-entendidos sobre criação e captura de valor;

d) Suposições equivocadas acerca da rede de valor.

Para George e Bock (2011, p. 87) a perspectiva de narrativa dos modelos de negócios permite confusão no seu desenvolvimento e sua implementação, desde que as firmas possam tentar múltiplos modelos de negócio ao mesmo tempo.

Segundo Al-Debei e Avison (2010, p. 368), para desenhar um modelo de negócios é necessário um balance entre diferentes e, muitas vezes, conflitantes requerimentos de desenho apresentados dentro das dimensões e blocos de construção conceituados pelos autores. Teece (2010, p. 176, tradução nossa) afirma que "selecionar, ajustar e/ou melhorar modelos de negócios é uma arte complexa" ${ }^{49}$; sendo que bons desenhos possivelmente sejam altamente situacionais e o desenho de processos demande iteração.

Embora Osterwalder, Pigneur e Tucci (2005) incluam como uma das funções dos modelos de negócios o Patenteamento, para Teece (2010, p. 181) um novo modelo de negócios, por ser mais geral que um método de negócios, é muito pouco provável de qualificar para uma patente.

Chesbrough (2010) adverte que se outros fora da firma descobrem um modelo de negócios mais adequado para uma tecnologia, eles podem obter mais valor dela do que a firma que

\footnotetext{
49 "Selecting, adjusting and/or improving business models is a complex art."
} 
originalmente a descobriu. Assim mesmo, nota que saber quando transferir recursos do modelo vigente ao novo, precisa de um delicado balance (Ibid., p. 361) e superar algumas barreiras de conhecimento, requer uma liderança, às vezes em conflito.

Assim mesmo, Chesbrough (2007, p. 15, tradução nossa) afirma que: “[...] nenhum grandioso modelo dura para sempre." ${ }^{, 50} \mathrm{Na}$ mesma linha, Teece (2010, p. 188) adverte que inclusive os modelos de negócios bem sucedidos, em algum ponto, vão ter que ser reformados ou até abandonados.

\subsection{Relação com outros conceitos}

\subsubsection{Modelos de Negócio x Estratégia}

Klang, Wallnöfer e Hacklin (2014) identificam como um dos temas recorrentes nas relações dos modelos de negócios com outros conceitos, à relação BM-Estratégia, e concluem com sua pesquisa que a maioria dos acadêmicos considera BM e Estratégia como conceitos diferentes, porém os fatores diferenciadores estão fragmentados, ao mesmo tempo que notam ambiguidade em termos de causalidade e interdependência sequencial (Ibid., p. 471).

Zott, Amit e Massa (2011) têm identificado entre um dos três fenômenos para os quais se utilizou a abordagem de modelo de negócios na literatura científica às questões estratégicas (strategic issues). Dentro de tal abordagem, três tópicos surgiram na apreciação dos autores: Criação de valor, Desempenho e Vantagem competitiva.

Para Zott, Amit e Massa (2011, p. 1031, tradução nossa): “O modelo de negócios estende ideias centrais em estratégia de negócios e suas associadas tradições teóricas." 51 . Os autores (Ibid.) sugerem que firmas podem terem similares estratégias e modelos de negócios muito diferentes. Por fim, concluem que BM não é estratégia de produto-mercado ou estratégia corporativa.

\footnotetext{
50 "[...] no great business model lasts forever."

51 "The business model extends central ideas in business strategy and its associated theoretical traditions."
} 
Casadesus-Masanell e Ricart (2010) defendem a posição de que estratégia e modelo de negócios são conceitos claramente diferentes. Para os autores modelo de negócios é o reflexo da estratégia realizada da organização (Ibid., p. 205). Por sua parte, estratégia é entendida pelos autores (CASADESUS-MASANELL; RICART, 2010, p. 196) como a escolha do modelo de negócios através do qual a firma vai concorrer no mercado. Os autores também fazem uma distinção com o conceito de tácticas, entendendo estas como escolhas residuais em virtude do modelo de negócios que escolhe, determinando este último, a variação das primeiras. O enfoque de Al-Debei e Avison (2010, p. 370, 374) aparenta reafirmar esta visão, indicando que o modelo de negócios é derivado diretamente da estratégia, e do qual, por sua vez, são derivados os processos e sistemas de informação. Para Onetti et al. (2012, p.358), Estratégia pertence a um nível superior, e modelo de negócios é apresentado em um nível operacional, porque define como executar a estratégia, representando escolhas estratégicas.

Numa analogia com uma máquina (carro) apresentada pelos autores (CASADESUSMASANELL; RICART, 2010, p. 197-198), o desenho do carro seria equivalente à estratégia; o carro mesmo, ao Modelo de Negócio; e, conduzir o carro, à tática.

A própria concepção de Casadesus-Masanell e Ricart (2010) se apresenta estreitamente ligada a temas estratégicos, ao mencionar que os elementos que constituem um modelo de negócios são as escolhas e suas consequências, ambos os termos ligados ao vocabulário da Estratégia.

A diferença chave para Casadesus-Masanell e Ricart (2010, p. 205) é que a estratégia é mais que uma simples seleção de BM, pois está é um plano de como o modelo de negócios deve ser configurado, dependendo das contingências que poderiam acontecer; e (Ibid. p. 206, tradução nossa) "[...] embora toda organização tem algum modelo de negócios [...], não toda organização tem estratégia $[\ldots],]^{, 52}$

No entanto, os autores (CASADESUS-MASANELL; RICART, 2010, p. 195) reconhecem que em situações competitivas simples, os conceitos de estratégia e modelo de negócios se pareiam, dificultando sua separação.

\footnotetext{
52 "[...] while every organization has some business model [...], not every organization has a strategy [...]"
} 
Para Yip (2004, p. 18-19) modelo de negócios, desde um ponto de vista estático, equivale à posição estratégica, e o termo estratégia é reservado para atividades dinâmicas utilizadas para mudar, entre outras coisas, modelos de negócios. Yip (2004, p. 21, tradução nossa) afirma que as: "Companhias usam estratégia real só quando buscam mudar seu modelo de negócios." 53 .

Dasilva e Trkman (2013, p. 5, tradução nossa) entram na conversa sobre as diferenças entre BM e Estratégia, indicando que "[...] estratégia molda o desenvolvimento das capacidades que podem alterar os modelos de negócios vigentes no futuro." e “[...] estratégia reflete o que uma companhia aponta se tornar, enquanto que modelos de negócios descrevem o que uma companhia realmente é num momento dado., ${ }^{, 54}$.

No framework de Dasilva e Trkman (Ibid.), a estratégia estabelece capacidades dinâmicas, as quais, por sua vez, coagem possíveis modelos de negócios a encarar contingências, vindouras ou existentes.

Teece $(2010,180)$ discorre sobre o pareamento de análise estratégica e desenho de modelo de negócios indicando que este:

[...] requer segmentar o mercado, criando uma proposta de valor para cada segmento, estabelecendo o aparato para entregar esse valor, e logo imaginar vários 'mecanismos de isolação' que podem ser usados para prevenir o modelo de negócio/estratégia serem solapados através da imitação por competidores ou desintermediação por clientes.

[...] requires segmenting the market, creating a value proposition for each segment, setting up the apparatus to deliver that value, and then figuring out various 'isolating mechanisms' that can be used to prevent the business model/strategy from being undermined through imitation by competitors or disintermediation by customers.

Para Magretta (2002), Modelo de negócios não é o mesmo que estratégia, indicando que o modelo de negócio pode ser o mesmo, mas a estratégia, diferente. A autora concebe que sobre o mesmo BM subjacente, podem se realizar escolhas estratégicas sobre: mercados geográficos, segmentos, quais consumidores, e quais produtos.

\footnotetext{
53 "Companies use real strategy only when they seek to change their business model."

54 "[...] strategy shapes the development of capabilities that can alter current business models in the future." [e] "[...] strategy reflects what a company aims to become, while business models describe what a company really is at a given time."
} 
Chesbrough (2007) oferece uma visão aparentemente dual entre BM e Estratégia ao incluir esta última como um dos 6 parâmetros que definem o primeiro, mas atribuindo a ele, nas funções associadas, o papel de formular a estratégia competitiva para ganhar e sustentar vantagem.

Para Osterwalder, Pigneur e Tucci $(2005$, p. 7) a diferença chave é que a estratégia também inclui competição e o modelo de negócios "É a tradução das questões estratégicas [...] num modelo conceitual que explicitamente estabelece como o negócio funciona." ${ }^{55}$ (Ibid., p. 2, tradução nossa).

Outra diferença observada por Osterwalder, Pigneur e Tucci (2005) é que Estratégia inclui implementação e execução, sendo que a primeira inclui a tradução do BM em elementos concretos: estrutura, processos, infraestrutura, etc. Al-Debei e Avison (2010, p. 365) coincidem com esta anotação, afirmando que o modelo de negócios “[...] abrange informação útil para traduzir objetivos estratégicos em tarefas de implementação e funções."

Ao respeito, Hacklin e Wallnofer (2012) num sentido contrario sugerem que o uso de modelo de negócios nas firmas pode significar certo lock-in coletivo na identidade, o qual gera forças inerciais que podem refrear as mudanças estratégicas.

Zott e Amit (2008) através de uma verificação empírica acharam que modelo de negócios e estratégia (especificamente de mercado do produto) não são substitutos, senão complementares.

Al-Debei e Avison (2010, p. 369) consideram que o debate sobre a diferença entre modelo de negócios e estratégia ainda não está resolvido, porém os autores identificaram que o modelo de negócios é uma camada (layer) intermediária entre estratégia de negócios e processos do negócio. Para os autores, modelo de negócios não é substituto de estratégia corporativa, mas sim a sustenta, devido as configurações do conceito estarem estrategicamente orientadas. Uma última referência ao tema (Ibid., p. 372) é que a informação que fornece um BM não é tão altamente agregada, como é o caso de uma estratégia de negócios.

\footnotetext{
55 "It is the translation of strategic issues [...] into a conceptual model that explicitly states how the business functions."

56 "[...] encompasses information helpful in translating strategic objectives into implementation tasks and functions."
} 
Teece (2010) acredita que modelo de negócios não é exatamente o mesmo que estratégia, mas seus argumentos se apresentam contrapostos aos apresentados previamente. Para o autor (TEECE, 2010, p. 180) um modelo de negócios é mais genérico que uma estratégia de negócios, e selecionar uma estratégia é um exercício mais granular que desenhar um modelo de negócios.

George e Bock (2011. p. 102, tradução nossa) apontam varias diferenças entre a estratégia e o conceito de modelo de negócios:

[...] estratégia é um conjunto dinâmico de iniciativas, atividades e processos; o modelo de negócios é uma configuração estática de elementos organizacionais e características de atividade. Uma estratégia pode ser reflexiva, [...] o modelo de negócios é inerentemente não reflexivo. Implementar um modelo de negócios pode gerar mudança organizacional, mas o modelo de negócios em sim mesmo não é uma descrição de ou receita para mudança. Os modelos de negócios são oportunidade-centristas, enquanto que a estratégia é concorrente ou ambiente-centrista.

[...] strategy is a dynamic set of initiatives, activities, and processes; the business model is a static configuration of organizational elements and activity characteristics. A strategy may be reflexive, [...]; a business model is inherently nonreflexive. Implementing a business model may generate organizational change, but the business model itself is not a description of or recipe for change. Business models are opportunity-centric, while strategy is competitor or environment centric.

Para Sorescu et al. (2011, p. S4-S5) são três as diferenças:

- $\quad$ Estratégia articula certa meta, Modelo de negócios detalha os mecanismos que movem a organização na direção dessa meta;

- $\quad$ A adoção de uma nova estratégia tipicamente implica dependência num novo modelo de negócios, porém mudanças em modelos de negócio podem ser feitas dentro de um marco estratégico existente;

- $\quad$ O modelo de negócios toma a estratégia da firma de um nível relativamente abstrato e a traduz num mecanismo interdependente mais específico que guia os gestores na sintonização das suas ações para concretizar vantagem competitiva.

Como acréscimo a estas visões, pode-se referenciar o postulado de Zott, Amit e Massa (2011, p. 1031), os quais fazem uma relação da estratégia na sua concepção tradicional com temas ligados a concorrência, captura de valor, e vantagem competitiva, enquanto que a relação do conceito modelo de negócios é feita com temas ligados a cooperação, parceria, e criação conjunta de valor. 
Neste sentido, Casadesus-Masanell e Ricart (2010, p. 202) pareceram divergir afirmando que o modelo de negócios de uma firma, mediante a interação tática, pode afetar outros modelos de negócios mediante a cooperação ou a competição. Hedman e Kalling (2003) também incluem dentro dos elementos que compõem seu modelo genérico de negócios aos competidores. Fazendo alusão ao pioneirismo dos modelos de negócios, no entendimento do autor (TEECE, 2010, p. 188, tradução nossa) eles: “[...] geralmente possuem - ou desenvolvem - uma compreensão de uma espécie de 'verdade profunda' sobre as necessidades fundamentais dos consumidores e como os concorrentes estão ou não satisfazendo essas necessidades [...]"57, aparentemente contrapondo-se também a alguns dos postulados prévios.

Analisada a literatura sobre este assunto, a pesquisa explorou qual a relação e a sequencialidade entre estratégia e modelo de negócios.

\subsubsection{Modelos de Negócio x Modelo de Receita ou Lucro}

Schweizer (2005, p. 42) nota que muitas às vezes “[...] um modelo de negócios é apenas analisado em termos de ou referido como sendo uma espécie de modelo de receita." ${ }^{58}$ Por sua parte, Zott e Amit (2010) consideram que o modelo de geração de receita complementa o modelo de negócios, e que este pode tomar forma, mas o modelo de receita ser incerto (e.g. FriCso, Ibid., p. 218).

Para Johnson, Christensen e Kagermann (2008), embora muita gente pense que modelo de negócios equivale Fórmula de Lucro, esta última é só uma peça do tudo. A pesquisa empírica de George e Bock (2011, p. 97) encontrou entre as suas conclusões que um modelo de negócios não é completamente explicado pelo modelo de receita de uma empresa, porém alguns aspectos se sobrepõem.

Para Dasilva e Trkman (2013, p. 7) ter um modelo de receita não define por si mesmo e na sua totalidade um modelo de negócios, porém é claramente um componente importante a ele.

\footnotetext{
57 '[...] often possess - or develop - is an understanding of some 'deep truth' about the fundamental needs of consumers and how competitors are or are not satisfying those needs [...]"

58 "[...] a business model is just analysed in terms of or referred to as being some kind of a revenue model."
} 
Sorescu et al. (2011, p. S4) compartilham da mesma visão. Da mesma forma, Schweizer (2005, p. 42) entende que o conceito de modelo de negócios se foca na criação de valor, enquanto que modelo de receita, na apropriação, sendo o segundo conceito, uma dimensão complementaria do primeiro.

O modelo de lucro é incluso no constructo da pesquisa por ser considerado um elemento que define um modelo de negócios e não está ausente na grande maioria das definições e visões estudadas.

\subsection{Conceitos de Modelo de Negócios em publicações em português}

As 20 publicações selecionadas para seu estudo (Ver Método na seção 2.1), encontradas nas bases de conhecimento de administração local no idioma português apresentam características distinguíveis e comparáveis com a pesquisa existente a nível internacional sobre o tema no idioma inglês.

O conjunto de publicações está constituído por 18 documentos, entre artigos, papers e relatórios produzidos no Brasil, um artigo produzido em Portugal e um livro internacional traduzido: Business Model Generation de Osterwalder e Pigneur, consultado por sua possível influência nas referências e na cognição das pessoas que trabalham com o conceito no meio local, ao ser a publicação mais citada (segundo Google Acadêmico em português) sob todas as variantes de busca utilizadas.

Uma exploração desta amostra de publicação científica permite observar que na pesquisa com base local, três grupos podem ser analisados: aquele no qual as publicações, baseadas em alguma referência ou não, apresentam uma definição própria do conceito, o qual representa aproximadamente um terço do total; aquele no qual os pesquisadores usam o conceito fazendo referência específica a outro(s) autor(es) que definiram o conceito a nível internacional, que é o majoritário em porcentagem (63\%); e por fim, o grupo de publicações que não definem explicitamente o conceito para sua utilização ou não aprofundam na discussão do mesmo, representando aproximadamente um $5 \%$ do total. (Tabela 4). 
Tabela 4 - Classificação das definições encontradas em publicações sobre modelos de negócios realizadas no Brasil

\begin{tabular}{|l|c|c|}
\hline \multicolumn{1}{|c|}{ Descrição } & $\begin{array}{c}\text { Número de } \\
\text { publicações }\end{array}$ & $\begin{array}{c}\text { Porcentagem } \\
(\mathbf{\%})\end{array}$ \\
\hline Apresentam sua definição do conceito & 6 & 32 \\
\hline Utilizam fazendo referencia a definições de outros autores & 12 & 63 \\
\hline Não definem explicitamente ou aprofundam na definição & 1 & 5 \\
\hline Total & $\mathbf{1 9}$ & $\mathbf{1 0 0}$ \\
\hline Outro que define (livro internacional traduzido) & 1 & - \\
\hline
\end{tabular}

Neste ponto resulta pertinente fazer uma comparação com alguns resultados ao nível internacional. Zott, Amit e Massa (2011, p. 1022) estimaram que no total das suas publicações revisadas em importantes meios de publicação científica, o $37 \%$ não definia o conceito explicitamente, $44 \%$ sim o definia, e o remanente $19 \%$ o definia fazendo referência a outros autores; mostrando uma inversão respeito aos resultados locais.

Uma olhada inicial poderia sugerir que na pesquisa no Brasil, os autores, em proporção majoritária, têm sustentado a sua produção fazendo referência a linhas reconhecidas (talvez convergentes) de estudo do conceito, sendo uma menor proporção a qual arriscou em apresentar uma conceitualização própria.

Porém, um exame aprofundado desse $63 \%$ de publicações no total, mostra que as referências a concepções desenvolvidas no nível internacional são relativamente diversas.

Em Araujo e Zilber (2011, 2013); na pesquisa sobre e-business e inovação organizacional, que neste caso é equiparada com a inovação em modelo de negócios; as referências são aos trabalhos de Amit e Zott (2001) e Teece (2010), mas com uma aderência explícita à conceitualização de Osterwalder, Pigneur e Tucci (2005). O modelo de negócios nestes dois trabalhos é entendido "[...] como orientador da arquitetura da empresa para entrega de valor." (ARAUJO; ZILBER, 2013, p. 148), e os autores apontam que "O conceito de modelo de negócios é mais amplo que o de modelo de e-business." (ARAUJO; ZILBER, 2011, p.3, 2013, p. 149).

Zmoginski et al. (2009) numa pesquisa na mesma área temática das citadas previamente, faz uso de uma definição proveniente da linha de pesquisa em inovação em modelo de negócios, referenciado ao trabalho "As regras da inovação: como gerenciar, como medir e como 
lucrar" de Davila, Epstein e Shelton, do ano 2007. Os pesquisadores brasileiros neste caso entenderam o conceito como uma descrição “[...d]a maneira pela qual a empresa será inovadora, e como gerará valor a partir da inovação" (Ibid., p.51).

Seguindo na mesma linha de pesquisa, inovação em modelo de negócios, Figueira et al. (2011) e Figueira, Sugano e Sette (2009), fazendo referência a autores como Osterwalder, Hamel e Chesbrough, entre outros autores mais, entendem e utilizam "modelo de negócios" sob a concepção genérica de Osterwalder (2004).

Cabe destacar que no caso da pesquisa de Figueira, Sugano e Sette (2009), faz referência a outro trabalho conceitual brasileiro sobre modelo de negócios (JOIA, FERREIRA, 2005) na discussão teórica, fato não observado em outras publicações similares sendo analisadas nesta parte da exploração.

Renault et al. (2011) no seu estudo de modelos de negócios utilizados por empresas criadas por professores e alunos da UFRJ apresentam sua perspectiva sobre BMs na direção de autores como Chesbrough e Rosenbloom (2002) e outros que utilizam o conceito de spin-offs e taxonomias para abordar o tema.

Num aparente subgrupo, mas ainda dentro das publicações que recorrem a bases teóricas já desenvolvidas, se encontram publicações ligadas à aplicação de modelos de negócio principalmente no âmbito de negócios digitais.

Angulo (2000) recorreu à concepção de Timmers (representada na pesquisa pelo artigo de TIMMERS, 1998), aplicando esta para o estudo taxonômico dos negócios pela Internet no caso de portais do Brasil, EE.UU. e Inglaterra.

Por sua parte, Siqueira e Crispim (2012) utilizam as ideias propostas por Shafer, Smith e Linder (2005), novamente Osterwalder, Pigneur e Tucci (2005), e principalmente, Al-Debei e Avison (2010); para discutir a conceitualização de modelo de negócios, algumas diferenças com conceitos relacionados como processos de negócios e sistemas de informação, e uma abordagem taxonômica a nível internacional. Esta última é relacionada ao caso de e-business. 
Luciano e Freitas (2002) utilizam componentes sobre modelos de negócios citados na literatura principalmente por autores da linha de taxonomias de negócios eletrônicos, para basear teoricamente o desenvolvimento da parte empírica de sua pesquisa, indicada como em andamento.

Sobre estes exemplos, deve se salientar neste ponto da revisão bibliográfica que o uso de tipologias e taxonomias para representar os sistemas de interdependência dos elementos de um modelo de negócios é identificado a nível internacional em Klang, Wallnöfer e Hacklin (2014, p. 469). De maneira similar Zott, Amit e Mass (2011) acharam que aproximadamente um quarto das publicações sobre modelos de negócios tem a ver com a temática de negócios eletrônicos (e-business), no seu total de artigos consultados em bases científicas internacionais.

O estudo de Oliveira, Spinola e Laurindo (2005, p. 4) sobre tecnologias de informação nas estratégias de organizações da saúde faz referência específica e direta à definição de Magretta (2002) para definir modelo de negócios, ao mesmo tempo que insinuam um pouco da sua própria concepção, ao afirmar que: "De forma simplificada, pode-se dizer que os modelos de negócios auxiliam a compreender e a gerenciar o sistema que cria valor, [...]”.

Deve-se também mencionar que na sua exploração das origens do termo, Dasilva e Trkman (2013, p. 2) identificam que o uso estendido da terminologia de modelo de negócios a nível internacional parece estar conectado com o tema das companhias baseadas em tecnologia.

Na sua análise de modelos de negócios de editoras de periódicos científicos, Gumieiro e Costa (2012) fazem uso de componentes propostos por um trabalho de Patrick Stahler ("Business models as an unit of analysis for strategizing”) de 2002. Estes componentes condizem com a proposição de valor, a descrição de produtos/serviços, a arquitetura de valor e as fontes de receitas. O particular da publicação é o uso do termo associado a disciplinas da ciência, enunciando, por exemplo, o "Modelo de negócio para as Ciências Sociais e Humana[s]" (Ibid,. p. 115) ou o "Modelo de negócio para as Artes e Humanidades" (Ibid,. p. 117), em alusão aos canais de publicação mas transitando por momentos no uso para referenciar as áreas em si mesmas. 
Por fim, no trabalho mais marcado pelo seu caráter teórico dentro da busca local, Joia e Ferreira (2005) apresentam uma discussão orientada a definir se modelo de negócios é 1) um constructo verdadeiro ou se sobrepõe aos usados para definir estratégia e 2) se agrega conteúdo ou valor às diversas abordagens sobre estratégia.

Os autores (JOIA; FERREIRA, 2005) utilizando um método de análise interpretativa hermenêutica vão contrastando algumas definições sobre modelo de negócios com duas visões estabelecidas sobre estratégia: a Visão baseada em Recursos e a visão de posicionamento estratégico de Michael Porter.

Fazendo referência a alguns dos artigos apresentados na discussão da relação modelo de negócios-estratégia (e.g. MAGRETTA, 2002 e SEDDON ET AL.,2004), Joia e Ferreira (2005, p. 7) colocam na sua fundamentação teórica que existem dúvidas sobre o grau de sobreposição dos dois conceitos.

As definições escolhidas por eles foram se interpretando segundo a técnica selecionada e os autores conseguem ajustar seus achados concluindo que " [...] não são termos completamente diferentes, uma vez que todas as definições de modelo de negócios relacionadas foram identificadas com uma ou com as duas abordagens de estratégia." (JOIA; FERREIRA, 2005, p. 13).

Porém, os autores fazem varias ressalvas a respeito, indicando que:

- $\quad$ "Fica claro que uma única abordagem de estratégia não consegue abranger o conceito de modelo de negócios, [...] (Ibid., p. 14), por não existir uma única definição de estratégia, o que então, "[...] dificulta comparações";

- “[...] é possível concluir que é muito variável a definição do constructo modelo de negócios. Como o termo é muito recente na literatura especializada [...], o fato de vários autores procurarem construir sua própria definição também dificulta comparações.” (Ibid., p. $14)$.

Assim mesmo, os autores concluem sugerindo um caráter integrativo dos modelos de negócios indicando que: 
Podemos afirmar ainda que numa única definição de modelo de negócios encontra-se uma ou todas as abordagens de estratégia apresentadas neste estudo. Por conseguinte, a utilidade dessa combinação está tanto em aumentar o poder explicativo das teorias de estratégia, quanto em permitir uma aplicação mais fácil destas, através de uma visão mais próxima da realidade e dos aspectos importantes de um determinado negócio. (JOIA; FERREIRA, 2005, p. 14), e

[...] modelo de negócios é um instrumento dinâmico e sistêmico de estratégia, altamente adaptável à realidade das empresas. (Ibid., p. 14) [...] é possível afirmar que modelo de negócios agrega valor às várias abordagens sobre estratégia; não de forma individualizada, mas de maneira dinâmica e sistêmica, permitindo promover uma interação entre as várias escolas de pensamento estratégico existentes. (Ibid., p. 15)

Os autores também apresentam (JOIA; FERREIRA, 2005, p. 15-16) possíveis linhas de pesquisa futura, as quais têm a ver com testar o tipo de sobreposição entre os dois constructos: Não existe sobreposição, existe interseção parcial, existe sobreposição total, modelo de negócios está inteiramente contido em estratégia, ou estratégia está inteiramente contida em modelo de negócios.

Com respeito a este último artigo analisado, deve-se mencionar que na literatura consultada, Osterwalder, Pigneur e Tucci (2005, p. 7) observam que alguns autores entendem os modelos de negócios como abstração da estratégia. Assim mesmo, Klang, Wallnöfer e Hacklin (2014, p. 466) na sua revisão também notam que muitos pesquisadores ligam o modelo de negócios a teorias dominantes (mainstream) da Administração Estratégica; como as de RBV, redes estratégicas, sistemas ou custos de transação; para explicar o conceito. Assim mesmo, identificam também o consenso sobre a natureza teoricamente integrativa do conceito de modelo de negócios, ao igual que Hedman e Kalling (2003, p. 49). Porém, para Dasilva e Trkman (2013, p. 1) a conexão entre BM e as teorias mais geralmente usadas em Administração é pouco clara.

Em um segundo grande grupo dentro das pesquisas consideradas para seu estudo, estão as pesquisas brasileiras que, mesmo em alguns casos, fazendo referência à literatura internacional, apresentam uma definição própria do conceito de modelo de negócios.

Dado o interesse da presente dissertação, no Quadro 6 se apresentam as definições tal qual foram enunciadas nos seus respectivos textos e uma breve discussão a seguir. 
Quadro 6 - Definições encontradas em publicações seletas nos resultados da revisão bibliográfica local

\begin{tabular}{|c|c|}
\hline Definição & Autoria \\
\hline $\begin{array}{l}\text { "Um Modelo de Negócio refere-se, em nossa definição, à estrutura e } \\
\text { lógica das transações que cercam a operação de um empreendimento, } \\
\text { e a forma como este empreendimento particular se posiciona no } \\
\text { mercado." }\end{array}$ & $\begin{array}{l}\text { (REIS; PROENÇA; PROENÇA JR., } \\
\text { 2003, p. 2) }\end{array}$ \\
\hline $\begin{array}{l}\text { "Pode-se definir como modelo de negócio o serviço ou conjunto de } \\
\text { serviços oferecidos num determinado suporte tecnológico, somado às } \\
\text { suas modalidades (formatos) disponíveis." }\end{array}$ & (BOLAÑO; VIEIRA, 2004, p. 111) \\
\hline $\begin{array}{l}\text { "O modelo de negócios na era digital é uma descrição de regras e } \\
\text { relacionamentos entre consumidores, clientes, parceiros e } \\
\text { fornecedores de uma empresa que identifica os principais fluxos de } \\
\text { produto, informação e dinheiro, e os principais benefícios aos } \\
\text { participantes." }\end{array}$ & (ALBERTIN; MOURA, 2002?, p. 32) \\
\hline $\begin{array}{l}\text { "Os modelos de negócio podem ser entendidos como sendo a relação } \\
\text { criada entre os ambientes interno e externo das organizações, suas } \\
\text { estratégias, estrutura e processos, indivíduos e cultura, e processos } \\
\text { gerenciais. Estes componentes e sua inter-relação definem como a } \\
\text { organização realizará sua participação no mercado." }\end{array}$ & (ALBERTIN; MOURA, 2003?, p. 15) \\
\hline $\begin{array}{l}\text { "Um Modelo de Negócios é um instrumento para apoio à tomada de } \\
\text { decisão. Como todo modelo, é uma simplificação da realidade. Não é } \\
\text { necessário, nem viável, nem útil, detalhar todos os aspectos do } \\
\text { sistema em análise. Deve-se, portanto, ter um objetivo claro que } \\
\text { permita excluir o que não é relevante." }\end{array}$ & $\begin{array}{l}\text { (JÚNIOR; JÚNIOR; BOMTEMPO, } \\
\text { 2007, p. 11) }\end{array}$ \\
\hline $\begin{array}{l}\text { "Ambas as palavras, negócio e modelo, por si mesmas têm um } \\
\text { significado específico. Pode-se dizer que o termo negócio se refere à } \\
\text { 'atividade de comprar e vender bens e serviços' e 'gerar dinheiro'. } \\
\text { Modelo se refere 'à representação de algo como uma simples } \\
\text { descrição de um objeto que poderia ser usado em cálculos'. Assim, } \\
\text { alcançamos o simples entendimento de que um modelo de negócios é } \\
\text { a representação de como uma companhia compra e vende bens e } \\
\text { serviços e gera dinheiro." }\end{array}$ & $\begin{array}{l}\text { (MACÁRIO; GALELO; MARTINS, } \\
\text { 2008, p. 87, tradução nossa)* }\end{array}$ \\
\hline $\begin{array}{l}\text { "Both words, business and model, by themselves have a specific } \\
\text { meaning. It can be said that the term business relates to "the activity } \\
\text { of buying and selling goods and services" and "earning money". } \\
\text { Model relates to "a representation of something as a simple } \\
\text { description of an object that might be used in calculations". Thus, } \\
\text { we reach a simple understanding that a business model is a } \\
\text { representation of how a company buys and sells goods and services } \\
\text { and earns money." }\end{array}$ & \\
\hline
\end{tabular}

* Única publicação considerada no grupo total não originada no Brasil (Portugal).

De forma inicial se pode comentar que existe heterogeneidade nas concepções dos autores que oferecem uma definição de modelo de negócios, é assim que nenhuma parece coincidir significativamente em algum tema em especial. Referências à lógica, regras, relacionamentos e simplificação/representação da realidade surgem em seu exame.

É também curiosa a ausência de menções ao tema valor, que, como se documentou previamente, é um tema recorrente na literatura internacional. Parece que no caso desta 
amostra de definições originais encontradas em bases de conhecimento local, o tópico "dinheiro" é uma aproximação mais direta a esse outro conceito: valor.

Também pode se detectar certo caráter holístico-sistêmico nas definições, por se incluir vários e diferentes atores, elementos e funções numa mesma definição.

A definição simples, encontrada em Macário, Galelo e Martins (2008), que mistura as palavras "modelo" e "negócios" na sua construção, tem muita similaridade com a citação de essa concepção encontrada em Schweizer (2005, p. 40).

Por fim, no grupo unitário de publicações onde o termo é utilizado sem aprofundar na definição específica, se encontra o caso de Souto (2007), no qual se faz recorrência a um "framework" específico de e-business models desenvolvido por Clarke em 2004 somente com fins taxonômicos. O artigo também tem como característica a de estar escrito em idioma inglês, a diferença de 17 das outras publicações que estão redigidas em português.

Considera-se relevante neste momento fazer referência ao caso de uma publicação que não surgiu na busca local, mas está inclusa nos resultados da busca realizada em bases internacionais, e que tem origem brasileira: Fleury e Fleury (2014).

Na base da experiência de multinacionais brasileiras, os autores (FLEURY; FLEURY, 2014) realizam um estudo dos facilitadores locais (local enablers) dos modelos de negócios. $\mathrm{Na}$ publicação, os pesquisadores (Ibid., p. 517, itálico nosso) consideram que “[...] o modelo de negócios de uma firma é o principal driver do seu posicionamento estratégico."59. Assim mesmo para os autores, fatores internos (competências organizacionais e estilo gerencial) e externos (ambiente institucional) influenciam a formulação e a implementação de um modelo de negócios. Os autores sugerem sua adesão principalmente com a posição teórica de David Teece (TEECE, 2010) e Morris, Schindehutte e Allen (2005).

\footnotetext{
59 "[...] a firm's business model to be the main driver of its strategic positioning."
} 


\subsection{Síntese conclusiva da revisão de literatura sobre modelo de negócios}

Nesta seção se apresenta uma síntese das principais ideias descobertas na revisão bibliográfica sobre o tema e os assuntos específicos estudados (Quadro 7).

Quadro 7 - Síntese conclusiva da literatura revisada sobre modelo de negócios

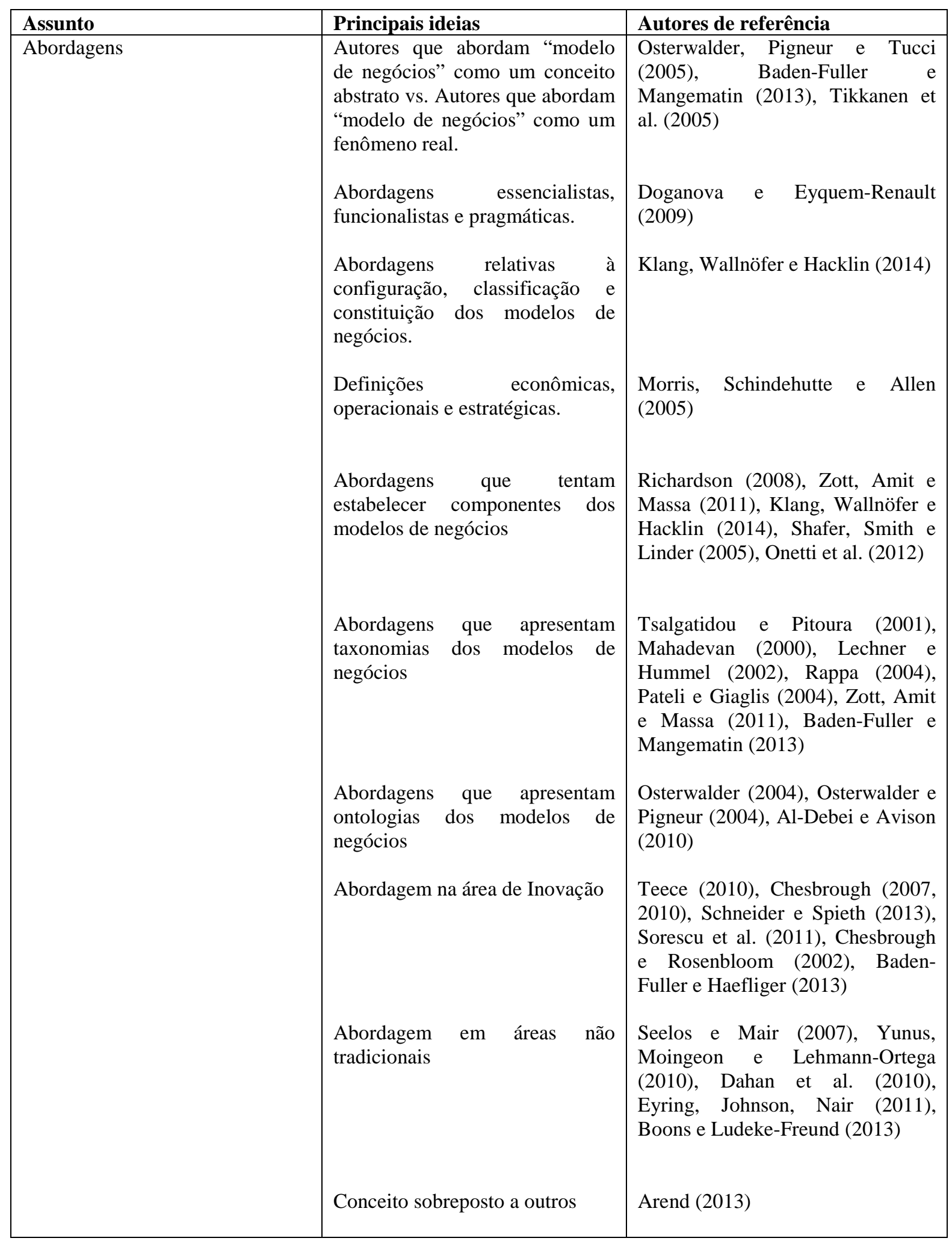




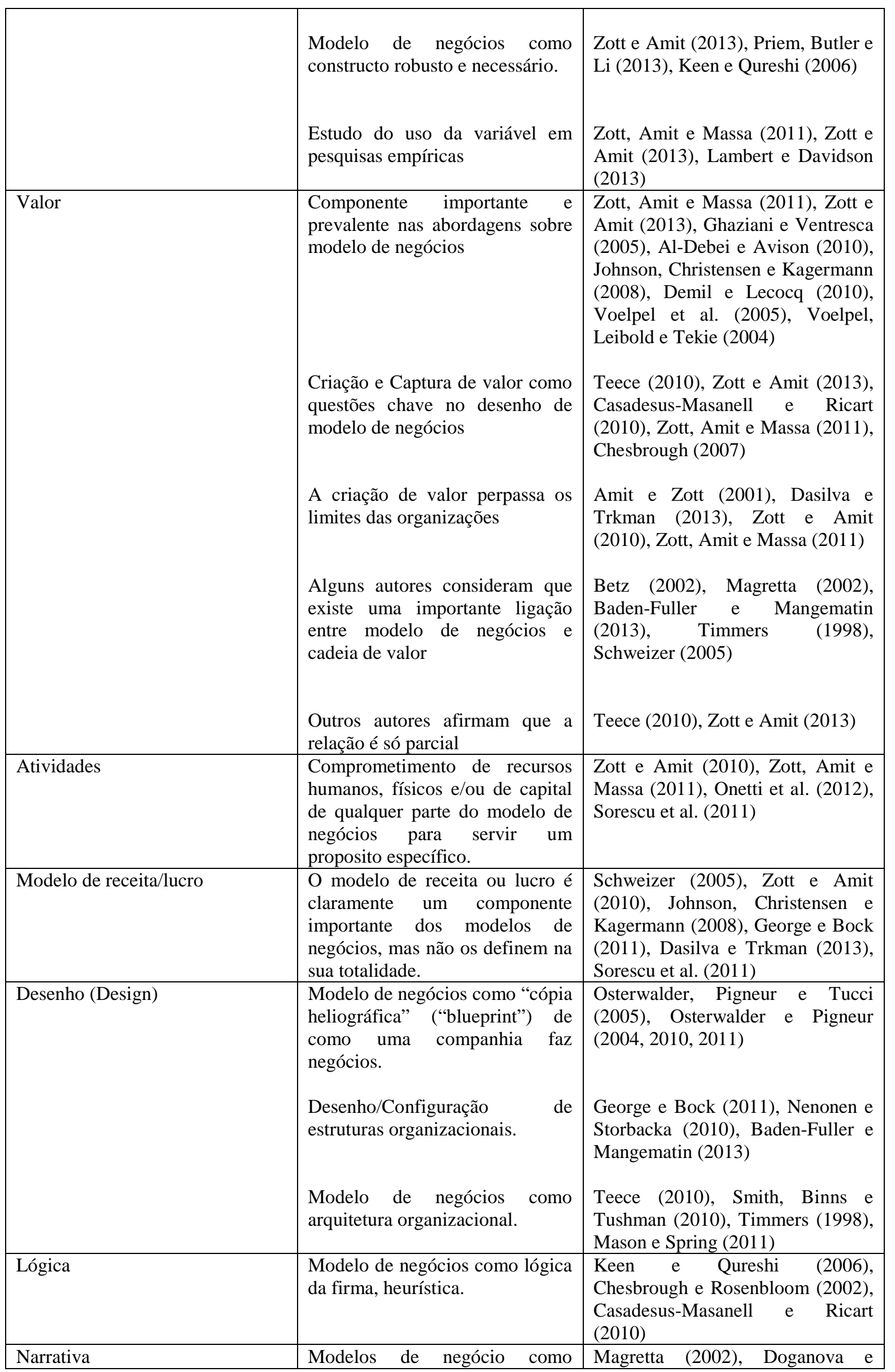




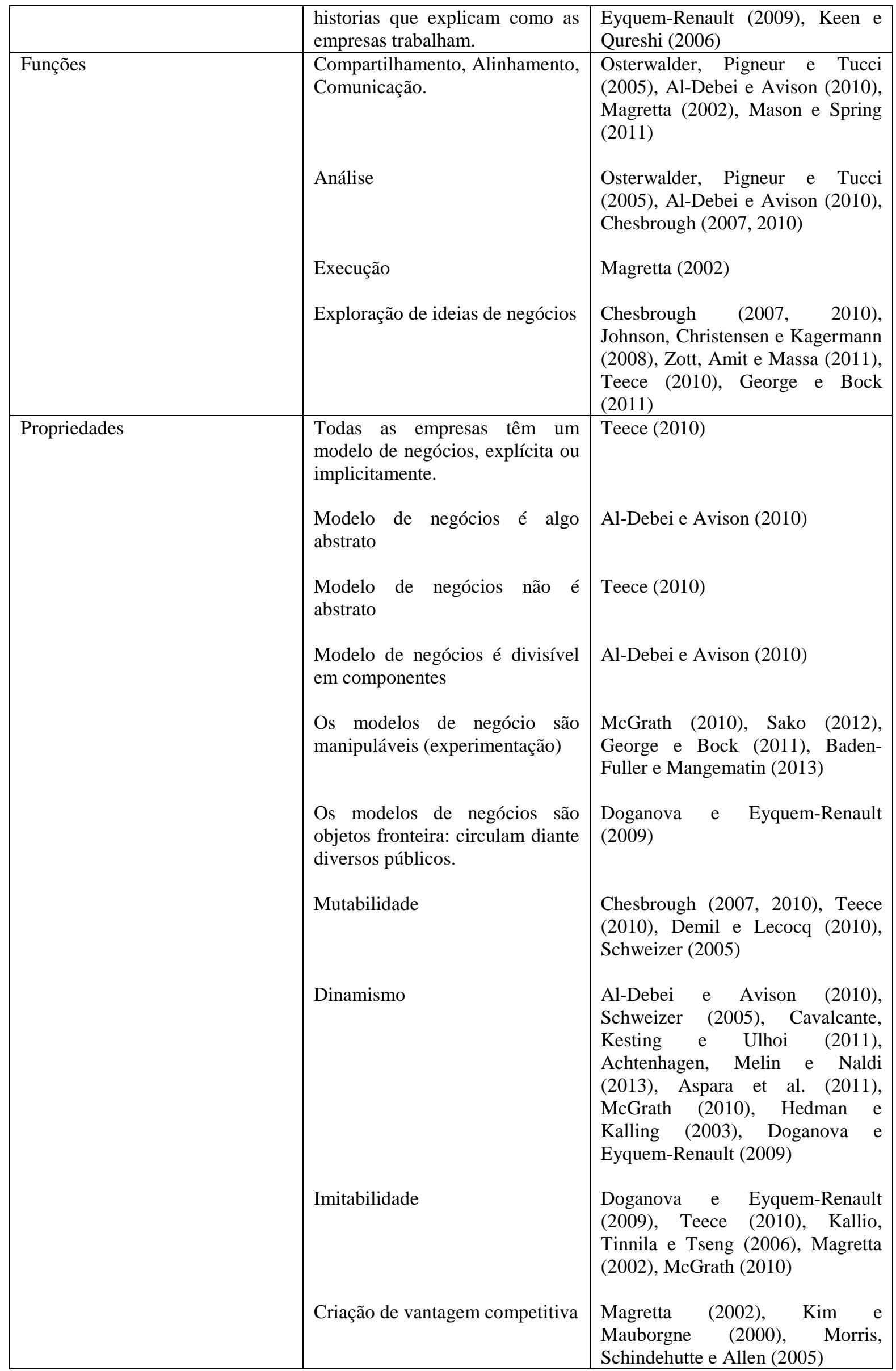




\begin{tabular}{|c|c|c|}
\hline & $\begin{array}{l}\text { Poucas empresas conhecem bem } \\
\text { ou podem racionalizar os seus } \\
\text { modelos de negócios } \\
\text { Nenhum modelo de negócios } \\
\text { dura para sempre }\end{array}$ & $\begin{array}{l}\text { Johnson, Christensen e Kagermann } \\
\text { (2008), Al-Debei e Avison (2010), } \\
\text { Teece (2010), Linder e Cantrell } \\
\text { (2001), Casadesus-Masanell e } \\
\text { Ricart (2010), Shafer, Smith e } \\
\text { Linder (2005) } \\
\text { Chesbrough (2007), Teece (2010) }\end{array}$ \\
\hline Estratégia e Modelo de Negócios & $\begin{array}{l}\text { Modelo de Negócios e Estratégia } \\
\text { são conceitos diferentes, mas } \\
\text { existe ambiguidade em termos de } \\
\text { causalidade e interdependência } \\
\text { sequencial. } \\
\text { Em situações competitivas } \\
\text { simples, os conceitos se pareiam, } \\
\text { dificultando separar estes. } \\
\text { As firmas podem ter estratégias } \\
\text { similares, mas modelos de } \\
\text { negócios diferentes. } \\
\text { As firmas podem ter o mesmo } \\
\text { modelo de negócios, mas } \\
\text { estratégias diferentes. } \\
\text { O modelo de negócios é o } \\
\text { reflexo da estratégia realizada da } \\
\text { organização. } \\
\text { Os modelos de negócios são } \\
\text { derivados da estratégia } \\
\text { Estratégia inclui concorrência e é } \\
\text { ambiente-centrista, Modelo de } \\
\text { negócios inclui criação conjunta } \\
\text { de valor e é oportunidade- } \\
\text { centrista. }\end{array}$ & 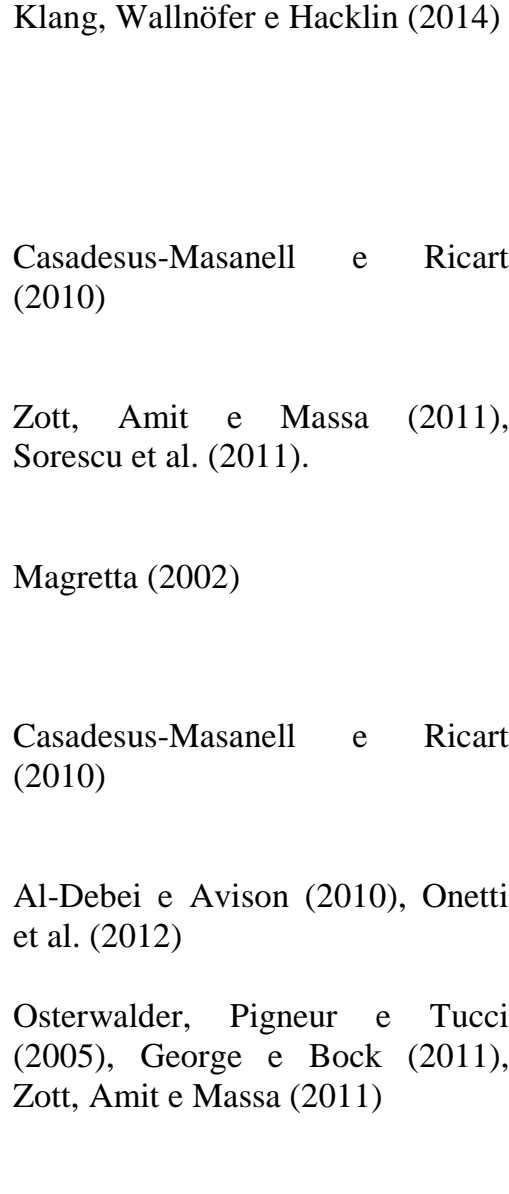 \\
\hline
\end{tabular}

\subsection{Abordagem integrada do constructo de Modelo de Negócios}

Nesta seção se apresenta o constructo (MARTINS, 2005) sobre modelo de negócios decorrente da pesquisa:

Modelo de Negócios: Unidade de análise na qual se incluem as principais atividades de uma organização, o seu modelo de lucro, os vínculos com outros atores do seu entorno e, principalmente, como é a troca de valor com os clientes. 
O enunciado representa uma definição constitutiva do constructo. Aproximando-se a uma definição operacional pode se dizer que, o constructo considera modelo de negócios como unidade de análise por ser uma entidade passível de estudo, configurável e separável de outras unidades conceituais. "Atividades" se refere às atividades essenciais de uma organização, entendidas como um comprometimento de recursos organizacionais para a consecução de um objetivo. O modelo de receita, ou modelo de lucro de forma mais abrangente quando se incluem custos, refere-se à forma de sustento que existe numa organização. Os vínculos são ligações geradas com parceiros e clientes. A troca de valor implica tanto a criação como a captura de valor na realização de um negócio.

Uma representação da conceição que foi derivada da revisão teórica apresentada nas seções prévias pode ser visualizada na figura 5 :

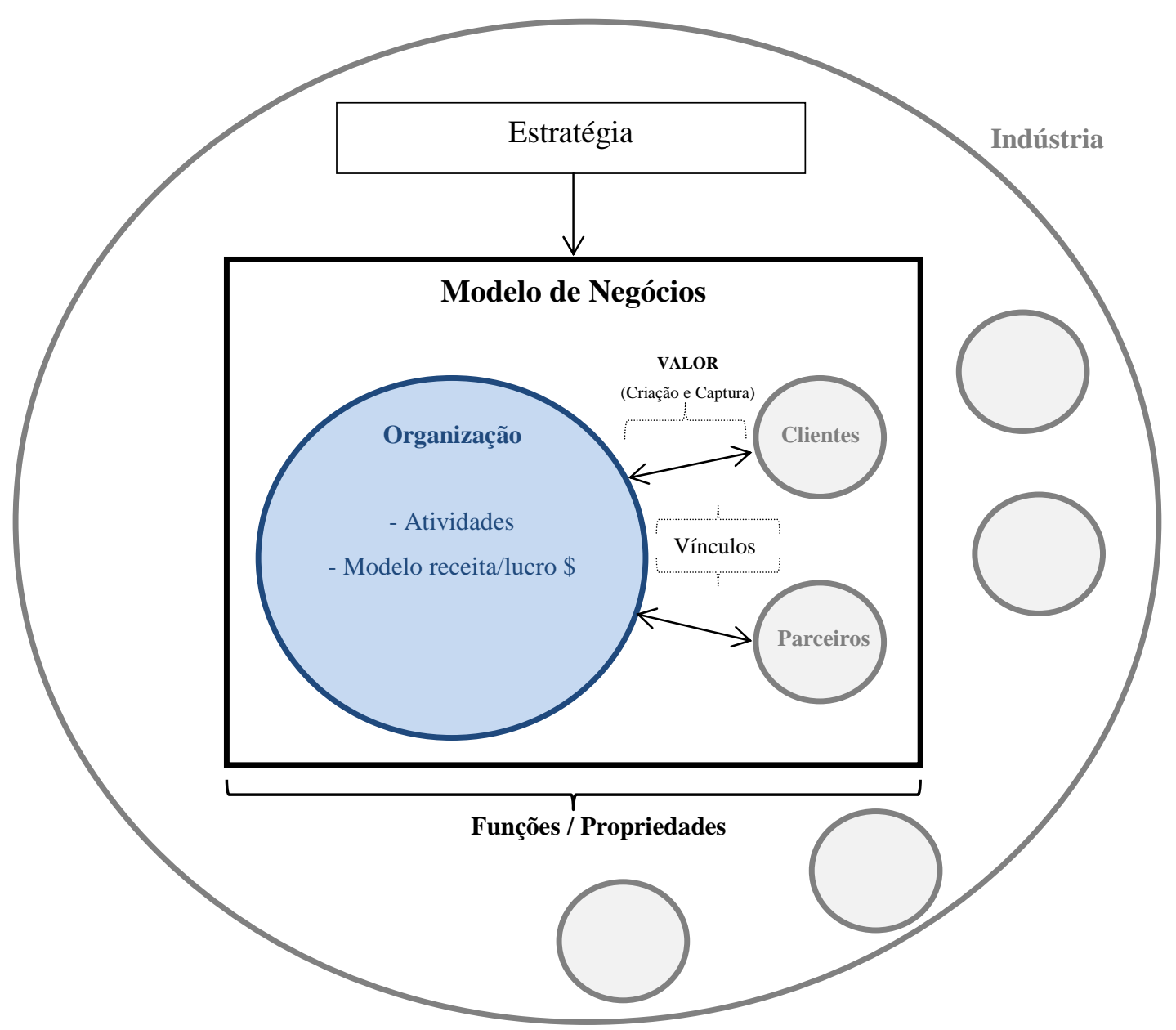

Figura 5 - Representação gráfica do constructo e das proposições 
Martins (2005, p. 35) indica que os constructos podem ser traduzidos em proposições observáveis. Eis aqui algumas delas, propostas a partir desta construção teórica:

- $\quad$ O modelo de negócios como unidade de análise está num nível intermediário entre organização e unidades maiores como a indústria, por transcender as fronteiras da organização, mas ao mesmo tempo ser possível que numa indústria, por exemplo, existam diferentes modelos de negócio;

- Os modelos de negócios são decorrentes da estratégia e/ou do funcionamento da organização;

- O modelo de negócios tem vários componentes. Estes não são isolados, mas interdependentes;

- Definir um modelo de negócios implica identificar quais os posicionamentos da empresa em relação a outros atores do seu entorno como são os seus parceiros mais importantes e os clientes;

- $\quad$ No modelo de negócios existe um fluxo financeiro, mesmo não de forma direta;

- $\quad$ O modelo de negócios pode ser explícito, racionalizado e planificado; ou implícito e determinado pelo funcionamento no mercado;

- $\quad$ O modelo de negócios tem diferentes funções. Ele pode funcionar tanto num nível cognitivo quanto operacional. Por ter, além de um caráter cognitivo, um caráter operacional, pode ser utilizado tanto em análises estratégicas, quanto em implementações tácticas, podendo servir como ponte entre planejamento da estratégia e execução da estratégia, e para fins de exploração;

- $\quad$ O modelo de negócios tem diferentes propriedades. Sua representação é configurável pelo que possibilita diferentes análises tanto estáticas quanto dinâmicas. 


\section{ANÁLISE DE DADOS}

\subsection{Apresentação da primeira empresa - Empresa " $X ", 60$}

A empresa "X" é uma organização com 27 anos no mercado. Desenvolve suas atividades no setor de Tecnologias de Informação e Comunicação. Fundada em 1988, atualmente conta com 260 funcionários, aproximadamente. O informante da empresa reportou um faturamento anual aproximado de 30 milhões de reais.

A organização é descrita no seu próprio material informativo, impresso e virtual, como uma empresa dedicada a fornecer consultoria tecnológica especializada a organizações tanto do setor privado quanto do público. Entre seus serviços se encontram uma série de soluções personalizadas em temas como mobilidade, educação, e gestão corporativa; testes de qualidade e certificação para software; e, assessoria em pesquisa e desenvolvimento.

A empresa se orgulha de ter sido uma pioneira no Brasil e de ter evoluído de forma conjunta ao progresso da tecnologia em geral e seu setor, em específico. Outros sucessos apontados pela empresa são a obtenção de certificações internacionais, em algum dos casos de forma única a nível regional, e credenciamento por parte do órgão público do Brasil mais importante no setor.

Pôde-se detectar da informação coletada; tanto durante a entrevista quanto na informação disponível, impressa e virtual encontrada em sites corporativos e de redes sociais; que a empresa " $\mathrm{X}$ " se visualiza a si mesma como um parceiro estratégico para as suas organizações clientes, por gerar uma serie de vantagens e ganhos para elas.

O informante para a pesquisa na organização é um profissional que está presente por um considerável período de tempo do que constitui o total da história da empresa. Ele está muito vinculado aos temas estratégicos da empresa e possui formação em temas de administração e

\footnotetext{
${ }^{60}$ No momento da realização da entrevista, o informante não tinha certeza sobre o uso do nome real da empresa no estudo de caso, devido a que a máxima autoridade da empresa não estava presente no país para ser consultada, pelo que na pesquisa se utiliza esse pseudônimo para a organização.
} 
estratégia. Na época da realização da entrevista, o informante manifestou estar envolvido na criação de novas unidades de negócio para sua organização.

\subsection{Apresentação da segunda empresa - RTM}

A segunda empresa pesquisada, a RTM, se define como a principal organização provedora de serviços na área de tecnologia para o setor financeiro brasileiro. Contando com 18 anos de atuação no mercado, atualmente cita presença em 19 estados, uma carteira de aproximadamente 550 clientes e relacionamento com 20 provedores de informações e serviços. Os bancos e corretoras destacam como os seus segmentos de clientes com maior participação nesta carteira (RTM, 2015a). O número de funcionários no momento da realização da pesquisa alcançava a 110 pessoas e seu faturamento anual aproximado a cerca de R\$ 65 milhões. Durante a entrevista, a informante da organização enfatizou que a organização é fundamentalmente uma empresa de serviços.

O setor no qual se desenvolve é o de serviços de telecomunicações e TI para o mercado financeiro. Suas atividades incluem o gerenciamento de serviços de voz, dados e imagens para os seus clientes, além de serviços de infraestrutura e Data Center. Destacam entre seus sucessos, parcerias como a existente com Embratel para o gerenciamento de uma importante rede do Sistema de Pagamentos Brasileiro (RTM, 2015a). A organização realça os seus credenciamentos para operar importantes atividades de infraestrutura do sistema financeiro nacional.

Criada em 1997 pela ANBIMA para interligar o setor financeiro do Brasil e sendo comprada uma participação de $20 \%$ pela CETIP dois anos depois, passou a ser sua rede de telecomunicações. A organização iniciou operações com um grupo restrito de 28 clientes do eixo Rio de Janeiro e São Paulo (RTM, 2015b, p.1). Segundo palavras contidas num dos seus boletins informativos:

[...] a RTM tinha como objetivo interligar o setor financeiro, reduzindo custos. Na época, as instituições utilizavam canais de comunicação individuais de baixa velocidade e equipamentos extremamente caros para falar com os seus parceiros e processar eletronicamente suas operações nos diversos mercados. A Rede foi a solução adotada para integrar os sistemas de negociação e liquidação em ambiente 
único de nuvem privada, com simplicidade e garantia de segurança imposta aos serviços de missão crítica do setor. (RTM, 2015b, p.1).

A informante para a pesquisa na empresa é uma profissional com muita experiência em negócios e que trabalha para a organização desde o inicio de suas operações. Ela relatou que discute permanentemente temas de Estratégia com a máxima autoridade, o Diretor Geral, e com as pessoas da área na empresa.

\subsection{Apresentação da terceira empresa - INW Group}

Criado há 18 anos, o INW Group é uma organização que engloba diferentes unidades de negócio pertencentes ao setor de Tecnologia da Informação. Contava com 19 empregados no tempo de realização da pesquisa e reportou um faturamento entre 750 mil y 800 mil reais por ano.

A organização se define como um grupo de empresas com alto desempenho em soluções tecnológicas que fornece suporte numa ampla gama de serviços. A otimização de processos, nas organizações que atende, é citada como elemento importante na oferta do grupo. Esta, junto às demais propostas oferecidas pelo INW Group, visa criar lucro para os seus clientes. (INW, 2015).

A organização oferece às empresas crescer através da otimização do tempo, a redução de custos e o desenvolvimento de projetos tecnológicos adequados à necessidade de cada uma delas.

O grupo gerencia cinco marcas ligadas a seu negócio principal (INW, 2015). A INWERP oferece assessoria no desenvolvimento e implantação de soluções relacionadas a ERP. Por sua parte, a INWTECH oferece suporte no planejamento, montagem e suporte de infraestruturas tecnológicas. Sua marca "Laboratório de Projetos" é descrita como a fábrica ideal para os projetos tecnológicos dos seus clientes. A Tvision é a empresa do grupo destinada a oferecer serviços de segurança mediante tecnologias de monitoramento. Por fim, a marca "Mercado de Soluções" esteve apontada como projeto em desenvolvimento no período da realização da presente pesquisa, mas tendo às pequenas empresas e empreendedores como segmento alvo. 
O informante da empresa para pesquisa é atualmente CEO da organização. A área que tem principalmente baixo sua responsabilidade é a área de Software. Ele esteve vinculado, desde há vários anos, à empresa, mas ele contabiliza efetivamente 6 anos como o tempo de sua permanência na organização.

Durante a entrevista, o informante manifestou algumas questões que ocupavam a atenção da empresa na sua atualidade: a necessidade de uma presença forte em Internet; o know-how para a prospecção da concorrência; o desafio de trabalhar com software open source no Brasil, onde ainda existe desconhecimento e até resistência ao respeito; e, enfrentar a demanda por funcionalidades adaptadas ao Brasil, no caso dos serviços que eles proveem.

\subsection{Discussão dos resultados}

Como a pesquisa tem como um dos seus objetivos responder se existe convergência em literatura e prática sobre modelo de negócios, contrastamos os resultados empíricos com o marco teórico e constructo estabelecidos.

Como se explicou na seção metodológica, a síntese cruzada de casos é uma opção interessante para começar a analisar os dados coletados nas fases prévias. O quadro 8 apresenta um resumo dos resultados da pesquisa utilizando esta modalidade. $\mathrm{O}$ quadro inclui uma estrutura onde se afrontam os principais tópicos abordados pelas questões do caso e as respostas de cada empresa estudada.

Quadro 8 - Síntese cruzada no estudo de casos múltiplos sobre modelo de negócios

\begin{tabular}{|c|c|c|c|}
\hline Tópico & Empresa "X" & RTM - Empresa 2 & INW Group - Empresa 3 \\
\hline Definição & $\begin{array}{l}\text { Maneira lógica, } \\
\text { estruturada de conseguir } \\
\text { conectar conhecimentos } \\
\text { internos (produtos ou } \\
\text { serviços), "o que a gente } \\
\text { tem", para ter uma sinergia } \\
\text { com o mercado. } \\
\text { "É uma maneira sinérgica, } \\
\text { pegar tudo o que eu posso } \\
\text { captar internamente ou } \\
\text { externamente e prover algo }\end{array}$ & $\begin{array}{l}\text { As formas com que a } \\
\text { empresa decide ofertar os } \\
\text { seus produtos ao } \\
\text { mercado de destino (os } \\
\text { clientes finais). }\end{array}$ & $\begin{array}{l}\text { Todas as características } \\
\text { necessárias para poder } \\
\text { levar a minha empresa, o } \\
\text { meu negócio para o } \\
\text { mercado, para conseguir } \\
\text { reaver meu investimento } \\
\text { com um determinado } \\
\text { lucro. }\end{array}$ \\
\hline
\end{tabular}




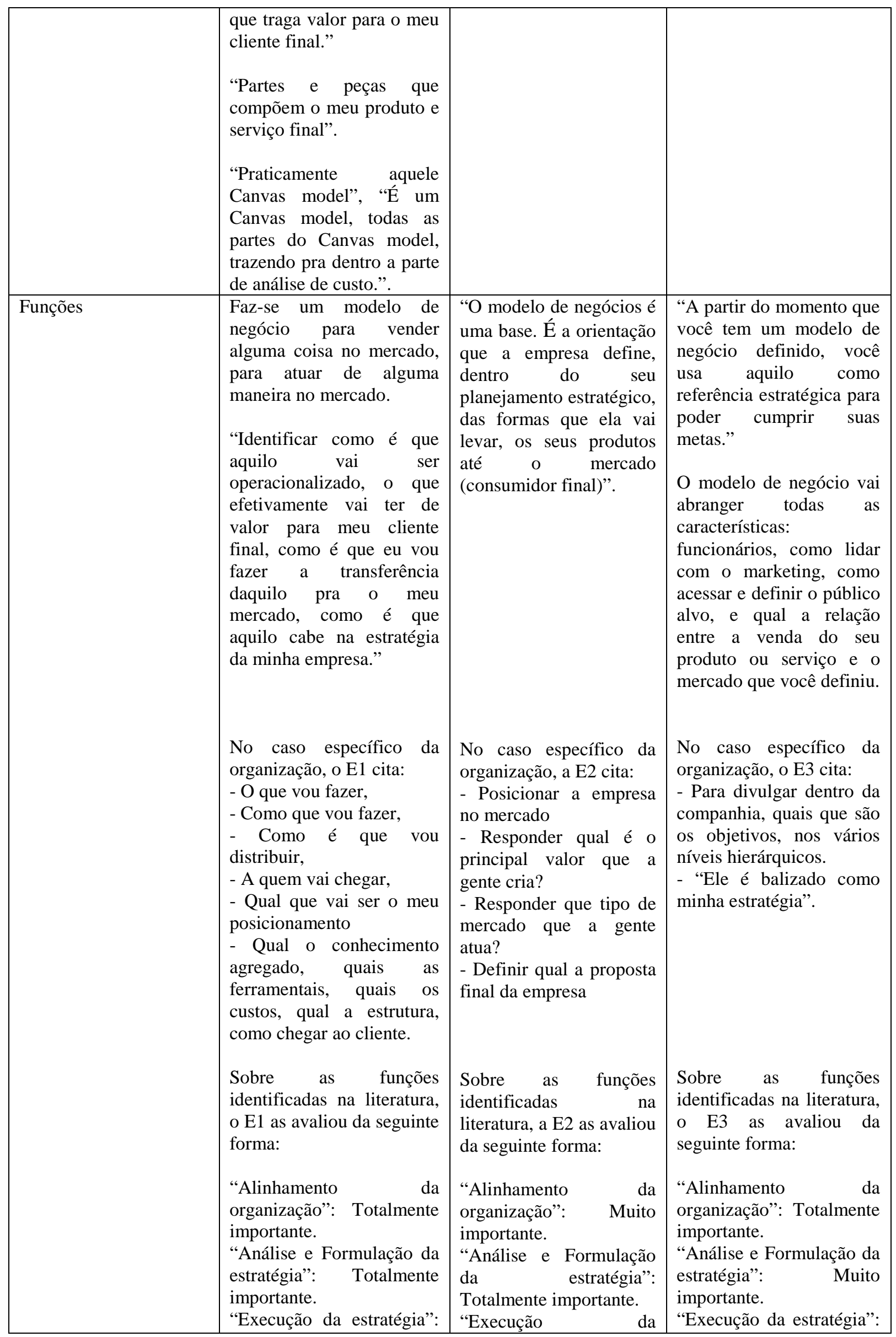




\begin{tabular}{|c|c|c|c|}
\hline & $\begin{array}{l}\text { Discorda que seja uma } \\
\text { função } \\
\text { "Exploração de ideias de } \\
\text { negócio (descoberta e } \\
\text { aproveitamento)": } \text { No } \\
\text { processo de construção, } \\
\text { sim é importante. }\end{array}$ & $\begin{array}{l}\text { estratégia": Considera } \\
\text { relativa sua importância. } \\
\text { Nem importante, nem } \\
\text { não importante. } \\
\text { "Exploração de ideias de } \\
\text { negócio (descoberta e } \\
\text { aproveitamento)": A } \\
\text { considera uma função } \\
\text { presente durante toda a } \\
\text { existência da empresa. }\end{array}$ & $\begin{array}{l}\text { Totalmente importante } \\
\text { "Exploração de ideias de } \\
\text { negócio (descoberta e } \\
\text { aproveitamento)": } \\
\text { Totalmente importante. }\end{array}$ \\
\hline Elementos & 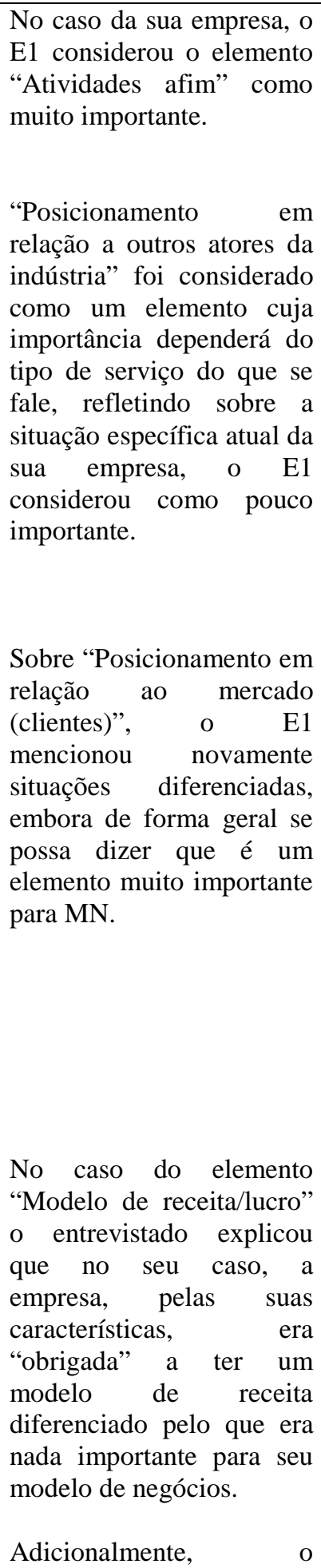 & 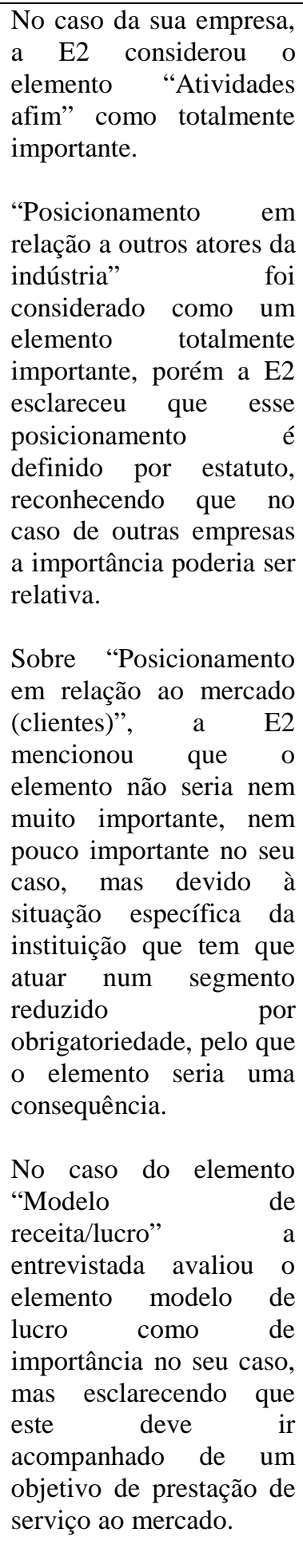 & $\begin{array}{l}\text { No caso da sua empresa, o } \\
\text { E3 considerou o elemento } \\
\text { "Atividades afim" como } \\
\text { totalmente importante. } \\
\text { "Posicionamento em } \\
\text { relação a outros atores da } \\
\text { indústria" foi considerado } \\
\text { pelo E3 como um } \\
\text { elemento cuja importância } \\
\text { dependerá do estágio de } \\
\text { maturação no qual esteja a } \\
\text { empresa, considerando } \\
\text { este num nível } \\
\text { intermediário de nem } \\
\text { importância, nem não } \\
\text { importância. } \\
\text { Sobre "Posicionamento } \\
\text { em relação ao mercado } \\
\text { (clientes)", o E3 pediu } \\
\text { avaliar o elemento como } \\
\text { totalmente importante, } \\
\text { mas fazendo umas } \\
\text { ressalvas sobre seu caso } \\
\text { específico. }\end{array}$ \\
\hline
\end{tabular}




\begin{tabular}{|c|c|c|c|}
\hline & $\begin{array}{l}\text { entrevistado sugeriu que a } \\
\text { Cultura pode ser um } \\
\text { elemento a considerar } \\
\text { quando se fala de modelo } \\
\text { de negócios. }\end{array}$ & & \\
\hline Valor & $\begin{array}{l}\text { Relação TOTAL no caso } \\
\text { da empresa "X" segundo o } \\
\text { entrevistado. } \\
\text { Entre criação de valor e } \\
\text { captura de valor, o E1 } \\
\text { considera que embora } \\
\text { ambas sejam importantes } \\
\text { para a organização, a } \\
\text { segunda (captação) às } \\
\text { vezes providencia } \\
\text { feedback para a primeira } \\
\text { (criação). }\end{array}$ & $\begin{array}{l}\text { Fundamental no caso do } \\
\text { modelo de negócios da } \\
\text { empresa. Prioriza-se a } \\
\text { criação de valor para o } \\
\text { cliente }\end{array}$ & $\begin{array}{l}\text { Para o E3, o Valor para o } \\
\text { cliente é um elemento } \\
\text { muito cuidado na sua } \\
\text { oferta. } \\
\text { O E3 sugere que num } \\
\text { modelo de negócios não } \\
\text { só se cria valor para o } \\
\text { cliente, senão também no } \\
\text { nível interno. } \\
\text { Para o E3 } \\
\text { preponderância } \\
\text { criação e captura de valor, } \\
\text { dependerá da situação da } \\
\text { empresa. Reconhecendo } \\
\text { que ambas } \\
\text { importantes para } \\
\text { modelo de negócios, o E3 } \\
\text { considera que existem } \\
\text { momentos nos quais uma } \\
\text { é mais importante do que } \\
\text { a outra, e vice-versa. }\end{array}$ \\
\hline Representação & $\begin{array}{l}\text { Na organização não têm } \\
\text { documento ou } \\
\text { representação explícita do } \\
\text { seu modelo de negócios, } \\
\text { citando o E1, às Atas de } \\
\text { Comité } \\
\text { documentais) como o mais } \\
\text { aproximado a } \\
\text { consultado. }\end{array}$ & $\begin{array}{l}\text { Na organização não têm } \\
\text { documento } \\
\text { representação explícita } \\
\text { do seu modelo de } \\
\text { negócios }\end{array}$ & $\begin{array}{l}\text { Ao respeito o E3 só pôde } \\
\text { indicar que tem partes de } \\
\text { um business plan. }\end{array}$ \\
\hline Narrativa & $\begin{array}{l}\text { A organização não possui } \\
\text { algo explícito. O E1 indica } \\
\text { que provavelmente outro } \\
\text { executivo faria com } \\
\text { facilidade, mas ele numa } \\
\text { tentativa consegue armar } \\
\text { uma narrativa para } \\
\text { descrever o seu modelo de } \\
\text { negócio. }\end{array}$ & $\begin{array}{l}\text { A E2 pôde armar uma } \\
\text { narrativa baseada na } \\
\text { origem da empresa e o } \\
\text { que ela providencia. }\end{array}$ & $\begin{array}{l}\text { Quando consultado sobre } \\
\text { a possibilidade de uma } \\
\text { narrativa para descrever o } \\
\text { modelo de negócios, o E3 } \\
\text { responde que consideraria } \\
\text { esta como a primeira parte } \\
\text { de um sumário executivo } \\
\text { de um plano de negócios } \\
\text { padrão. Coisa que ele não } \\
\text { tem, nem chegou a fazer. }\end{array}$ \\
\hline Propriedades & $\begin{array}{l}\text { O E1 não acha que o } \\
\text { modelo de negócios seja } \\
\text { algo abstrato para sua } \\
\text { empresa. } \\
\text { Modelo inicialmente } \\
\text { planificado, mas mutável } \\
\text { frente a alterações do } \\
\text { mercado. }\end{array}$ & $\begin{array}{l}\text { A E2 não acha que o } \\
\text { modelo de negócios seja } \\
\text { algo abstrato para sua } \\
\text { empresa e pelo contrario } \\
\text { indica que ele está muito } \\
\text { presente. } \\
\text { Modelo de negócios } \\
\text { previamente definido, } \\
\text { mas que mudou ao longo } \\
\text { dos anos. }\end{array}$ & $\begin{array}{l}\text { O E3 indica que não seu } \\
\text { caso o modelo de negócio } \\
\text { não está tão presente } \\
\text { como deveria. } \\
\text { Na organização o modelo } \\
\text { não foi planificado nunca. }\end{array}$ \\
\hline
\end{tabular}




\begin{tabular}{|c|c|c|c|}
\hline & & $\begin{array}{l}\text { O modelo de negócios } \\
\text { sim é compartilhado } \\
\text { internamente a todos os } \\
\text { níveis da empresa, mas } \\
\text { não ao nível externo, } \\
\text { salvo aos acionistas. }\end{array}$ & $\begin{array}{l}\text { Indica-se que o modelo de } \\
\text { negócios, ou pelo menos } \\
\text { "partes" são divulgadas a } \\
\text { todos os níveis de forma } \\
\text { interna e de maneira } \\
\text { formal. O modelo não é } \\
\text { divulgado a agentes } \\
\text { externos. }\end{array}$ \\
\hline \multirow[t]{4}{*}{ Relação Estratégia-MN } & $\begin{array}{l}\text { Segundo o E1 conhecer } \\
\text { bem o modelo de negócios } \\
\text { torna a } \\
\text { competitiva. }\end{array}$ & $\begin{array}{l}\text { Para a E2 a vantagem de } \\
\text { ter um modelo de } \\
\text { negócios no seu caso é } \\
\text { trabalhar com um } \\
\text { modelo de pagos fixo, } \\
\text { algo desejável no seu } \\
\text { setor. Como } \\
\text { desvantagem está a } \\
\text { menor flexibilidade } \\
\text { frente a demandas do } \\
\text { mercado. }\end{array}$ & $\begin{array}{l}\text { Para o E3 uma vantagem } \\
\text { de ter modelo de negócios } \\
\text { é o saber exatamente onde } \\
\text { a empresa está e o que } \\
\text { acontece com ela. Como } \\
\text { problema ficaria que para } \\
\text { pequenas empresas se } \\
\text { complica gerenciar na } \\
\text { prática. }\end{array}$ \\
\hline & $\begin{array}{l}\text { Definindo Estratégia como } \\
\text { o "como vencer no } \\
\text { mercado reduzindo } \\
\text { barreiras para atingir } \\
\text { objetivos", o executivo da } \\
\text { Empresa "X" considera } \\
\text { que às vezes os conceitos } \\
\text { se confundem, mas o } \\
\text { modelo de negócios é algo } \\
\text { estratégico por si só e que } \\
\text { o planejamento estratégico } \\
\text { leva à sustentação do que } \\
\text { se conhece por modelo de } \\
\text { negócios. }\end{array}$ & $\begin{array}{l}\text { Definindo } \\
\text { como "O caminho a } \\
\text { seguir para atingir } \\
\text { determinados objetivos" } \\
\text { a executiva considera } \\
\text { que sim existe relação } \\
\text { entre conceitos, sendo } \\
\text { que o modelo de } \\
\text { negócios é parte da } \\
\text { estratégia. }\end{array}$ & $\begin{array}{l}\text { Definindo Estratégia } \\
\text { como "identificar qual é o } \\
\text { seu caminho para alcançar } \\
\text { as oportunidades as quais } \\
\text { você está buscando" e } \\
\text { "você tem um ponto } \\
\text { aonde quer chegar, é } \\
\text { definir o seu caminho } \\
\text { para chegar naquele } \\
\text { ponto", o E3 quase } \\
\text { considera MN e estratégia } \\
\text { como a mesma coisa. }\end{array}$ \\
\hline & $\begin{array}{l}\text { O E1 considera que a } \\
\text { estratégia precede ao } \\
\text { modelo de negócios. }\end{array}$ & $\begin{array}{l}\text { A E2 considera que a } \\
\text { estratégia precede ao } \\
\text { modelo de negócios. }\end{array}$ & $\begin{array}{l}\text { O E3 considera que } \\
\text { estratégia e modelo de } \\
\text { negócios, acontecem ao } \\
\text { mesmo tempo. }\end{array}$ \\
\hline & $\begin{array}{l}\text { Na ordem, o executivo } \\
\text { considera que a Estratégia } \\
\text { fica como o conceito mais } \\
\text { abstrato, as tarefas } \\
\text { operacionais como o mais } \\
\text { tangível e o modelo de } \\
\text { negócios fica numa } \\
\text { camada intermedia. }\end{array}$ & $\begin{array}{l}\mathrm{Na} \text { ordem, a executiva } \\
\text { classificou a Estratégia } \\
\text { como o conceito mais } \\
\text { abstrato, as tarefas } \\
\text { operacionais como o } \\
\text { mais objetivo e modelo } \\
\text { de negócios fica num } \\
\text { nível intermediário. }\end{array}$ & $\begin{array}{l}\text { Na ordem, o executivo } \\
\text { considerou às atividades } \\
\text { operacionais como o } \\
\text { aspecto mais tangível na } \\
\text { sua organização, } \\
\text { Estratégia como um } \\
\text { conceito que fica no meio, } \\
\text { e o conceito mais abstrato } \\
\text { segundo ele é o modelo } \\
\text { de negócios, para o caso } \\
\text { específico de sua } \\
\text { organização. }\end{array}$ \\
\hline
\end{tabular}




\subsubsection{Discussão sobre a definição e as funções dos modelos de negócios nas empresas estudadas}

O entrevistado 1 (E1) reconheceu no momento que dava a sua definição que quando se reflete sobre o tema, este se demonstra "confuso". A executiva entrevistada na segunda organização, chamada E2 a partir de agora, não teve nenhum problema para providenciar sua definição de modelo de negócios. O Entrevistado 3, chamado de E3, também tinha clara sua definição pessoal de modelo de negócios.

Deve-se salientar que nas definições dos executivos apresentadas no Quadro 8, apreciasse correspondência com as categorias de definições identificadas por Morris, Schindehutte e Allen (2005), existindo nestas alusões à lógica de geração de lucro (definições econômicas), a processos e desenhos estruturais (definições operacionais), e à posição e interação da firma em relação ao mercado (definiçõos estratégicas).

Também se deve fazer referência ao trabalho de Nenonen e Storbacka (2010), os quais encontraram entre as características comuns nas definições revisadas no seu estudo: a menção à lógica dos ganhos (lucro), como se observa na definição do terceiro executivo; a alusão aos recursos e capacidades que a firma tem, como no caso da definição providenciada pelo primeiro executivo; e a referência a algum tipo de decisão estratégica, escolha ou princípio, como se observa no caso da definição da segunda executiva consultada.

Baden-Fuller e Mangematin (2013) acreditam que existe consenso acadêmico sobre que o modelo de negócios tem que ligar empregados dentro da firma com elementos externos, incluindo o lado do cliente e a questão do valor, aspectos todos que são mencionados nas definições do entrevistado na primeira organização. Também se encontrou semelhança entre a definição do E1 e a visão de modelo de negócios de Timmers (1998) como uma arquitetura de fluxos de produto, serviço e informação.

Por sua parte, nas definições e funções sobre modelos de negócios citadas pelos executivos das segunda e terceira empresas se percebe semelhança com o enunciado por Sorescu et al. (2011), para os quais modelo de negócios detalha os mecanismos que movem a uma organização na direção de uma meta. 
Nas definições dos executivos entrevistados nas duas primeiras organizações se faz referência a uma "maneira lógica" e "formas", pelo que pode se relacionar estas com definições teóricas como as encontradas em Keen e Qureshi (2006), Chesbrough e Rosenbloom (2002) ou Casadesus-Masanell e Ricart (2010), os quais entendem modelo de negócios como uma "lógica básica do negócio", como uma lógica heurística que conecta potencial com realização de valor, e como a maneira como se opera e cria valor para os stakeholders.

Quando os entrevistados foram desafiados a descrever seu próprio modelo de negócios as respostas foram diversas. Por exemplo, o E1 sem definir exatamente qual era seu modelo de negócio, revelou que para ele existiam diferenças dependendo da unidade de negócio, existindo "micro-modelos de negócios separados" partes posteriores da entrevista de modelo MACRO. È importante mencionar que segundo o E1, todos esses modelos micro estão estrategicamente alinhados. Reforçando esta afirmação o E1 citou em outra parte da entrevista e respondendo a outra pergunta que: "Estruturamos um modelo específico de negócios para conseguir atender a um cliente.”.

Resulta relevante salientar que na resposta a esta solicitação, a segunda entrevistada, E2, coincidiu com o anterior caso, ao afirmar que na sua organização não têm exatamente um ÚNICO modelo de negócios, senão alguns modelos. A entrevistada pôde descrever esse modelo, em termos gerais e para a maior parte dos serviços que sua organização oferece, principalmente, como um modelo de receita da empresa.

O entrevistado 3, por sua parte, definiu seu modelo de negócio de forma muito simples como uma venda de serviços encima de software livre.

Discutindo sobre as funções de um modelo de negócios, os entrevistados trouxeram à luz interessantes considerações. Como se observa no Quadro 8, quando consultados para definir livremente as funções de um modelo de negócios, os entrevistados providenciaram respostas variadas, nas quais as funções tiveram a ver com identificar as atividades que se precisam para atuar no mercado; a orientação sobre as formas para levar os produtos ao mercado; ou o uso como referência estratégica.

\footnotetext{
${ }^{61}$ Num momento da entrevista o E1 chega a chamar de "micro-máquinas" que rodam, ao mesmo conceito.
} 
As funções citadas pelos executivos das duas primeiras empresas, que têm a ver com operacionalizar atividades e refletir respeito a um posicionamento em relação ao mercado, têm relação com a concepção de Al-Debei e Avison (2010), para os quais um modelo de negócios providencia uma visão holística de um negócio que é útil para entender tanto a estrutura interna de uma empresa quanto como esta se conecta e interage com o seu ambiente externo.

As funções específicas citadas pelo Entrevistado 1 têm semelhança com a concepção de Magretta (2002), para quem podem se realizar escolhas estratégicas; acerca de mercados geográficos, segmentos, consumidores e produtos; sobre um modelo de negócios subjacente.

Também se achou muita relação entre as funções específicas citadas pelos entrevistados nas três organizações e as funções do modelo de negócios propostas por Chesbrough (2007, 2010).

O executivo da terceira empresa também citou como uma das funções específicas no caso da sua organização à da divulgação dos objetivos dentro da companhia nos vários níveis hierárquicos. Para Magretta (2002) um bom modelo de negócios pode servir para alinhar à organização nos seus valores. Mason e Spring (2011) também entendem os modelos de negócios como mecanismos "[...] de framing para influenciar e moldar a ação coletiva e individual.”. Osterwalder, Pigneur e Tucci (2005) também incluem entre as funções dos modelos de negócios à compreensão e compartilhamento numa organização. Al-Debei e Avison (2010), por sua parte, consideram que os modelos de negócios fornecem uma maneira poderosa para comunicar e administrar escolhas estrategicamente orientadas.

Consultados sobre as funções dos modelos de negócios extraídas da literatura revisada os informantes apontaram o seguinte respeito às suas organizações:

No caso da função "Alinhamento da organização", o E1 citou a função como totalmente importante "porque se as pessoas não sabem pra onde ir, o que fazer, quais os envolvidos, você não consegue fazer a maquina andar.”. A E2 citou a importância desta função, mas advertindo que se deve tomar cuidado para que os modelos de negócios não se transformem num "gesso" para as empresas. A executiva acrescenta o seguinte: 
"Muitas vezes, você tem necessidade de realinhamentos, às vezes rápidos no modelo de negócio. Você não pode estar preso a um modelo previamente definido, porque se não é difícil a empresa toda caminhar em outra direção ou fazer algum ajuste." (Depoimento entrevistada 2).

Coincidindo plenamente com a ideia contribuída pela entrevistada, Hacklin e Wallnofer (2012) observam que a adesão a um modelo de negócios numa companhia pode significar certo lock-in coletivo na identidade, o que por sua parte pode gerar forças inerciais que refreiem as mudanças estratégicas.

O E3, no seu caso, indica o seguinte:

O que eu faço internamente é o quê? É divulgar dentro da própria companhia, quais que são os objetivos, nos vários níveis hierárquicos, para que todo o mundo [...] vamos nos limitar às partes do modelo de negócio que são importantes pra todo o mundo. Mas pelo menos você consegue balizar a informação em todos os níveis hierárquicos. Todo mundo caminha para o mesmo lugar. Essa pra mim a principal função. (Depoimento entrevistado 3).

Sobre as funções de "Análise e Formulação de estratégia", o E1 mencionou que o modelo de negócios está acoplado à estratégia e tem a ver com os seus objetivos, sugerindo que sem modelo de negócios "não se sabe o que fazer". Para a E2, esta função é "fundamental" indicando que inclusive talvez seja a mais importante e que o modelo de negócios "tem que estar completamente alinhado com a estratégia.”. O E3 admite que não pensou tanto em "análise e formulação", como sim em aferição da estratégia formulada como uma função do modelo de negócios.

No caso da função "Execução da estratégia" identificada na literatura, o entrevistado 1 teve para dizer que discorda que seja uma função porque no seu caso seria como inverter e ter a estratégia a partir dos modelos de negócios, quando no seu caso o modelo de negócios fica embaixo da sua estratégia. No máximo, ele considera que poderiam ir de forma paralela. Para a E2, o modelo de negócios não deixa de ser um orientador para a execução, mas no caso da sua própria empresa a importância era média. O E3 colocou está função do MN mais direcionada para vendas e marketing.

Sobre a função dos modelos de negócios no sentido de "Exploração (descoberta) e Exploração (aproveitamento) de ideias de negócio" os entrevistados mencionaram o seguinte. Para o E1 a importância está presente no processo de construção e criação do modelo de negócios. A E2 explica nas suas próprias palavras que: 


\begin{abstract}
A gente começou com um serviço dentro de um modelo de negócios e partir do momento que você tira esse novo serviço, que tal eu também agregar mais esse serviço, e na realidade a RTM é um conjunto de serviços que foram agregados ao primeiro serviço e a partir daí a gente praticamente todos esses anos, a gente vem agregando, [...] o grosso dos serviços que foram agregados ao longo dos anos, eles foram realmente agregados do modelo original. A partir dele. (Depoimento entrevistada 2).
\end{abstract}

Sobre este último depoimento, resulta interessante fazer referência a McGrath (2010) que afirma que a evolução de modelos de negócios é altamente dependente da trajetória, isto é, experimentos precoces nos modelos de negócio vão ter influência nos modelos por vir.

O executivo da terceira organização explicou o seguinte: “A gente fez todo o planejamento, você trava um modelo, coloca aquele modelo em utilização, afere o resultado, volta e revê o seu modelo. Então, modelo é uma coisa que está em constante evolução.”. Adicionalmente, indica: Que no fundo é o que ninguém numa empresa pequena consegue fazer direito. Por
quê? Porque a gente não tem recursos apropriados para fazer isso. Para eu poder
fazer aferição do meu modelo com a frequência que eu gostaria, eu teria que fazer só
isso, entendeu? Mais nada. E no dia a dia acaba-se não conseguindo. Então estar
aferindo meu modelo a cada, botou pra rodar a cada 3, 4 meses, eu vou lá, volto e
vejo que é o que eu posso corrigir, 'isso aqui não está legal', 'vamos mudar isso
aqui', 'vamos mudar aquilo ali'. (Depoimento entrevistado 3).

\title{
4.4.2 Discussão sobre os elementos dos modelos de negócios
}

Considerando os elementos identificados na revisão bibliográfica da pesquisa e traduzidos nos elementos considerados no constructo proposto, os entrevistados foram consultados sobre sua concordância e experiência ao respeito nas suas organizações. Da mesma forma se abriu a possibilidade que os consultados proponham qualquer outro elemento merecedor de consideração na discussão do tema.

Embora, posteriormente, todos os entrevistados coincidissem sobre a importância do elemento “Atividades da empresa" para o conceito modelo de negócios, de inicio teve que se discutir com todos eles a definição deste elemento segundo a teoria utilizada. No primeiro caso, o E1 explicando sobre sua concordância com o elemento, mencionou que existe um "histórico de clientes", "histórico de conhecimento", "ferramentas, pessoas, conhecimento e investimento históricos" e, salvo que a empresa esteja fazendo um redirecionamento estratégico drástico, o elemento pesa e é muito importante. No caso da E2, a importância decorre da necessidade do 
tipo de empresa na qual ela atua. Esta implica ter os recursos e a estrutura mínima para prestar os seus serviços. Segundo palavras da entrevistada: "Na hora que você está montando um modelo de negócios, você tem que ter isso [as atividades], tudo muito bem estruturado para que o seu modelo de negócio não vire um tiro no pé.”. Para o E3, o elemento é importante, principalmente em dois sentidos: comprometimento de recursos de capital e na alocação das pessoas certas nos lugares certos. Nas suas palavras: "A gente tem uma serie de atividades chave para a gente poder conseguir, se manter no negócio.”.

No caso do "Posicionamento em relação a outros atores da indústria", como ser fornecedores e parceiros, o E1 mencionou que no caso de sua empresa depende, sendo que para algum tipo de produto ou serviço (e.g. desenvolvimento de software) sim, existe importância para seu modelo de negócio, enquanto que para outros tipos, não. Para a E2, embora a importância do elemento no seu caso era grande, reconheceu que este posicionamento era um tema definido por um Conselho de Administração e que sua organização só podia atuar num determinado segmento, relacionando-se com determinados atores quase como condição sine qua non. A executiva refletiu que se não fosse o caso, uma empresa teria que estabelecer todo o seu network ao redor de um foco. O E3 faz uma importante distinção, ao ser consultado sobre o elemento, pois para ele num início da organização o relacionamento com seus parceiros (e.g. parceiro na Bélgica) foi determinante no seu modelo de negócio, mas depois quando se passa por um período de maturação, torna-se menos importante, segundo a sua experiência.

Sobre "Posicionamento em relação ao mercado (clientes)", o E1 indicou que no modelo de negócios de sua organização existiam posicionamentos diferenciados de acordo com o setor do cliente: Governo, mercado, P\&D, etc. No caso da segunda empresa, a E2 mencionou que este posicionamento é uma consequência da obrigatoriedade de atuação num determinado setor, o financeiro. Embora segregando por tipo de instituição, sua organização só se circunscreve a um universo reduzido.

Não entanto, é interessante salientar que num momento posterior da entrevista, uma vez concluídas as questões do roteiro e ampliando na discussão sobre o tema de forma aberta, a executiva da segunda empresa enfatizou na importância do cliente para seu próprio modelo de negócios. Nas suas palavras: 
Não sei se são todas as empresas, mas aqui, o nosso foco, assim, só se fala da palavra cliente. Ele é o que pode dar uma guinada, até dar uma estratégia... é o nosso cliente, que é pra quem os olhos têm que estar sempre voltados. Então a empresa tem que estar de olho em qualquer mudança no seu mercado pra ver se você precisa revisitar seu planejamento estratégico, sua estratégia, e até o seu modelo de negócio. $\mathrm{Eu}$ acho que o planejamento estratégico é o inicio, mas talvez o principal valor dentro de um modelo de negócios, na minha visão é o CLIENTE. É ele quem determina isso e que no final das contas vai determinar o sucesso ou fracasso da empresa. (Depoimento entrevistada 2)

Para o E3, o cliente influencia importantemente o seu modelo de negócios, mas admitiu que, no seu caso específico e situação atual, eles estão tentando profissionalizar ao máximo sua relação, para não abrir mais certas portas que no passado geraram um peso desmedido da influência do cliente no negócio. Nas palavras do executivo, se espera que o cliente influencie no modelo, que ensine e ajude a aprender à organização, mas não que determine o modelo de negócios.

Sobre o modelo de receita ou lucro, no caso da Empresa "X" e pelas suas características, o elemento foi avaliado como nada importante. Porém é necessário notar que o E1, numa resposta a uma questão posterior e sobre outro tema, também indicou que para ele modelo de negócio é: "como é que vai pagar isso e como se sustenta? Ao falar modelo de negócio, penso de imediato em um $P \& L^{62}$ ". Coincidente com sua definição de modelo de negócios, a entrevistada 2, salientou a importância do modelo de lucro para o modelo de negócios de sua empresa, mas sem deixar de mencionar que sua organização tem como um objetivo, tão grande quanto ser lucrativa, o de prestar serviço ao mercado. O E3 releva a importância do modelo de receita para um modelo de negócios e acredita que ele deve ser extremamente abrangente e ao mesmo tempo não ser muito complexo. Sobre o tema, o executivo acrescenta relatando que no caso da sua organização, se passou de não ter modelo nenhum a ter um modelo mais organizado na atualidade.

Entre os elementos não citados pela literatura, mas levantados pelos entrevistados, se pode citar o seguinte. Para o E1, a cultura da organização seria um "item importantíssimo" no modelo de negócios de uma organização.

\footnotetext{
${ }^{62}$ Fazendo referência ao conceito de "Profit and Loss" em operações.
} 


\subsubsection{Discussão sobre valor}

Consultados sobre a importância e relação do tema VALOR com o conceito modelo de negócios, os entrevistados deram as seguintes impressões. Segundo palavras do E1:

"Um modelo de negócio tem como base..., o sucesso dele está diretamente ligado a que?: Qual o valor que ele traz para o cliente.... Não é racional montar um modelo de negócio que não considere valor." (Depoimento entrevistado 1)

Discutindo sobre criação de valor e captura de valor, o E1 avaliou ambas como importantes para seu modelo de negócio e relevou que muitas vezes a captação de valor termina providenciando retroalimentação e insights para retornar valor novamente. Ampliando, refletiu sobre a importância do tempo no qual a organização se encontre e a relação que se tenha com o cliente, sugerindo que num momento no qual a relação está estabelecida a captura é mais relevante, mas num primeiro momento no se consegue ir diretamente a querer captar valor e o que se prioriza é dar valor porque o que se quer é "entrar e ficar dentro".

Num momento posterior na sua entrevista, o informante E1 menciona que: "quando você tem um modelo de negócio formado e rodando, você tem geração bidirecional de valor.”.

A executiva entrevistada na segunda organização manifestou que o conceito de valor é "fundamental" no caso de sua empresa. Estendendo a explicação, a E2 comentou que no seu caso o grande valor que fornece a organização a seus clientes é um atendimento diferenciado, o conhecer o negócio do cliente e o conhecer o impacto do serviço prestado pela empresa no negócio do cliente. Consultada sobre o balanço entre criação de valor e captura de valor no caso do modelo de negócios de sua empresa, a E2 não hesitou em mencionar que a primeira, criação de valor, era mais importante para eles. Duas considerações são levantadas pela entrevistada sobre esta importância. Primeiro, que as características do seu mercado, muito concorrido e disputado, fazem com que este aspecto cobre relevância. Segundo, que a criação de valor implica um investimento grande e constante em treinamento e capacitação de pessoas, e um custo de gerenciar essa criação de valor para o cliente.

A informação tirada das declarações da entrevistada 2 tem correspondência com a discussão de Zott, Amit e Massa (2011) sobre a importância de aspectos da proposta de valor e a ênfase no papel do cliente nos modelos de negócios. 
O E3 providenciou valiosos exemplos de como é cuidado esse aspecto no seu modelo de negócios. Ele assevera que hoje uma das coisas mais importantes para sua empresa é a imagem. $\mathrm{O}$ executivo se orgulha de que numa carteira muito numerosa de clientes; a empresa não tem reclamos sobre o seu trabalho pelo esforço que dedicam nesse tema. Nas suas palavras: "Eu procuro não só, e ai isso vem um pouco da experiência que eu tive no mercado, eu procuro não só deixar o cliente satisfeito, mas eu procuro agregar valor encima da operação do cliente com o conhecimento que eu tenho, operacional.”.

Resulta interessante mencionar nesta parte que o executivo da terceira organização coloca um tema distinto e merecedor de maior exploração. O E3 sugere que manter um modelo de negócios não só gera valor para os seus clientes, mas para a empresa mesma de forma interna e para ele mesmo de maneira pessoal, em outra forma além da do valor monetário. Segundo suas palavras:

\begin{abstract}
"[...] mas hoje minha empresa, me da uma satisfação muito maior, do que me manter fechado num cubículo gerenciado um projeto dentro da [cita uma multinacional]. Qual é essa satisfação? Eu tenho relacionamento com 'n' empresas diferentes. Eu não estou mais trabalhando 16 horas por dia como eu trabalhava no mercado. $\mathrm{O}$ trade off do lado interno é um pouco mais pessoal. A gente até pode parar e olhar para o lado financeiro [...], eu não tenho nenhum trade off, eu estou indo porque eu acredito e por vontades pessoais. Entendeu? Por satisfação pessoal." (Depoimento entrevistado 3).
\end{abstract}

Pode-se buscar uma leve aproximação da ideia no depoimento com a definição de Dasilva e Trkman (2013), os quais afirmam que modelo de negócios é uma representação de uma “[...] combinação específica de recursos, a qual mediante transações gera valor tanto para clientes como para a organização.”.

Para o E3, o balanço entre criação e captura de valor depende da situação da empresa. Segundo ele, na sua organização existem determinados momentos nos quais não se deixa de lado a criação de valor, mas eles se importam mais com a captura de valor; e existem outros momentos, nos quais "a criação de valor para o cliente é muito mais estratégica do que a captura”. O E3 anota que esta dualidade também dependerá do tipo de cliente. Refletindo sobre o tema o E3 relata:

Isso é um ciclo. Depende do cliente com o qual você está trabalhando. Eu tenho alguns clientes, por exemplo, acontece ao mesmo tempo, [...] agora, nesse momento, eu tenho um cliente em [cita uma cidade do estado de Rio de Janeiro] em que eu estou muito mais interessado em capturar valor de ele do que criar valor para ele. $\mathrm{E}$ eu tenho um outro cliente aqui em São Paulo, que eu estou fazendo tudo o que puder para melhorar a operação dele, porque eu quero que ele carregue meu nome pra 
cima. Depende muito do momento, as duas são importantes, só que é uma questão de análise de caso a caso. [...] Você nunca vai ter uma barreira clara dizendo: 'Eu quero capturar mais, eu quero focar em capturar ou eu quero focar em criar', as duas têm suas vantagens e eu acho que estrategicamente você tem que analisar: em que momento a empresa se encontra? e, em que momento o outro lado se encontra? para decidir no que você vai focar. (Depoimento entrevistado 3).

Destaca nos depoimentos das pessoas entrevistadas nas três organizações estudadas, a circulação entre captura e criação de valor centrada no cliente, às vezes com preeminência da última sem desconhecer a primeira, tal como indicam Zott, Amit e Massa (2011) quando falam do foco dual nos modelos de negócios.

Indagando sobre a relação cadeia de valores e modelo de negócios, o pesquisador constatou que em geral os executivos têm conhecimento do primeiro conceito, mas não foi possível aprofundar muito na discussão sobre similitudes ou diferenças entre ambos os conceitos. No primeiro caso, o E1 citou que no processo "de uma maneira ou de outra se consegue ter um paralelismo de conceitos". A entrevistada 2, por sua parte, informou que na sua empresa existe o desenho da cadeia de valor da empresa e que pessoalmente considera que existe muita correlação entre os conceitos de cadeia de valor e modelo de negócios. Nas suas palavras:

[...] na medida em que você consegue estruturar e organizar, estar acompanhando a sua cadeia de valor, você consegue pontualmente fazer ajustes no seu modelo de negócio, pra adaptar mercado, pra adaptar economia, pra adaptar o momento de seus clientes, você tem uma margem de gerenciamento, [...] você pode eventualmente mexer com isso. (Depoimento entrevistada 2).

A ideia expressada no depoimento da entrevistada tem afinidade com a imagem de variações na cadeia de valor genérica subjacente encontrada na discussão sobre modelo de negócios de Magretta (2002) e com a visão de Schweizer (2005).

O E3 desenhou a cadeia de valor da empresa, espontaneamente num papel no momento da sua entrevista, para conferir que ele tenha entendido a consulta. Ele considera que: "Você não tem modelo de negócios se você não tiver uma cadeia de valor. Você precisa de uma cadeia de valor para poder balizar o seu modelo de negócios. Porque se não você não, ai a gente volta lá para a primeira página, você não define quais são as suas atividades.”.

Magretta (2002) diz que os modelos de negócio têm a ver com as cadeias de valor, fazendo referência às atividades que são parte da cadeia. 


\subsubsection{Discussão sobre a representação dos modelos de negócios nas empresas estudadas}

Todas as empresas estudadas mencionaram que não têm uma representação formal ou documentada do que é seu modelo de negócios, mas sim indicaram sobre a existência de alguns documentos afins ou partes de uma representação. Entre estes estão atas de comitê, software de planejamento estratégico, desenhos de cadeia de valores, e planos de negócio.

Para Mason e Spring (2011), os modelos de negócios; incorporados como regras de ação em artefatos como "slides" de apresentações, reportes, metas, ou documentos de estratégia; atuam como framing devices que dão forma e influenciam as ações das pessoas na organização.

É importante salientar que no caso da primeira organização, Empresa "X", o informante consultado sobre outra pergunta menciona o seguinte:

Existe alinhamento? Todo mundo sabe o que tem que fazer? Está certo? Onde está escrito?... Existe ata, não sei o que, só que eu comecei a pensar que... temos um folder de serviços e não é um modelo de negócios. Você tem um monte..., nós sabemos o que deve ser feito, mas está tudo muito fragmentado. Existe a necessidade de estrutura e formalização. (Depoimento entrevistado 1)

Por sua parte, a entrevistada na segunda organização, consultada sobre a existência de alguma representação ou documento sobre seu modelo de negócios, afirma: "[...] o modelo de negócios, ele é, eu acho que ele é tão vivo, a gente não tem assim um modelo de negócios [...], não tem, não..., é que ele é muito vivo.”.

Consultado sobre a existência de uma representação de seu modelo de negócios, o entrevistado 3 faz referência à existência de partes de um business plan, no qual inclusive ele ainda declara estar trabalhando. Explicando sobre o tema, o executivo narra:

[...] eu montei a empresa lá trás informalmente, voltei em 2012, e conforme eu fui vendo a importância de algumas coisas, eu fui criando. Então hoje eu tenho, sim, uma cadeia de valor desenhada, com todos meus processos operacionais, hoje eu tenho sim um plano de marketing desenhado [...], eu tenho sim um plano financeiro [...]. Então assim, não é completo, não tenho todo o que eu deveria ter, mas eu tenho um guideline. [...] Eu gostaria realmente de ter um plano de negócios completo, só que chega num ponto onde você assume uma empresa que já esta com 15 anos de 
trabalho rodando, você fala 'não da pra fazer tudo ao mesmo tempo'. (Depoimento entrevistado 3).

Casadesus-Masanell e Ricart (2010) e Teece (2010) citam à "decomposição" e à "desconstrução" respectivamente, como alternativas para trabalhar e afrontar a complexidade de um modelo de negócios, analisando componentes dele em isolamento. Também cabe citar que Teece (2010) e Linder e Cantrell (2001) advertem que um empreendedor pode ser capaz de intuir o modelo, mas não ser capaz de racionaliza-lo e articulá-lo completamente.

Sobre a aparente equivalência que por momentos faz o entrevistado 3 entre modelo de negócios e business plan, pode se referenciar a Doganova e Eyquem-Renault (2009, p. 1560, tradução nossa), as quais notam que: "Os modelos de negócios moldados por empreendedores são prospectivos.[...] Por isso, eles são parte de uma atividade de planejamento que depende principalmente da escrita de planos de negócios.",63

\subsubsection{Discussão sobre a abordagem de narrativa nos modelos de negócios}

Considerando a abordagem de narrativa no tema de modelo de negócios, nenhuma empresa possui ou utiliza uma narrativa explícita para descrever seu modelo de negócios, mas quase todos os entrevistados conseguiram realizar uma ao serem desafiados a fazê-lo.

O entrevistado 1 listou os recursos da empresa, as suas estratégias e sua cobertura de necessidades dos clientes, para armar uma narrativa que descreva o modelo de negócios da empresa, a entrevistada 2 armou sua narrativa remontando-se às origens da empresa e o que esta providencia como serviço. $\mathrm{O}$ executivo 3 indica que seria uma espécie de introdução a um sumário executivo de um plano de negócios, mas ele nunca chegou a fazer. Aporta o seguinte ao respeito:

Considero importante? sim, [...] academicamente. Não conheço a função exata do o quê que isso vai me refletir. Hoje não. Eu acredito muito [...] que o meio acadêmico por mais complexo que ele seja, ele tem razão em muitas coisas. Então acredito que eu tenho que ter, eu tenho que ter um plano de negócios completo, tenho que ter um sumário executivo, eu tenho que ter uma narrativa de como minha empresa vai ou trabalha. Só que até hoje eu vou pegando por partes, e ainda não deu tempo de chegar lá. (Depoimento entrevistado 3).

\footnotetext{
${ }^{63}$ The business models crafted by entrepreneurs are prospective [...]. Hence, they are part of a planning activity that relies mainly on the writing of business plans.
} 


\subsubsection{Discussão sobre as propriedades dos modelos de negócios}

Indagando sobre o tema das propriedades dos modelos de negócios, a pesquisa obteve as seguintes respostas.

Para o E1 o modelo de negócios não é algo abstrato no caso da sua empresa, pois para eles "aparentemente é claro o que a empresa faz e espera como resultados" e é algo presente, entretanto não documentalmente formalizado. Na mesma linha, a E2 indica que o modelo de negócios na sua empresa está "superpresente" e, por exemplo, as pessoas que estão na linha de frente são treinadas sobre qual é o modelo de negócios da organização. Nas suas palavras: “[...] toda a empresa já é permeada desse modelo de negócios. Então a gente trabalha sempre com isso na cabeça. Não é que você não possa estar descobrindo variações, mas você tem a linha mestre do modelo de negócios.".

Contrariamente, o entrevistado 3 expôs que no caso de sua organização o modelo de negócios não estava tão presente como ele gostaria. Nas suas palavras:

[...] Precisaria ser muito mais aproveitável de como está hoje. É importante só que infelizmente, não estamos dando o valor que deveria. Por falta de tempo e por falta de conceito na cabeça dos sócios. [...] Por mais que você divulgue, por mais que você coloque, você precisa reforçar para que ele aconteça. Isso não vem acontecendo nos últimos tempos. Existe um modelo, o modelo foi divulgado, só que não é toda hora que você está ali cobrando encima daquilo. Então ele acaba não se tornando tão presente no dia a dia quanto deveria. (Depoimento entrevistado 3).

No caso da empresa " $\mathrm{X}$ " se indica que ela nasceu com um fim, mas a própria alteração do mercado foi criando um redirecionamento da organização, sugerindo que a empresa nasceu com um modelo de negócios, mas a atuação da empresa no mercado mudou este, para fazer uma referência à questão original no roteiro. As seguintes palavras pareceriam confirmar esta ideia: "O modelo de negócio, ele se molda..., ele é mutável frente às alterações de mercado. Existe uma necessidade de avaliação dele.".

De maneira equivalente à primeira organização, na empresa da E2 o modelo de negócios foi previamente definido, mas foi mudando ao longo dos seus 18 anos de existência, até estar hoje "completamente alinhado com a estratégia da empresa" segundo declarações de sua executiva. 
Consultado sobre o mesmo tema, o E3 fez a equivalência modelo de negócios-plano de negócios e mencionou que nunca existiu um plano do negócio nos primeiros 15 anos, e de repente se viram obrigados a planejar algumas coisas que não se planejavam antes. Indica que, depois que a empresa está caminhando, o meio real influencia o planejamento.

Sobre a difusão dos modelos de negócios, os entrevistados fizeram ilustrativas declarações. No caso da empresa "X" a difusão do modelo de negócios (seu objetivo) fica reduzida aos altos níveis, da Diretoria para cima, no nível interno. Citando o compartilhamento do modelo de negócios com agentes externos, o informante da empresa "X", questionando se falamos de como ela opera e de quê maneira ela atua; indica que a organização, sim, comunica isso aos seus clientes, indicando que nessa parte, para eles, existe mais uma formação de amizade do que uma execução de venda.

De forma oposta, na organização 2, o modelo é compartilhado a todos os níveis da organização, de forma interna, mas não é compartilhado a agentes externos, salvo os acionistas da empresa, segundo a entrevistada 2.

O executivo da empresa 3 conta o seguinte:

A gente na verdade divulga as informações necessárias a todos os níveis. Mesmo no último nível que é o analista júnior, ele sabe: Quais são as metas da empresa, quais são os processos que a empresa segue para poder atingir essas metas, [...] dentro o que ele necessita saber, sim a gente divulga. Quais são as nossas expectativas com relação ao tratamento do cliente. Quanto meu importo com meu cliente. Quanto eu quero esse cliente satisfeito. Ele conhece de cabo até rabo, o que necessário ao trabalho dele. Divulgado de forma formal por escrito, não de boca. (Depoimento entrevistado 3).

Além disso, o E3 indica que aos agentes externos só se comunica a missão e visão e similares. Esclarece: "Na verdade como a gente é uma empresa pequena, uma empresa familiar, as pessoas que estão lá dentro, estão lá muito tempo, e são todas muito conhecidas, então a discrição de informação também não é tão grande.”.

Todos os entrevistados concordaram com a ideia que os modelos de negócios mudam no tempo dando exemplos nas suas organizações. Na empresa " $X$ " o entrevistado indicou que antes sua empresa tinha uma visão de consultoria e na atualidade estavam tentando se focar 
em algo mais ligado a produtos e serviços com seus modelos de negócios. A E2, por sua parte, tem certeza que os modelos mudam no tempo. Ela acrescenta o seguinte:

\begin{abstract}
O mercado de tecnologia é um mercado que, até independente do modelo de negócio, está sempre mudando. E as novas empresas, os novos entrantes aparecem com formas de você conseguir entrar no mercado, num segmento atrativo, como por exemplo, o setor financeiro, é você criar novos modelos de negócio. E as organizações que já existem, que já estão funcionando, se esse modelo de negócio é bem visto pelo seu público final, você tem que se adaptar a esse modelo e começar a ofertar modelos de negócios diferentes. Então o grande modelo de negócios, o nosso, continua [...], mas eventualmente, a gente teve que criar alguns modelos de negócio que se adaptassem a nichos específicos de instituições ou tamanhos de instituições [...], então você tem que ser flexível, normalmente em função do cliente, do que o cliente demanda. (Depoimento entrevistada 2)
\end{abstract}

Sobre este último depoimento pode se dizer que para Teece (2010, p.181), novos modelos de negócios ou refinamentos a existentes, usualmente derivam em redução de custos ou incremento do valor para o consumidor, e podem providenciar oportunidades para gerar maiores retornos para o pioneiro, pelo menos até que os atributos de novidade sejam copiados.

Em relação ao mesmo comentário, é conveniente lembrar que McGrath (2010) postula que quando um modelo de negócios é feito irrelevante por acontecimentos do ambiente ou já não é mais apropriado para os clientes, existe a oportunidade para que novos modelos de negócio floresçam.

Sobre a velocidade de mudança dos modelos de negócios, o E1 indicou que acredita que sim é possível mudar, principalmente quando se trata de serviços, mas as alterações geralmente não são de fácil aplicação. Chesbrough $(2007,2010)$ e Teece (2010) anotam que, sim, podem existir dificuldades para mudar um modelo de negócios pela existência de inércia, conforto ou barreiras à experimentação.

A E2 considera que é o mercado que demanda e dita essa velocidade, e, por exemplo, no mercado financeiro se demandam rápidas mudanças, do ponto de vista de modelo de negócios. Teece (2010) anota que os modelos de negócios devem metamorfosear no tempo enquanto os mercados mutáveis e as tecnologias o ditem.

O E3 aponta: "O meu modelo, o meu plano, ele muda sempre, com constância. Por quê? Porque tenho que me adaptar ao mercado e ao momento. Então, que acontece? Hoje isso aqui 
da certo, amanha não vai dar certo. Então ele deveria estar em constante revisão e replanificação.”. O executivo não se animou a dar uma resposta sobre a velocidade de mudança e indicou que nos últimos três anos, para seu caso, as revisões foram minoritárias, em temas operacionais, de metas e conceitos gerais.

Ao respeito, Schweizer (2005) nota que na medida em que o panorama e condições de concorrência mudam no tempo, as empresas podem necessitar mudar seus modelos de negócios para permanecerem competitivas. McGrath (2010) e Hedman e Kalling (2003) coincidem em que os modelos de negócios evoluem, madurecem, e tem que ser administrados e desenvolvidos ao longo do tempo,

Consultados sobre a possibilidade de copiar ou adaptar os modelos de negócios os entrevistados providenciaram a seguinte informação. Para o E1, um modelo de negócios sim pode ser copiado e acrescentou o seguinte comentário:

Se você tem as partes e peças necessárias, você pode copiar ou até adaptar [...] se pegar um Canvas model, um planejamento..., uma cadeia de valor, cruzar dados, sairei com uma espinha dorsal. É possível replicar, mas eu não sei com qual nível de sucesso [...] O mercado vai ter um reflexo ao modelo de negócio, a cultura das pessoas que trabalham nessa empresa, elas podem estar aderentes a aquele modelo de negócio ou não. [O outro] pode ter dado certo, um modelo de negócio, porque as pessoas são muito mais proativas, muito mais compradoras daquela marca em si. (Depoimento entrevistado 1)

Teece (2010) cita aos sistemas, processos e ativos difíceis de replicar e à opacidade nas fontes de aceitabilidade dos clientes como dois dos fatores que podem impedir uma imitação que solape as vantagens de um modelo de negócios pioneiro.

De forma similar, a executiva da segunda organização declara:

[...] as novas empresas que entram nesse segmento de mercado, eles olham o mercado, fazem análise de concorrência, de clientes. A gente já viu casos de novos entrantes buscarem modelos de negócios muito similares. [...], você pode copiar o modelo de negócio? Acredito que possa, agora pra você conseguir efetividade nisso, você tem que trazer algum diferencial Copiar é fácil, mas entrar é que um pouco mais complicado. Não depende só de copiar o modelo de negócio de alguma empresa já estabelecida. Mas copiar, você pode. (Depoimento entrevistada 2)

Para o E3, sim, é possível copiar e adaptar um modelo de negócios e dá como exemplo as regras de aferição de custo-lucro que aplicou no modelo da sua própria empresa. O executivo 
relata que não possuía nem sabia como fazer esta e aprendeu do modelo de um cliente: "Eu trouxe o modelo de gestão de custo dele pra cá e retransformei de acordo com as minhas necessidades.”.

Destaca nos depoimentos dos executivos consultados, a ideia de que, embora um modelo de negócios possa ser copiado, isto não implica que o sucesso dele esteja garantido. Ao respeito pode se dizer que McGrath (2010) postula que é quase impossível dizer com antecedência qual desenho de modelo de negócios vai ganhar dominância. Por sua parte, Magretta (2002) indica que os modelos de negócio podem se copiar, muitas vezes sem os mesmos resultados.

A possibilidade de comparação e imitação dos modelos de negócios é concordante com as ideias expostas em Doganova e Eyquem-Renault (2009); Teece (2010); e Kallio, Tinnila e Tseng (2006).

\subsubsection{Discussão sobre a relação estratégia-modelo de negócios}

No quesito estratégia-modelo de negócios as respostas foram variadas também. O E1, inicialmente confundindo modelo de negócio com estratégia, quando consultado sobre seu próprio modelo de negócio respondeu que eles atuavam por "diferenciação de conhecimento", mas esclarecendo posteriormente que quando se foca no seu modelo do negócio implica "pegar partes e peças para atuar no mercado". Desenvolvendo sobre este "pegar partes e peças", o E1 explica que isso significa "pegar todos os conhecimentos" e "pegar todas as pessoas" que se tem, para trabalhar de forma diferente. Para a E2 o modelo de negócios é parte da estratégia. Para ela, ambos precisam ir na mesma direção para chegar no objetivo final. Foi chamativo no caso do entrevistado 3 que no momento de providenciar sua definição de modelo de negócios, o executivo utilizou a palavra estratégia para explicar esta: "Qual é a minha estratégia de acesso ao mercado". Num momento posterior da entrevista, ao ser consultado sobre a relação modelo de negócios-estratégia, o E3 comenta: "Olhando de longe, as duas coisas são a mesma coisa. De longe.”. Reforçando esta ideia, ao responder a outra questão o entrevistado também mencionou o seguinte: "Pra mim, eu não consigo dentro da minha visão, diferenciar, ter uma divisão clara entre uma coisa e outra. Pra mim é assim, o modelo de negócios é uma estratégia, e a estratégia é um modelo de negócios.”. Concluindo a 
entrevista, o E3 refletiu: “[...] entendo modelo de negócios como várias estratégias para cada área de conhecimento dentro de uma empresa.”.

Sobre este último enunciado, achou-se similitude com a definição de Smith, Binns e Tushman (2010), para os quais modelo de negócios implica um “[...] desenho pelo qual uma organização converte um conjunto dado de escolhas estratégicas [...] em valor, e usa uma arquitetura organizacional particular [...] a fim de criar e capturar esse valor.”.

Cabe lembrar nesta parte que segundo Klang, Wallnöfer e Hacklin (2014) ainda existe ambiguidade, em termos de causalidade e interdependência sequencial, quando se relaciona estratégia e modelos de negócios na Academia. Também que Casadesus-Masanell e Ricart (2010) advertem que em situações competitivas simples, os conceitos se pareiam, dificultando separar estes. Como exemplo também citar que Chesbrough (2007) inclui à estratégia como um dos parâmetros que define um modelo de negócios.

Consultado sobre as vantagens de ter um modelo de negócios, o E1 aponta que ter clareza sobre o conceito e estrutura do que é o modelo de negócio, torna uma organização competitiva. Adicionando, afirma: "Se você consegue ver de maneira isolada todos os pontos, você consegue adequar, você consegue explicar, você consegue justificar e trazer valor para aquilo que você está fazendo.”.

Magretta (2002); Teece (2010); e Kim e Mauborgne (2000) falaram sobre a criação de vantagem competitiva forte através dos modelos de negócios.

Para a E2 a vantagem de ter um modelo de negócios é conjuntural a seu setor, sendo que no segmento financeiro se gosta de trabalhar com números fixos, saber quanto se vai pagar, condizendo com a sua definição de modelo de negócios. Como desvantagem, a executiva citou que com um modelo de negócios você não consegue ser tão flexível quanto às vezes a demanda do mercado exige.

Segundo o E3, com o modelo de negócios: "você sabe exatamente onde você está. Você consegue aferir aonde você quer chegar. Estrategicamente, ele deixa claro pra você o quê que está acontecendo na sua empresa. Se você esta se comportando da maneira como deveria.". O mesmo executivo citou como um problema a ser solucionado que "em empresas pequenas, 
não têm como gerenciar isso no dia a dia. Fica muito na teoria e não acontece quase nada na prática.”.

Sobre este último comentário, pode se fazer referência à observação de Casadesus-Masanell e Ricart (2010), os quais indicam que os modelos de negócios completos frequentemente são muito complexos e incômodos de representar como para trabalhar com eles diretamente.

Para o executivo da Empresa "X", a estratégia precede ao modelo de negócios e providenciou um exemplo relativo a uma situação específica. Para sua organização um acontecimento externo, como um problema com a taxa cambiaria no país, implicou que a empresa decidisse a estabelecer uma estratégia como foi a de lançar um serviço fora para compensar problemas internos obtendo ganhos no mercado externo. Uma vez estabelecida esta estratégia, o entrevistado indica que a empresa definiu:

Como é que eu vou fazer isso? Como é que eu vou entregar? Como é que eu chego nele? Que valor eu vou agregar pra ele sendo que eu sou um cara de outro país? [...], então assim, aí eu começo a pegar as minhas funções do meu modelo de negócio e começo a preencher, fill the blanks, e aí eu vou chegar ao racional pra atender aquela estratégia inicial. Eu tive uma estratégia, mas se eu não tenho o modelo de negócio.... Como eu vou fazer, modelo de negócio, é o meu segundo passo de toda a estruturação para viabilizar minha estratégia. (Depoimento entrevistado 1)

Consultada sobre esta sequencialidade, a E2 afirma o seguinte:

Acho que o caminho correto... acho que você tem que ter uma estratégia, e da estratégia você define seu modelo de negócios. Assim foi. A gente tinha uma estratégia [...] e a partir do que a gente tinha [...]. Como é que a gente decidiu traçar isso? O modelo de negócio, ele teve que vir colado à estratégia, mas o modelo de negócio veio da estratégia. (Depoimento entrevistada 2)

Ampliando sobre o tema, a executiva da segunda organização, falou da importância do planejamento estratégico para o tema. Segundo ela é de vital importância definir um objetivo, realizar o planejamento estratégico e dai traçar um modelo de negócios.

Tal visão é concordante com os trabalhos de Casadesus-Masanell e Ricart (2010); Al-Debei e Avison (2010), e Yip (2004). De forma similar, Tikkanen et al. (2005, p. 793) afirmam que a função da estratégia é fornecer significado e direção ao desenvolvimento do modelo de negócios de uma companhia. 
Consultado sobre a sequencialidade, o executivo da terceira organização mencionou que acredita que ambas as coisas acontecem ao mesmo tempo.

Na ordem de tangibilidade dos conceitos, o E1 situou à estratégia como a menos objetiva até acoplar com o modelo de negócios. O conceito de modelo de negócios foi situado pelo executivo num patamar intermédio porque "Modelo de negócio é como realizar aquela estratégia" (tal qual afirmam Sorescu et al. (2011)), e por fim, as tarefas operacionais foram classificadas como as mais objetivas por ser o "breakdown das atividades efetivamente". No entanto, refletindo sobre sua classificação, o entrevistado admitiu que ela o fez pensar e que o tema ainda pode ser propício para uma maior exploração e discussão. A executiva da segunda empresa estabeleceu a mesma ordem de classificação.

O terceiro executivo ordenou de forma distinta os conceitos, sendo que as tarefas operacionais eram o mais tangível na sua organização, classificou a estratégia no meio, e considerou o conceito de modelo de negócios como o mais abstrato, explicando que:

[...] apesar de hoje ter partes dele, dentro do dia a dia da empresa, é a coisa mais abstrata, porque dentro de uma empresa pequena é difícil estar lá checando aquilo toda hora, acompanhando, cobrando funcionários, seguir o quê que está aqui dentro. A minha estratégia operacional para acesso a cliente é uma coisa de dia a dia, eu tenho que viver ela senão não vendo, e as minhas atividades também é uma coisa de dia a dia.

Teece (2010) coincide com esta visão ao acreditar que um modelo de negócios é mais genérico que uma estratégia de negócios.

Cabe ressaltar que as ordenações e considerações dos dois primeiros executivos são coincidentes com as visões de Onetti et al. (2012); Casadesus-Masanell e Ricart (2010); e, AlDebei e Avison (2010). 


\section{CONSIDERAÇÕES FINAIS E RECOMENDAÇÕES}

A presente pesquisa teve como objetivos entender os conceitos e os conteúdos de "modelo de negócios", tanto ao nível da literatura disponível, quanto ao nível de casos específicos de empresas; obter um constructo de modelo de negócios mediante a busca sistemática na literatura existente; e identificar as principais divergências e convergências entre este constructo e os resultados empíricos obtidos.

Por ser uma pesquisa qualitativa e com características específicas, não se podem emitir "conclusões" no mesmo sentido que uma pesquisa quantitativo-probabilística, pelo que se espera providenciar neste capítulo, as principais observações, respostas e considerações relativas às perguntas que guiaram este trabalho.

\subsection{Considerações sobre a definição do modelo de negócios}

$\mathrm{Na}$ presente pesquisa estudou-se a definição de modelo de negócios vigente na discussão acadêmica, explorando os componentes, as funções e as propriedades postuladas na literatura relevante encontrada sobre o assunto. As principais anotações são:

- Pôde-se observar que o termo se originou há mais de meio século, seu boom começou na década de 90, e a sua exploração acadêmica mais profunda é recente: na década atual.

- Muitas vezes, o uso do termo é idiossincrático e compelido segundo os propósitos das pesquisas. Além disso, quando se tenta definir o termo, se observa que existem múltiplas abordagens para o conceito e diferentes elementos componentes foram surgindo e se adicionando.

- Não obstante o anterior comentário, observa-se que existem cada vez mais vozes que concordam que "modelo de negócios" é um constructo necessário na disciplina da Administração e que existem avanços na busca da consolidação de sua definição. 
- Resultado da afirmação prévia é o surgimento de alguns temas comuns apontados por vários autores estudiosos do assunto, na presente pesquisa selecionaram-se os elementos, que segundo consideração, podem ser os mais relevantes para uma exploração mais profunda. Neste sentido, o elemento "Valor", tratado como criação e captura dentro de um modelo, aparece como muito relevante na discussão. Um segundo elemento condiz com as atividades essenciais de uma empresa (entendidas como comprometimento de recursos) como relevantes para definir um modelo de negócios. Por fim, dada a ubiquidade, de uma ou outra forma, do elemento "modelo de lucro ou receita" na maioria das definições, na presente pesquisa considera-se que esse elemento é de importância para definir o modelo de negócios de uma organização.

- Discorrendo um pouco mais sobre a importância do elemento valor para estabelecer uma definição de modelo de negócios, nesta pesquisa considera-se que é mais apropriado entender Negócio como troca de valor. Pelo que "modelo de negócios", expressado em poucas palavras, seria uma representação simplificada dessa troca.

- No que se refere às abordagens, a exploração sugere que a visão de modelo de negócios como desenho, na linha de autores como Osterwalder e Pigneur, tem influência principalmente em publicações da área praticante. Em similar linha se encontram algumas abordagens pioneiras que visionam o modelo de negócios como uma narrativa. A publicação nessa área de abordagem também aparenta estar mais ligada com a prática.

- Consideram-se às abordagens de modelo de negócios como conjunto de atividades (na linha de Zott e Amit) como as com maior potencial para se acompanhar e possivelmente, consolidar. A abordagem de modelo de negócios como uma lógica ao fazer negócios foi também considerada como útil pela sua simplicidade e possível abrangência de descrições providenciadas em definições de outras abordagens.

- Outro dos achados decorrentes da literatura revisada é que o modelo de negócios aparece como unidade de análise intermediária entre a organização individual e a indústria, devido a que seus vínculos perpassam os limites organizacionais e numa mesma indústria podem existir diferentes modelos de negócios. 
- Acerca das funções de um modelo de negócios, pode se mencionar que, na literatura são citados diversos papéis, mas a pesquisa considerou que a sua configuração e funcionamento têm a ver com temas como o alinhamento da organização, a análise, formulação e execução estratégicas e a exploração de ideias de negócios.

- Dentre as propriedades dos modelos de negócios extraídas da literatura, se identificou as seguintes como potencialmente passíveis a um aprofundamento do seu estudo e sua discussão: tangibilidade, previsibilidade, mutabilidade, dinamismo, e imitabilidade.

- Como consequência da revisão, também surgiu a discussão do tema da relação entre estratégia e modelo de negócios. Considera-se peça-chave enxergar as diferenças, similitudes e relacionamentos entre os dois conceitos para se aproximar à definição de "modelo de negócios". Apesar da ambiguidade muitas vezes encontrada na literatura, na pesquisa pôde-se sintetizar concordando que os conceitos estão muito ligados, mas a estratégia teria a ver muito mais com temas de ambiente externo e concorrência do que modelo de negócios, que é um conceito mais focado em aspectos internos que criam valor. Outros dos temas em que aparentemente pode se atingir concordância é que modelo de negócios se situa numa camada intermediária entre estratégia e aspectos mais operacionais, e que a sequencialidade sugere que a estratégia de uma empresa precede ao seu modelo de negócios.

- Na pesquisa de literatura disponível em idioma português em importantes bases científicas de administração local, se evidenciou que:

i) a abordagem de Osterwalder e Pigneur tem muita influência se considerando o número de citações numa das bases como indicador;

ii) As publicações que fazem referência às definições de outros autores a nível internacional representam uma maioria porcentual no total de publicações consultadas; e,

iii) As publicações que apresentam sua própria definição do conceito exibem diferenças e nenhuma parece coincidir significativamente em algum tema em especial. Observam-se referências à lógica, regras, relacionamentos e simplificação/representação da realidade, mas curiosamente, nenhuma referência ao tema de valor, aspecto citado como fundamental na literatura encontrada nas bases administradas internacionalmente. 


\subsection{Considerações sobre a correspondência entre teoria e prática no assunto “modelo de negócios"}

Nesta seção, espera-se responder às perguntas indicando se existe convergência ou divergência entre o apontado na literatura e o observado na prática mediante a pesquisa de campo, realizada mediante a aplicação do método de estudos de caso múltiplos em três organizações vinculadas ao setor de tecnologia no Brasil.

- As definições providenciadas pelos executivos consultados nas organizações estudadas sugerem alguma afinidade com as abordagens de modelo de negócios como lógica, ao falar de "maneira lógica" ou "forma" de fazer negócios oferecendo um produto/serviço ao mercado. Também se intui certa alusão à abordagem de modelo de negócios como desenho (design), ao fazer referência a "partes e peças" ou "características" nas definições. A referência a valor surgiu numa definição e a referência a lucro, em outra delas. A alusão a clientes também esteve presente em duas delas.

- Consultados sobre as funções de um modelo de negócios, todos os executivos fizeram alusão a sua utilidade como referência para definir temas operativos, porém curiosamente quando consultados sobre a função de "execução da estratégia", apenas um dos casos concordou, sendo que em outro dos casos se considerou irrelevante a função e em outro deles, se discordou com a função.

- No referido às funções específicas consultadas os executivos concordaram unanimemente sobre a importância das funções "alinhamento da organização" e "análise e formulação de estratégia" ao citar modelo de negócios, como indica alguma da literatura consultada na primeira parte da pesquisa.

- Ao indagar sobre os elementos propostos como candidatos a definir o modelo de negócios da empresa e que foram selecionados para sua avaliação, observou-se concordância nas respostas dos entrevistados sobre a alta importância do elemento "Atividades" para definir o conceito. No caso dos outros elementos consultados como o posicionamento respeito a parceiros, clientes ou o modelo de lucro, as respostas foram diversas. 
- Consultados especificamente sobre o elemento Valor, todos os executivos relataram da importância para o caso dos modelos de negócios de suas empresas. Todos afirmam que tanto a criação como a captura estão presentes, mas ressalvam que a preponderância de uma sobre outra é situacional.

- Se observou que nenhuma das organizações estudadas possui uma representação formal do seu modelo de negócios, como sugere alguma da literatura. Também que por momentos para um dos executivos era difícil separar modelo de negócios de um plano de negócios, como também prevê um dos artigos consultados, ao afirmar que existem artefatos na organização que dão corpo aos modelos de negócios.

- De similar forma, embora nenhuma organização possuísse uma narrativa formal sobre seu modelo de negócios, na mesma forma como se postula numa das abordagens do assunto, a maioria pôde construir uma narrativa para descrever o modelo de negócios próprio.

- Consultados sobre as propriedades dos modelos de negócios selecionados da literatura para a sua exploração neste estudo, os entrevistados afirmaram que não consideram que o modelo de negócios seja algo abstrato, mas sendo que em um dos casos, o executivo reconheceu que era algo que não estava tão presente como deveria. Sobre a previsibilidade, e concordante com a teoria encontrada em muita da literatura revisada, dois executivos atestaram que os modelos nas suas organizações foram inicialmente planificados, mas mudaram com o tempo. Um dos executivos, também concordante com alguma da literatura consultada, afirmou que seu modelo não foi nunca planificado. Os executivos concordaram que seu modelo, sim, circula internamente, mas não para agentes externos.

- No caso da propriedade de imitabilidade dos modelos de negócios, todos os executivos chegaram a coincidir em que um modelo de negócios, sim, pode ser copiado, porém que a replicação pode não ser fácil. Entretanto, o sucesso não pode ser garantido apenas pelo fato de copiar.

- Na discussão da relação entre estratégia e modelo de negócios, os executivos de duas organizações indicaram que a estratégia precede ao modelo de negócios, de forma concordante a como sugere a maioria da literatura consultada. Para um dos executivos, estratégia e modelo de negócios acontecem ao mesmo tempo, o que faz pensar em uma 
relação com alguma teoria similar encontrada na literatura e sobre a ambiguidade que ainda existe na discussão sobre o tema.

- Consultados sobre a tangibilidade dos conceitos para o caso das suas organizações, dois executivos coincidiram ao classificar a estratégia como o conceito mais abstrato, modelo de negócios como um conceito em um nível intermediário e as tarefas operacionais como o elemento mais tangível. Porém, para um dos executivos, parte do ordenamento se alterava por considerar modelo de negócios como algo mais abstrato do que a estratégia, para o caso específico de sua organização.

- Citando especificamente a concordância/divergência entre o constructo obtido com a teoria revisada e a exploração na pesquisa empírica, pôde-se concluir que as atividades, o modelo de lucro, e o valor foram ratificados como importantes para a definição de modelo de negócios. No caso do vínculo com outros atores, a situação foi diferente: os consultados relataram da importância dos clientes para os seus modelos de negócios, mas no caso do posicionamento a respeito de outros atores como são os parceiros, o elemento não foi considerado como definitivo.

\subsection{Considerações sobre elementos comuns na definição de "modelo de negócios" encontrados na pesquisa de campo}

Discorrendo sobre os elementos comuns e distinguíveis nos depoimentos dos executivos sobre modelos de negócios, pôde-se observar o seguinte:

- Os executivos coincidiram em mencionar "maneira" ou "formas" para definir "modelo de negócios” de forma básica. De forma similar, todos os consultados coincidiram na citação do termo "mercado" nas suas definições.

- As definições providenciadas insinuam certa alusão a transferir (“conectar”, "prover", “ofertar", "levar”) determinado produto ou serviço gerado internamente (“conhecimentos”, “o que a gente tem", "seus produtos”, "minha empresa", "meu negócio") para o mercado. 
- Os entrevistados coincidiram em indicar que um modelo de negócios serve para detalhar os mecanismos que moverão uma organização na direção do cumprimento de metas.

\subsection{Outras considerações}

- Um elemento dos modelos de negócios que não foi identificado na literatura, mas mencionado nas entrevistas foi a Cultura da organização.

- Ficou evidente que no depoimento de dois dos executivos surgiu espontaneamente a menção de que não existe um modelo único de negócios nas suas empresas, insinuando a presença de modelos diferentes ou "micromodelos" como citou algum deles. Tal tema pode ser passível a uma maior exploração. Uma das publicações que não formou parte das publicações selecionadas, segundo os critérios metodológicos estabelecidos, mas que, sim, foi consultada, aborda este tema: Benson-Rea, Brodie e Sima (2013), os quais discorrem sobre a possibilidade de coexistência de modelos de negócios.

\subsection{Limitações}

As limitações foram enxergadas em cada etapa do projeto de pesquisa. Presume-se que algumas delas podem ter correspondência com (mas não se reduzir a) o seguinte:

- O uso das citações para escolher as publicações consideradas pelo seu impacto: Como Silva e Bianchi (2001, p. 8) notam "[...] impacto e qualidade de um trabalho científico não são sinônimos." devendo estar cientes que o número de citações é somente um indicador parcial de qualidade.

- A pesquisa foi realizada em um sector específico da economia e em organizações com características muito similares, por ter se definido replicações literais (YIN, 2015) nos estudos de casos, o que pode significar que esteja se deixando de abordar algumas nuances sobre o assunto, que possivelmente poderiam se identificar estudando organizações em setores diferentes e com características mais diversas. 
- O nível de experiência para a condução dos estudos de casos. Yin (2015) e outra literatura afim, advertem sobre a importância da preparação e experiência para o sucesso na condução de uma pesquisa com esse método. Embora se tenha preocupado por fazer uma preparação prévia longa e sustentada em literatura de qualidade, deve se notar que esta foi a primeira experiência em campo do pesquisador com este método.

- Embora o pesquisador ter residido permanentemente no Brasil durante um ano antes de começar a investigação, limitações relativas ao idioma português podem ter influenciado diferentes etapas da pesquisa pelo fato de ter o idioma espanhol como língua materna.

- Na pesquisa de campo sobre os depoimentos brindados, talvez, pode-se citar como limitação a possível existência de aspectos da realidade que ainda podem permanecer "ocultos" ante um pesquisador visto como um estranho para o grupo social estudado, como insinua Flick (2009, p. 111).

\subsection{Sugestões de pesquisa futura}

Da mesma forma, ideias sobre possíveis pesquisas foram surgindo em todo momento durante a realização da pesquisa, pelo que algumas delas são apresentadas como sugestões a continuação:

- Provavelmente a pesquisa mais relacionada à realizada nesta dissertação pode ser uma que considere replicações teóricas (YIN, 2015) dos estudos de caso.

- Alternativas de abordagem para as mesmas ou similares questões às que foram encaradas nesta pesquisa, podem ser levadas em consideração. Por exemplo, estudos baseados em métodos como a Grounded Theory (FLICK, 2009).

- Surge como possibilidade também uma pesquisa que consulte a acadêmicos de diferentes escolas no Brasil sobre sua posição acerca das definições, funções, propriedades e outros temas abordados nesta pesquisa. Outra pesquisa similar pode ter a ver com estudar como é o 
ensino, teórico e prático, relacionado a este assunto, vigente nas escolas de formação de executivos no Brasil.

- Pode ser interessante um estudo de análise de conteúdo sobre o uso do termo "business model" nas publicações mais relevantes (citações) na literatura geral. Esta pesquisa pode ser direcionada mais especificamente, por exemplo, no caso de publicações no idioma espanhol.

- Um estudo que analise a pesquisa latino-americana, relacionando os resultados que assim surgirem com as três grandes linhas de conceituação utilizadas em Zott, Amit e Massa (2011) pode resultar de interesse para a exploração e classificação da publicação existente nesta parte do continente.

- Resultaria interessante testar a observação de Zott, Amit e Massa (2010) de que os modelos de negócio funcionam como pontes entre a formulação e a implementação da estratégia, pesquisando empresas que explicitamente utilizam os modelos de negócio como ferramentas e analisando seu desempenho na execução estratégica, em comparação com outras que não o fazem.

- Outro estudo poderia testar empiricamente a existência de dominância dimensional nos modelos de negócios segundo o enfoque de George e Bock (2011, p. 102-105).

- Decorrentes da pesquisa em campo surgiram como ideias de pesquisa as de estudar a coexistência de múltiplos modelos de negócio numa mesma organização; estudar a existência ou ausência de representações dos modelos de negócios em organizações no Brasil, discutindo suas características; e estudar empiricamente algumas das propriedades identificadas nos modelos de negócios, como ser a mutabilidade ou a imitabilidade. Por fim, acredita-se que uma pesquisa que estude em profundidade a relação entre estratégia e modelo de negócios, teórica e empiricamente, pode contribuir para a elucidação do conceito. 


\section{REFERÊNCIAS BIBLIOGRÁFICAS ${ }^{64}$}

ACHTENHAGEN, Leona; MELIN, Leif; NALDI, Lucia. Dynamics of business modelsstrategizing, critical capabilities and activities for sustained value creation. Long Range Planning, v. 46, n. 6, p. 427-442, dez. 2013.

ALBERTIN, Alberto Luiz; MOURA, R. M. A realidade dos negócios na era digital no mercado brasileiro. Relatório de pesquisa No. 24/2002. [S.1.]: EAESP/FGV/NPP - Núcleo de pesquisas e publicações, [2002?]. 112 p. Disponível em: <http://bibliotecadigital.fgv.br/dspace/handle/10438/3127>. Acesso em 17 out. 2014.

ALBERTIN, Alberto Luiz; MOURA, R. M. Enfoque gerencial dos benefícios e desafios da tecnologia de informação para o desempenho empresarial. Relatório de pesquisa No. 20/2003. [S.1.]: FGV-EAESP-NPP - Núcleo de pesquisas e publicações, [2003?]. 140 p. Disponível em: < http://bibliotecadigital.fgv.br/dspace/handle/10438/3026>. Acesso em 17 out. 2014.

AL-DEBEI, Mutaz M.; AVISON, David. Developing a unified framework of the business model concept. European Journal of Information Systems, v. 19, n. 3, p. 359-376, 2010.

ALT, Rainer; ZIMMERMANN, Hans-Dieter. Preface: introduction to special section business models. Electronic Markets, v. 11, n. 1, p. 3-9, 2001.

AMIT, Raphael; ZOTT, Christoph. Value creation in e-business. Strategic Management Journal, v. 22, n. 6-7, p. 493-520, jun./jul. 2001.

ANGULO, Marcelo Junqueira. Um estudo do modelo de negócio dos portais na internet. Relatório final de pesquisa. São Paulo: EAESP/FGV, 2000.

ARAUJO, J. B.; ZILBER, S. N. Adoção de e-business e reflexos no modelo de negócios: inovação organizacional em pequenas empresas dos setores de comércio e serviços. In: XXXV Encontro da Associação Nacional de Pós-Graduação e Pesquisa em Administração, 4/7 set. 2011, Rio de Janeiro. Trabalhos, Rio de Janeiro: ANPAD, 2011. Disponível em: <http://www.anpad.org.br/diversos/trabalhos/EnANPAD/enanpad_2011/GCT/2011_GCT232 8.pdf>. Acesso em 13 out. 2014.

ARAUJO, Jose Braz de; ZILBER, Silvia Novaes. Adoção de E-Business e mudanças no modelo de negócio: Inovação organizacional em pequenas empresas dos setores de comércio e serviços. Gestão \& Produção, São Carlos, v. 20, n. 1, p. 147-161, jan./mar. 2013.

AREND, Richard J. The business model: Present and future-beyond a skeumorph. Strategic Organization, v. 11, n. 4, p. 390-402, nov. 2013.

\footnotetext{
${ }^{64}$ De acordo com a Associação Brasileira de Normas Técnicas. NBR 6023. (ABNT, 2002).
} 
ASPARA, Jaakko et al. Strategic management of business model transformation: lessons from Nokia. Management Decision, v. 49, n. 4, p. 622-647, 2011.

ASSOCIAÇÃO BRASILEIRA DE NORMAS TÉCNICAS - ABNT. NBR 6023: informação e documentação - referências - elaboração. Rio de Janeiro, ago. 2002. 24 p.

BADEN-FULLER, Charles; HAEFLIGER, Stefan. Business models and technological innovation. Long Range Planning, v. 46, n. 6, p. 419-426, dez. 2013.

BADEN-FULLER, Charles; MANGEMATIN, Vincent. Business models: A challenging agenda. Strategic Organization, v. 11, n. 4, p. 418-427, nov. 2013.

BADEN-FULLER, Charles; MORGAN, Mary S. Business models as models. Long Range Planning, v. 43, n. 2/3, p. 156-171, abr./jun. 2010.

BAUER, Martin W. Análise de conteúdo clássica: uma revisão. In: BAUER, Martin W.; GASKELL, George (Ed.). Pesquisa qualitativa com texto, imagem e som: um manual prático. Tradução Pedrinho A. Guareschi. Petrópolis, RJ: Vozes, 2002. cap. 8, p.189-215.

BENBASAT, Izak; GOLDSTEIN, David K.; MEAD, Melissa. The case research strategy in studies of information systems. MIS Quarterly, p. 369-386, set. 1987.

BENSON-REA, Maureen; BRODIE, Roderick J.; SIMA, Herbert. The plurality of co-existing business models: Investigating the complexity of value drivers. Industrial Marketing Management, v. 42, n. 5, p. 717-729, jul. 2013.

BETZ, Frederick. Strategic business models. Engineering Management Journal, v. 14, n. 1, p. 21-28, mar. 2002.

BOLAÑO, César; VIEIRA, Vinícius Rodrigues. TV digital no Brasil e no mundo: estado da arte. Revista de Economía Política de las Tecnologías de la Información y Comunicación, v. 6, n. 2, p. 102-134, ago. 2004.

BONOMA, Thomas V. Case research in marketing: opportunities, problems, and a process. Journal of Marketing Research, v. 22, n. 2, p. 199-208, maio 1985.

BOONS, Frank; LÜDEKE-FREUND, Florian. Business models for sustainable innovation: state-of-the-art and steps towards a research agenda. Journal of Cleaner Production, v. 45, p. 9-19, abr. 2013.

CAPPELLI, Peter. The future of the US business model and the rise of competitors. Academy of Management Perspectives, v. 23, n. 2, p. 5-10, maio 2009.

CASADESUS-MASANELL, Ramon; RICART, Joan Enric. From strategy to business models and onto tactics. Long Range Planning, v. 43, n. 2/3, p. 195-215, apr./jun. 2010. 
CASADESUS-MASANELL, Ramon; RICART, Joan E. How to design a winning business model. Harvard Business Review, v. 89, n. 1/2, p. 100-107, jan./fev. 2011.

CAVAlCANTE, Sérgio; KESTING, Peter; ULHØI, John. Business model dynamics and innovation:(re) establishing the missing linkages. Management Decision, v. 49, n. 8, p. 13271342, 2011.

CHESBROUGH, Henry. Business model innovation: it's not just about technology anymore. Strategy \& Leadership, v. 35, n. 6, p. 12-17, 2007.

CHESBROUGH, Henry. Business model innovation: opportunities and barriers. Long Range Planning, v. 43, n. 2/3, p. 354-363, abr./jun. 2010.

CHESBROUGH, Henry; ROSENBLOOM, Richard S. The role of the business model in capturing value from innovation: evidence from Xerox Corporation's technology spin-off companies. Industrial and Corporate Change, v. 11, n. 3, p. 529-555, jun. 2002.

CHUNG, Walter W.C.; YAM, Anthony Y. K.; CHAN, Michael F. S. Networked enterprise: A new business model for global sourcing. International Journal of Production Economics, v. 87, n. 3, p. 267-280, fev. 2004.

COFF, Russ et al. So!apbox forum: The business model: A valuable concept for strategic organization?. Strategic Organization, v. 11, n. 4, p. 389-389, nov. 2013.

COOMBES, Philip H.; NICHOLSON, John D. Business models and their relationship with marketing: A systematic literature review. Industrial Marketing Management, v. 42, n. 5, p. 656-664, jul. 2013.

COORDENAÇÃO DE APERFEIÇOAMENTO DE PESSOAL DE NÍVEL SUPERIOR CAPES. Estatísticas de Uso. Disponível em: <http://www.periodicos.capes.gov.br/index.php?option=com_pestatistics\&Itemid=111>.

Acesso em: 4 out. 2014.

COORDENAÇÃO DE APERFEIÇOAMENTO DE PESSOAL DE NÍVEL SUPERIOR CAPES. Portal de periódicos. Disponível em: <http://www.periodicos.capes.gov.br/>. Acesso em: 4 out. 2014.

CRESWELL, John W. Research design: Qualitative, quantitative, and mixed methods approaches. 3rd. ed. Los Angeles: SAGE Publications, 2009. 260 p.

DAHAN, Nicolas M. et al. Corporate-NGO collaboration: co-creating new business models for developing markets. Long Range Planning, v. 43, n. 2/3, p. 326-342, abr./jun. 2010. 
DASILVA, Carlos M.; TRKMAN, Peter. Business Model: What it is and What it is Not. Long Range Planning, p. 1-11, 2013. In press.

DEMIL, Benoît; LECOCQ, Xavier. Business model evolution: in search of dynamic consistency. Long Range Planning, v. 43, n. 2/3, p. 227-246, abr. jun. 2010.

DOGANOVA, Liliana; EYQUEM-RENAULT, Marie. What do business models do? Innovation devices in technology entrepreneurship. Research Policy, v. 38, n. 10, p. 15591570, dez. 2009.

EISENHARDT, Kathleen M. Building theories from case study research. Academy of Management Review, v. 14, n. 4, p. 532-550, out. 1989.

ELSEVIER. Scopus. Disponível em: <http://www.elsevier.com/online-tools/scopus>. Acesso em: 7 out. 2014.

EYRING, Matthew J.; JOHNSON, Mark W.; NAIR, Hari. New business models in emerging markets. Harvard Business Review, jan./fev. 2011.

FIGUEIRA, Mariane; GONÇALVEZ, Eduardo Jardel Veiga; SUGANO, Joel Yutaka; ZAMBALDE, Andre Luiz. Inovação organizacional e inovação de modelo de negócios: um estudo comparativo. Revista Espacios, v. 32, n. 3, 2011. . Disponível em: <http://www.revistaespacios.com/a11v32n03/11320341.html>. Acesso em 14 out. 2014.

FIGUEIRA, Mariane; SUGANO, Joel Yutaka; SETTE, Ricardo Souza. Inovação de Modelo de Negócio: um estudo de caso. In: XXV Simpósio de Inovação Tecnológica, 22/24 out. 2008, Brasília, DF. Trabalhos, Brasília: ANPAD, 2008. Disponível em: < http://www.anpad.org.br/diversos/trabalhos/Simp\%C3\%B3sio/simposio_2008/2008_SIMPOS IO531.pdf $>$. Acesso em 16 out. 2014.

FLEURY, Afonso; FLEURY, Maria Tereza Leme. Local enablers of business models: The experience of Brazilian multinationals acquiring in North America. Journal of Business Research, v. 67, n. 4, p. 516-526, 2014.

FLICK, Uwe. An introduction to qualitative research. 4th ed. London: Sage, 2009. 504 p.

FOX, Mark. E-commerce business models for the music industry. Popular Music and Society, v. 27, n. 2, p. 201-220, 2004.

GEORGE, Gerard; BOCK, Adam J. The business model in practice and its implications for entrepreneurship research. Entrepreneurship theory and practice, v. 35, n. 1, p. 83-111, jan. 2011. 
GHAZIANI, Amin; VENTRESCA, Marc J. Keywords and cultural change: Frame analysis of business model public talk, 1975-2000. Sociological Forum, v. 20, n. 4, p. 523-559, dez. 2005.

GOOGLE. Google acadêmico. Disponível em: <http://scholar.google.com.br>. Acesso em: 5 out. 2014.

GUMIEIRO, Katiucia Araujo; COSTA, Sely Maria de Souza. O uso de modelos de negócios por editoras de periódicos científicos eletrônicos de acesso aberto. Perspectivas em Ciência da Informação, v. 17, n. 4, p. 100-122, out./dez. 2012.

HACKLIN, Fredrik; WALLNÖFER, Maria. The business model in the practice of strategic decision making: insights from a case study. Management Decision, v. 50, n. 2, p. 166-188, 2012.

HEDMAN, Jonas; KALLING, Thomas. The business model concept: theoretical underpinnings and empirical illustrations. European Journal of Information Systems, v. 12, n. 1, p. 49-59, 2003.

INW. Disponível em: <http://www.inwgroup.com.br/>. Acesso em: 4 jun. 2015.

JOHNSON, Mark W.; CHRISTENSEN, Clayton M.; KAGERMANN, Henning. Reinventing your business model. Harvard Business Review, v. 86, n. 12, p. 57-68, dez. 2008.

JOIA, Luiz Antonio; FERREIRA, Sinval. Modelo de negócios: constructo real ou metáfora de estratégia?. Cadernos EBAPE.BR, v. 3, n. 4, p. 01-18, dez. 2005.

JÚNIOR, Angelo Milani; JÚNIOR, Helder Queiroz Pinto; BOMTEMPO, José Vitor. A indústria do petróleo como uma organização complexa: modelagem de negócios e processo decisório. Produção, v. 17, n. 1, p. 8-32, jan./abr. 2007.

KALLIO, Jukka; TINNILÄ, Markku; TSENG, Anne. An international comparison of operator-driven business models. Business Process Management Journal, v. 12, n. 3, p. 281-298, 2006.

KEEN, Peter; QURESHI, Sajda. Organizational transformation through business models: a framework for business model design. In: 39th Annual Hawaii International Conference on System Sciences HICSS'06, 2006, Hawaii. Proceedings... Hawaii: IEEE, 2006.

KIM, W. Chan; MAUBORGNE, Renée. Knowing a winning business idea when you see one. Harvard Business Review, v. 78, n. 5, p. 129-138, set./out. 2000. 
KLANG, David; WALLNÖFER, Maria; HACKLIN, Fredrik. The Business Model Paradox: A Systematic Review and Exploration of Antecedents. International Journal of Management Reviews, v. 16, n. 4, p. 454-478, 2014.

KUK, George; JANSSEN, Marijn. The business models and information architectures of smart cities. Journal of Urban Technology, v. 18, n. 2, p. 39-52, abr. 2011.

KVALE, Steinar; BRINKMANN, Svend. Interviews: Learning the craft of qualitative research interviewing. 2nd ed. Los Angeles: Sage, 2009. 354 p.

LAMBERT, Susan C.; DAVIDSON, Robyn A. Applications of the business model in studies of enterprise success, innovation and classification: An analysis of empirical research from 1996 to 2010. European Management Journal, v. 31, n. 6, p. 668-681, dez. 2013.

LECHNER, Ulrike; HUMMEL, Johannes. Business models and system architectures of virtual communities: From a sociological phenomenon to peer-to-peer architectures. International Journal of Electronic Commerce, v. 6, n.3, p. 41-53, spring 2002.

LINDER, Jane C.; CANTRELL, Susan. Five business-model myths that hold companies back. Strategy \& Leadership, v. 29, n. 6, p. 13-18, 2001.

LUCIANO, Edimara Mezzomo; FREITAS, Henrique Mello Rodrigues de. Comércio Eletrônico de Produtos Virtuais: Definição de um Modelo de Negócios para a comercialização de software. Escola de Administração. UFRGS: Porto Alegre, 2002. Disponível em: <http://www.egov.ufsc.br/portal/sites/default/files/anexos/27413-27423-1PB.pdf >. Acesso em 16 out. 2014.

MACÁRIO, Rosário; GALELO, Ana; MARTINS, Paulo M. Business models in urban logistics. Ingeniería y Desarrollo, n. 24, jul./dez. 2008.

MAGRETTA, Joan. Why business models matter. Harvard Business Review, v. 80, n. 5, p. 86-92, maio 2002.

MAHADEVAN, B. Business models for Internet-based E-Commerce: An anatomy. California Management Review, v. 42, n. 4, p. 55-69, summer 2000.

MÄKINEN, Saku; SEPPÄNEN, Marko. Assessing business model concepts with taxonomical research criteria: A preliminary study. Management Research News, v. 30, n. 10, p. 735-748, 2007.

MARTINS, Gilberto de Andrade. Manual para elaboração de monografias e dissertações. São Paulo: Atlas, 2002. 134 p.

MARTINS, Gilberto de Andrade. Sobre conceitos, definições e constructos nas ciências administrativas. Gestão \& Regionalidade, a. 22, n. 62, p. 28-35, dez. 2005. 
MARTINS, Gilberto de Andrade; THEÓPHILO, Carlos Renato. Metodologia da investigação científica para ciências sociais aplicadas. São Paulo: Atlas, 2007. 225 p.

MASON, Katy; SPRING, Martin. The sites and practices of business models. Industrial Marketing Management, v. 40, n. 6, p. 1032-1041, ago. 2011.

MCGRATH, Rita Gunther. Business models: a discovery driven approach. Long Range Planning, v. 43, n. 2/3, p. 247-261, abr./jun. 2010.

MORRIS, Michael; SCHINDEHUTTE, Minet; ALLEN, Jeffrey. The entrepreneur's business model: toward a unified perspective. Journal of Business Research, v. 58, n. 6, p. 726-735, jun. 2005.

MORRIS, Michael H.; SHIROKOVA, Galina; SHATALOV, Alexander. The business model and firm performance: the case of Russian food service ventures. Journal of Small Business Management, v. 51, n. 1, p. 46-65, jan. 2013.

MORSE, Janice M. Designing Funded Qualitative Research. In: N. Denzin and Y.S. Lincoln (eds.), Strategies of Qualitative Research. London: SAGE, 1998 apud FLICK, Uwe. An introduction to qualitative research. 4th ed. London: Sage, 2009. 504 p.

NENONEN, Suvi; STORBACKA, Kaj. Business model design: conceptualizing networked value co-creation. International Journal of Quality and Service Sciences, v. 2, n. 1, p. 43$59,2010$.

OLIVEIRA, Macir Bernardo de; SPINOLA, Mauro de Mesquita; LAURINDO, Fernando José Barbin. A Influência da Tecnologia da Informação nas Estratégias de Negócios do Setor da Saúde. In: XI Seminário Latino-Iberoamericano de Gestión Tecnológica, 25/28 out. 2005, Salvador, Bahia. Salvador: ALTEC, 2005. Disponível em: <http://www.redetec.org.br/publique/media/influencia\%20TI.pdf>. Acesso em 16 out. 2014.

ONETTI, Alberto et al. Internationalization, innovation and entrepreneurship: business models for new technology-based firms. Journal of Management \& Governance, v. 16, n. 3, p. 337-368, ago. 2012.

OSTERWALDER, Alexander. The business model ontology: A proposition in a design science approach. 2004. $172 \mathrm{f}$. These pour l'obtention du grade de Docteur en Informatique de Gestion - Ecole des Hautes Etudes Commerciales, Université de Lausanne, Lausanne, Switzerland, 2004.

OSTERWALDER, Alexander; PIGNEUR, Yves. An ontology for e-business models. In: CURRIE, Wendy L. (Ed.). Value creation from e-business models, p. 65-97, 2004. 
OSTERWALDER, Alexander; PIGNEUR, Yves. Business Model Generation: A handbook for visionaries, game changers, and challengers. New Jersey: Wiley, 2010. 281 p.

OSTERWALDER, Alexander; PIGNEUR, Yves. Business Model Generation: Inovação em Modelos de Negócios. Rio de Janeiro: Alta Books, 2011. 300 p.

OSTERWALDER, Alexander; PIGNEUR, Yves; TUCCI, Christopher L. Clarifying business models: Origins, present, and future of the concept. Communications of the Association for Information Systems, v. 16, n. 1, p. 1-25, 2005.

PAGE, Michael. Business models as a basis for regulation of financial reporting. Journal of Management \& Governance, v. 18, n. 3, p. 683-695, ago. 2014.

PARENTE, Stephen T. Beyond the hype: A taxonomy of e-health business models. Health Affairs, v. 19, n. 6, p. 89-102, nov./dez. 2000.

PATELI, Adamantia G.; GIAGLIS, George M. A research framework for analysing eBusiness models. European Journal of Information Systems, v. 13, p. 302-314, 2004.

PORTER, Michael E. Strategy and the Internet. Harvard Business Review, v. 79, n. 3, p. 6278, mar. 2001.

PRIEM, Richard L.; BUTLER, John E.; LI, Sali. Toward reimagining strategy research: Retrospection and prospection on the 2011 AMR decade award article. Academy of Management Review, v.38, n. 4, p. 471-489, mar. 2013.

RAPPA, Michael A. The utility business model and the future of computing services. IBM Systems Journal, v. 43, n. 1, p. 32-42, 2004.

RAUSCH, Gabriel. Modelo de negócios: proposição de um metamodelo conceitual. 2012. 184 f. Dissertação (Mestrado em Ciências). Faculdade de Economia, Administração e Contabilidade de Ribeirão Preto, Universidade de São Paulo, Ribeirão Preto, 2012.

REIS, Samira Dias dos; PROENÇA, Adriano; PROENÇA JR., Domício. Modelo de Negócio: um exercício conceitual sobre o caso TV aberta x TV por assinatura. XXIII Encontro Nac. de Eng. de Produção, 21/24 out. 2003, Ouro Preto, MG. Anais... Ouro Preto: ENEGEP, 2003.

RENAULT, Thiago Borges et al. Empreendedorismo acadêmico na COPPE/UFRJ: Reflexões sobre empresas criadas com a participação de professores. Organizações em Contexto (online), v. 7, n. 14, p. 1-28, jul./dez. 2011.

RICHARDSON, James. The business model: an integrative framework for strategy execution. Strategic Change, v. 17, n. 5-6, p. 133-144, ago. 2008.

RTM. Disponível em: <http://www.rtm.net.br/>. Acesso em: 11 maio 2015. 
RTM. 18 anos a serviço do mercado financeiro. Conexão. [S.1.], n. 176, p.1, mar./abr. 2015.

SABATIER, Valérie; MANGEMATIN, Vincent; ROUSSELLE, Tristan. From recipe to dinner: business model portfolios in the European biopharmaceutical industry. Long Range Planning, v. 43, n. 2/3, p. 431-447, abr./jun. 2010.

SAKO, Mari. Business models for strategy and innovation. Communications of the ACM, v. 55, n. 7, p. 22-24, jul. 2012.

SAMPIERI, Roberto Hernandez; COLLADO, Carlos Fernandez; LUCIO, María del Pilar Baptista. Metodología de la investigación. 5. ed. México: McGraw Hill, 2010.

SCAPENS, Robert W. Researching management accounting practice: the role of case study methods. British Accounting Review, v. 22, n. 3, p. 259-281, set. 1990.

SCHNEIDER, Sabrina; SPIETH, Patrick. Business model innovation: towards an integrated future research agenda. International Journal of Innovation Management, v. 17, n. 1, fev. 2013.

SCHWEIZER, Lars. Concept and evolution of business models. Journal of General Management, v. 31, n. 2, p. 37-56, winter 2005.

SCIELO. Disponível em: <http://www.scielo.org/php/index.php>. Acesso em: 5 out. 2014.

SEDDON, Peter B.; LEWIS, Geoffrey P.; FREEMAN, Phil; SHANKS, Graeme. The case for viewing business models as abstractions of strategy. Communications of the Association for Information Systems, v. 13, n. 1, p. 427-442, 2004.

SEELOS, Christian; MAIR, Johanna. Profitable business models and market creation in the context of deep poverty: a strategic view. Academy of Management Perspectives, v. 21, n. 4, p. 49-63, nov. 2007.

SHAFER, Scott M.; SMITH, H. Jeff; LINDER, Jane C. The power of business models. Business Horizons, v. 48, n. 3, p. 199-207, maio/jun. 2005.

SHELLEY, Louise. Trafficking in women: The business model approach. Brown Journal of World Affairs, v. 10, n. 1, p. 119-131, sum./fall 2003.

SIQUEIRA, Luciene Diana; CRISPIM, Sergio Feliciano. Modelos de negócio na era digital. Revista Espacios, v. 33, n. 7, 2012. Disponível em: <http://www.revistaespacios.com/a12v33n07/12330721.html>. Acesso em 15 out. 2014.

SILVA, José Aparecido da; BIANCHI, Maria de Lourdes Pires. Cientometria: a métrica da ciência. Paidéia, v. 11, n. 21, p. 5-10, 2001. 
SMALL, Mario Luis. 'How many cases do I need?' On science and the logic of case selection in field-based research. Ethnography, v. 10, n. 1, p. 5-38, mar. 2009.

SMITH, Wendy K.; BINNS, Andy; TUSHMAN, Michael L. Complex business models: Managing strategic paradoxes simultaneously. Long Range Planning, v. 43, n. 2/3, p. 448461, abr./jun. 2010.

SORESCU, Alina et al. Innovations in retail business models. Journal of Retailing, v. 87, s. 1, p. S3-S16, jul. 2011.

SOUTO, Patricia Nascimento. E-publishing development and changes in the scholarly communication system. Ciência da Informação, v. 36, n. 1, p. 158-166, jan./abr. 2007.

SVEJENOVA, Silviya; PLANELLAS, Marcel; VIVES, Luis. An individual business model in the making: A chef's quest for creative freedom. Long Range Planning, v. 43, n. 2/3, p. 408-430, abr./jun. 2010.

TEECE, David J. Business models, business strategy and innovation. Long Range Planning, v. 43, n. 2/3, p. 172-194, abr./jun. 2010.

THOMSON REUTERS. Web of Science. Disponível em: <http://wokinfo.com/>. Acesso em: 6 out. 2014.

TIKKANEN, Henrikki et al. Managerial cognition, action and the business model of the firm. Management Decision, v. 43, n. 6, p. 789-809, 2005.

TIMMERS, Paul. Business models for electronic markets. Electronic Markets, v. 8, n. 2, p. 3-8, 1998.

TSALGATIDOU, Aphrodite; PITOURA, Evaggelia. Business models and transactions in mobile electronic commerce: requirements and properties. Computer Networks, v. 37, n. 2, p. 221-236, 2001.

VIEIRA, Paula Vanessa Medeiros; WAINER, Jacques. Correlações entre a contagem de citações de pesquisadores brasileiros, usando o Web of Science, Scopus e Scholar. Perspectivas em Ciência da Informação, v. 18, n. 3, p. 45-60, jul./set. 2013.

VILHENA, Valéria; CRESTANA, Maria Fazanelli. Produção científica: critérios de avaliação de impacto. Revista da Associação Médica Brasileira, São Paulo, v. 48, n. 1, p. 20-21, Jan./Mar. 2002.

VOELPEL, Sven et al. Escaping the red queen effect in competitive strategy: Sense-testing business models. European Management Journal, v. 23, n. 1, p. 37-49, fev. 2005. 
VOELPEL, Sven C.; LEIBOLD, Marius; TEKIE, Eden B. The wheel of business model reinvention: how to reshape your business model to leapfrog competitors. Journal of Change Management, v. 4, n. 3, p. 259-276, set. 2004.

YIN, Robert K. Estudo de caso: planejamento e métodos. 4. ed. Porto Alegre: Bookman, 2010.

YIN, Robert K. Estudo de caso: planejamento e métodos. 5. ed. Tradução Cristhian Matheus Herrera. Porto Alegre: Bookman, 2015. 290 p.

YIP, George S. Using strategy to change your business model. Business Strategy Review, v. 15 , n. 2, p. 17-24, summer 2004.

YUNUS, Muhammad; MOINGEON, Bertrand; LEHMANN-ORTEGA, Laurence. Building social business models: lessons from the Grameen experience. Long Range Planning, v. 43, n. 2/3, p. 308-325, abr./jun. 2010.

ZMOGINSKI, Amanda Saraiva et al. Co-criação de Valor: Inovação no Modelo de Negócio Obtendo Vantagem Competitiva. Revista Jovens Pesquisadores, ano VI, n. 10, p.46-65, jan./jul. 2009.

ZOTT, Christoph; AMIT, Raphael. Business model design: an activity system perspective. Long Range Planning, v. 43, n. 2/3, p. 216-226, apr./jun. 2010.

ZOTT, Christoph; AMIT, Raphael. The business model: A theoretically anchored robust construct for strategic analysis. Strategic Organization, v. 11, n. 4, p. 403-411, nov. 2013.

ZOTT, Christoph; AMIT, Raphael. The fit between product market strategy and business model: implications for firm performance. Strategic Management Journal, v. 29, n. 1, p. 126, jan. 2008.

ZOTT, Christoph; AMIT, Raphael; MASSA, Lorenzo. The business model: recent developments and future research. Journal of Management, v. 37, n. 4, p. 1019-1042, jul. 2011.

ZOTT, Christoph; AMIT, Raphael; MASSA, Lorenzo. The business model: Theoretical roots, recent developments, and future research. Working Paper WP-862. Madrid: IESE Business School-University of Navarra, p. 1-43, set. 2010. 


\section{APÊNDICES}

APÊNDICE A - PROTOCOLO DO ESTUDO DE CASO

APÊNDICE B - ROTEIRO E QUESTIONÁRIO DA ENTREVISTA SEMIESTRUTURADA APÊNDICE C - DEFINIÇÕES AUXILIARES PARA OS ENTREVISTADOS 


\section{APÊNDICE A - PROTOCOLO DO ESTUDO DE CASO}

Elaborado em função a Yin (2010, p.104-117)

\section{Introdução ao Estudo de Caso e finalidade do protocolo}

\subsection{Título da pesquisa:}

Modelo de Negócios: teoria e prática empresarial

\subsection{Antecedente do estudo de caso:}

Estudo de caso realizado como parte da pesquisa do trabalho de dissertação de mestrado.

\subsection{Tipo de Estudo de Caso}

O estudo de caso é do tipo exploratório (YIN, 2010, p. 29). O desenho de pesquisa contempla um projeto de casos múltiplos de tipo holístico (YIN, 2010, P. 69-86).

\subsection{Objetivo do Estudo de Caso:}

O objetivo busca verificar em campo quais são os componentes, propriedades e funções que constituem o conceito Modelo de Negócios.

\subsection{Problema de pesquisa}

Os elementos identificados na teoria, mediante a revisão bibliográfica, conduzida para a definição do constructo de modelo de negócios têm correspondência com o existente em empresas?

\subsection{Estrutura teórica para o Estudo de Caso}


O caso se utilizará de a revisão teórica que conforma o trabalho de dissertação para verificar as proposições. Uma consolidação resumida da estrutura teórica é apresentada mediante a ilustração 1:

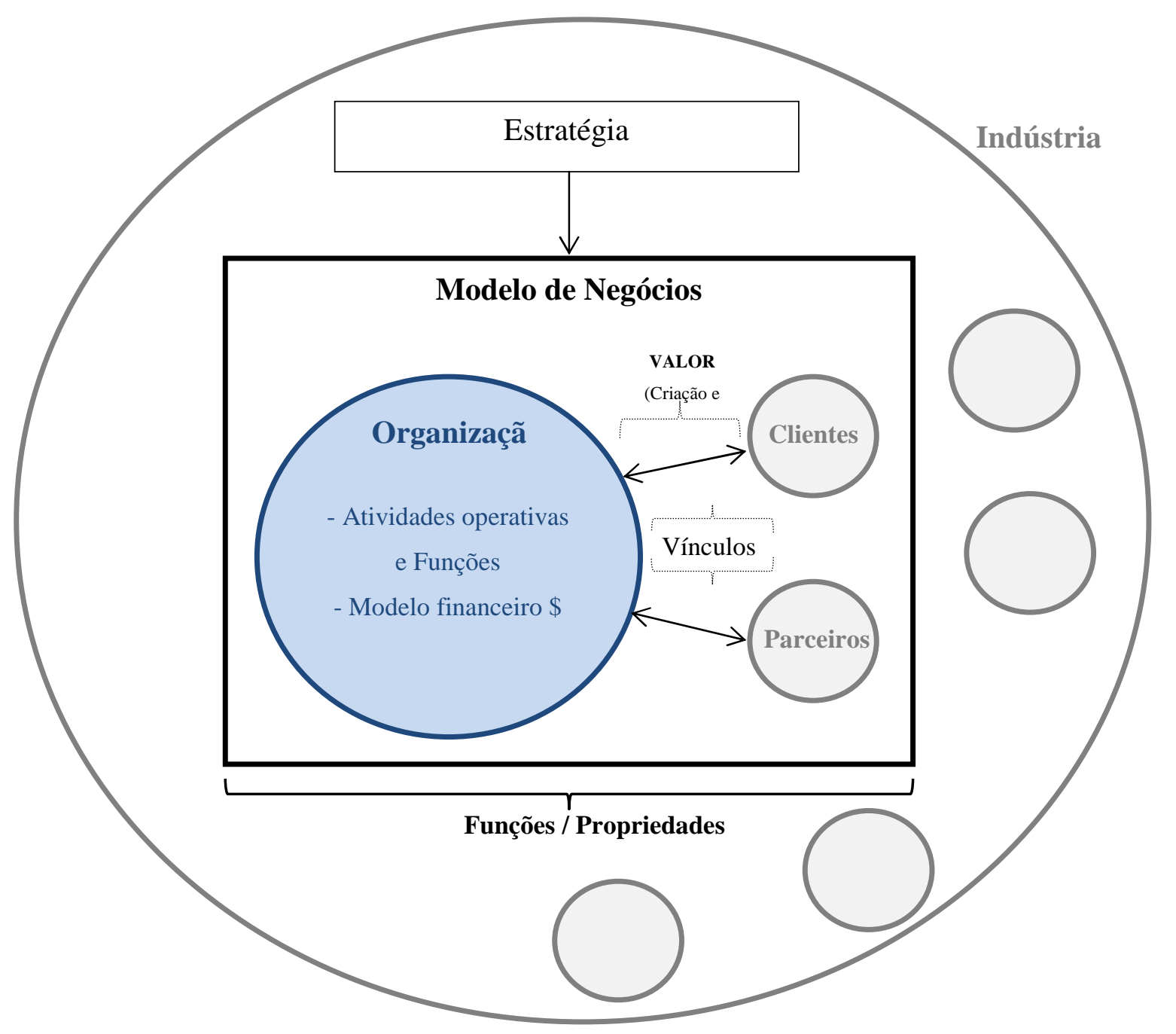

Ilustração 1. Representação da fundamentação teórica para a orientação na condução do Estudo de Caso.

\subsection{Justificativa na seleção dos casos}

Foram escolhidas as empresas A e B que, em ambos os casos, cumprem com os seguintes critérios:

a) São empresas com mais de 18 anos no mercado

b) Pertencem a um setor no qual existe concorrência e possibilitam adequadamente estudar as proposições da pesquisa

c) Consentiram acesso as suas informações para a realização da pesquisa. 


\subsection{Relevância da investigação}

Espera-se que a realização do estudo de caso contribua à discussão sobre a definição do conceito Modelo de Negócios e possibilite comparações com o constructo e concluir sobre os objetivos propostos.

\subsection{Papel do protocolo na orientação do pesquisador}

O protocolo servirá de guia para a condução da pesquisa, por resumir os principais objetivos, problemas e fundamentos da mesma. Constitui-se, portanto, de guia das atividades operacionais a ser levadas a cabo na etapa de coleta de dados e um auxilio para projetar a posterior análise e apresentação de resultados.

Cabe lembrar que as questões incluídas neste protocolo não são exatamente as mesmas a ser aplicadas às fontes de informação (entrevistados), como ressalva Yin (2010, p. 112-114), são orientadoras do pesquisador. As questões aplicadas em campo serão apresentadas no Apêndice B.

A utilização deste instrumento, o protocolo, visa atribuir confiabilidade á pesquisa e garantir qualidade ao Estudo de Caso (YIN, 2010, passim).

\section{Procedimentos de coleta de dados}

Nesta seção do protocolo, apresentam-se as indicações para conduzir o Estudo de Caso em sua etapa de coleta de dados.

\subsection{Carta de apresentação e solicitude de acesso à organização}

A seguir se exibe o texto da carta padrão enviada às organizações convidadas a participar da pesquisa: 
Senhor(a)

Nome e Sobrenome

Cargo

Organização

Presente.-

Prezado senhor(a):

Informamos que Maks Wilhem Gutiérrez Rocha, estudante do programa de pós-graduação em Administração da FEA-USP, está conduzindo uma pesquisa como parte de seu trabalho de Dissertação para a obtenção do seu título.

O tema de sua pesquisa é "Modelo de Negócios" e ela tem basicamente como objetivo contribuir com o conhecimento existente, estudando os elementos, funções e propriedades dos modelos de negócios nas organizações.

Solicitamos, portanto, sua importante participação nesta etapa, concedendo uma entrevista com o responsável pelas estratégias/negócios da empresa e com outro executivo não vinculado diretamente com a construção das estratégias e definição dos negócios da empresa, bem como informações acerca do tema.

Cabe ressaltar que a pesquisa tem caráter exclusivamente acadêmico e as informações coletadas serão tratadas de forma confidencial e, se preferir, o nome da organização e dos entrevistados poderão ser preservados.

Ficamos a sua disposição para fornecer detalhes da participação ou para esclarecer quaisquer dúvidas.

Agradecemos de antemão a participação da sua organização.

Atenciosamente. 


\section{Maks Wilhem Gutiérrez Rocha}

Mestrando em Administração

Faculdade de Administração, Economia e

Contabilidade

Universidade de São Paulo

E-mail: maks@usp.br

Tel. Cel.: (11) 9414249XX

\section{Prof. Dr. Edison Fernandes Polo}

Orientador

Faculdade de Administração, Economia e

Contabilidade

Universidade de São Paulo

E-mail:polo@usp.br

Tel.: (011) 3091-5805

\subsection{Nomes dos locais a serem visitados e pessoas de contato}

\begin{tabular}{|c|c|c|c|c|}
\hline Organização & Localização & Contato & $\begin{array}{l}\text { Pessoas a serem } \\
\text { entrevistadas }\end{array}$ & Data e hora \\
\hline Empresa "X" & São Paulo & $\begin{array}{l}\text { MP } \\
\text { Diretor Operacional }\end{array}$ & $\begin{array}{l}\text { - Executivo na área } \\
\text { de operações } \\
\text { (Entrevistado 1) }\end{array}$ & $\begin{array}{l}\text { 30-abr-2015, 08:00 } \\
\text { am }\end{array}$ \\
\hline RTM - Empresa 2 & São Paulo & $\begin{array}{l}\text { Adriane Rego } \\
\text { Diretora Comercial } \\
\text { e de Novos } \\
\text { Produtos }\end{array}$ & $\begin{array}{l}\text { - Executivo na área } \\
\text { comercial } \\
\text { (Entrevistada 2) }\end{array}$ & $\begin{array}{l}\text { 12-maio-2015, } \\
\text { 03:30 pm }\end{array}$ \\
\hline $\begin{array}{l}\text { INW Group - } \\
\text { Empresa } 3\end{array}$ & São Paulo & $\begin{array}{l}\text { Alexandre Leitão } \\
\text { CEO }\end{array}$ & $\begin{array}{l}\text { - Diretor / Sócio } \\
\text { (Entrevistado 3) }\end{array}$ & $\begin{array}{l}\text { 18-junho-2015, } \\
\text { 12:00 pm }\end{array}$ \\
\hline
\end{tabular}

\subsection{Plano de coleta de dados}

A principal fonte de informação são os depoimentos dos executivos ligados à definição dos negócios e/ou estratégia na empresa. Espera-se entrevistar pelo menos uma pessoa que não pertença à área específica de estratégia ou negócios. O quadro 1 exibe a relação entre as questões e o papel dos entrevistados.

Quadro 1. Relação entre as questões do estudo de caso e a participação dos entrevistados

\begin{tabular}{|l|l|}
\hline Seção/Questão do caso & Papel dos entrevistados \\
\hline Questões ligadas à definição & - Colocar seu entendimento sobre o que é um modelo de negócio e \\
& estratégias vinculadas. \\
& - Avaliar afirmações propostas com base na teoria, para identificar as \\
\hline
\end{tabular}




\begin{tabular}{|c|c|}
\hline & concordâncias ou discordâncias. \\
\hline Questões ligadas às funções & $\begin{array}{l}\text { - Discutir as principais funções do modelo de negócios para a organização } \\
\text { pesquisada }\end{array}$ \\
\hline Questões ligadas às propriedades & $\begin{array}{l}\text { - Discutir algumas propriedades apontadas na literatura em função a sua } \\
\text { experiência com modelo de negócios }\end{array}$ \\
\hline Questões ligadas à Estratégia & $\begin{array}{l}\text { - Definir a posição do entrevistado em quanto à sequencia entre os } \\
\text { conceitos de Estratégia e Modelo de Negócios, assim como a sua relação. }\end{array}$ \\
\hline Dados básicos da empresa & $\begin{array}{l}\text { - Só no caso que não se possa contar com esta informação de antemão, se } \\
\text { pedirá aos entrevistados proporcionar algum dado faltante ou conferir } \\
\text { algum dado que estiver em dúvida. }\end{array}$ \\
\hline
\end{tabular}

O estudo de caso também pretende realizar observações durante as visitas para a realização das entrevistas, no intuito de aproveitar qualquer material disponível como, por exemplo, organogramas, esquemas, planos ou similares que possam contribuir à coleção de evidência que ajude a responder as perguntas da pesquisa. Qualquer outro tipo de evidência observada ou vivenciada presencialmente como pode ser a decorrente de visitas guiadas a departamentos, inspeção aos recursos da empresa, exemplificação in situ das atividades e/ou relacionamentos, ou similares, será muito valorizada. Nesse sentido o pesquisador deve estar preparado e atento para receber e assimilar qualquer tipo de dados ou experiência além da planejada.

A coleta de dados para análise também considera o uso de outras fontes como podem ser relatórios, anuários, correspondência, matérias jornalísticas na imprensa, propaganda, redes sociais e/ou sítios web institucionais.

O plano de coleta manterá em sigilo as informações fornecidas, bem como será assinado um acordo sobre o anonimato, ou não, da empresa e dos entrevistados, abaixo apresentado:

$\mathrm{Eu}$, , tendo participado da pesquisa elaborada como parte da dissertação de Maks Gutierrez Rocha da FEA-USP sobre modelo de negócios, solicito que ( ) não sejam divulgados o nome da empresa e dos entrevistados; ou que ( ) podem ser divulgados o nome da empresa e dos entrevistados 
Assim mesmo, autorizo a utilização da informação proporcionada ao pesquisador, no entendido que esta será utilizada com propósitos meramente académicos, tal como se compromete o pesquisador ao assinar esta folha.

Eu, Maks Wilhem Gutiérrez Rocha, me comprometo a resguardar a informação obtida da empresa e utiliza-la só com fins acadêmicos, assim como a enviar às pessoas participantes uma copia de qualquer publicação na qual se utilize esta informação.

Nome:

Cargo:

Empresa
Maks W. Gutiérrez Rocha

Mestrando

FEA-USP

Local e data: de de

\subsection{Preparação prévia à visita aos locais de coleta}

A preparação prévia á coleta incluiu primeiramente uma revisão da literatura sobre o método de estudo de caso, realizada entre dezembro de 2014 e março de 2015, consultando-se as obras de Yin (2010), Stake (1995), Simons (2009) e Swanborn (2010). Adicionalmente se fez uma revisão de artigos teóricos sobre o tema como Stake (1978); Yin (1981); Scapens (1990, 1992); Llewellyn (1992); Bonoma (1985); Flyvbjerg (2006); Gibbert, Ruigrok e Wicki (2008); Benbasat, Goldstein e Mead (1987), Eisenhardt (1989) e Campomar (1991). Também se realizou uma revisão de artigos clássicos de aplicação de Estudo de Caso como são os trabalhos de Mintzberg e Mchugh (1985); e Eisenhardt e Bourgeois (1988), assim como algumas dissertações que utilizaram esta estratégia nas suas verificações empíricas. ${ }^{65}$

\footnotetext{
${ }^{65}$ Yin, Robert K. Estudo de caso: planejamento e métodos. Porto Alegre: Bookman, 2010; Stake, Robert E. The art of case study Research. Thousand Oaks: Sage, 1995; Swanborn, P. G. Case study research: what, why and how? Los Angeles: SAGE, 2010; STAKE, Robert E. The case study method in social inquiry. Educational Researcher, p. 5-8, 1978; YIN, Robert K. The case study crisis: some answers. Administrative Science Quarterly, p. 58-65, 1981; SCAPENS, Robert W. The role of case study methods in management accounting research: a personal reflection and reply. The British Accounting Review, v. 24, n. 4, p. 369-383, 1992; LLEWELLYN, Sue. The role of case study methods in management accounting research: A comment. The British Accounting Review, v. 24, n. 1, p. 17-31, 1992; FLYVBJERG, Bent. Five misunderstandings about casestudy research. Qualitative Inquiry, v. 12, n. 2, p. 219-245, 2006; GIBBERT, Michael; RUIGROK, Winfried; WICKI, Barbara. What passes as a rigorous case study? Strategic Management Journal, v. 29, n. 13, p. 14651474, 2008; CAMPOMAR, Marcos Cortez. Do estudo de caso em pesquisas para dissertações e teses em administração. Revista de Administração, v. 26, n. 3, p. 95-97, 1991; MINTZBERG, Henry; MCHUGH,
} 
A preparação prévia a coleta também incluiu uma nova revisão da fundamentação teórica apresentada no capítulo 3, com o objetivo de coadjuvar no desenho das e familiarização com as questões orientadoras do caso, as quais são apresentadas na seguinte seção.

Como parte da etapa de preparação também se repassaram as considerações e sugestões para a condução de Entrevistas, contidas em publicações como Kvale e Brinkmann (2009) e Sampieri, Collado e Lucio (2010).

Na fase especificamente prévia à visita às organizações se deve realizar a pesquisa em procura da informação disponível sobre a empresa fora dela, como ser, por exemplo, em sítios web, redes sociais, notícias na imprensa, mensagens de propaganda, e similares. Este passo tem dois propósitos: gerar alguns insights iniciais sobre as questões de pesquisa de forma anterior às entrevistas e ter uma ideia da informação básica sobre a empresa (dados requeridos para preencher a última seção do roteiro de entrevista (Apêndice B)).

Uma vez realizado o passo anterior se deve averiguar se alguma área ou contato na organização (e.g. Relações Públicas ou Secretaria) podem conferir ou completar esta informação requerida, tentando-se que esta não tenha que ser coletada diretamente com o executivo entrevistado, salvo necessidade, no intuito de aproveitar ao máximo o tempo disponível com os entrevistados para a consulta dos outros temas mais profundos que aborda a pesquisa.

Assim mesmo, a preparação previa requer repassar o roteiro de entrevista, realizar um teste dos aparelhos de registro da entrevista (fisicamente e do software), e aprontar o material para tomar as anotações necessárias como respaldo às entrevistas e observações a realizar.

\section{Questões de Estudo de Caso}

\subsection{Unidades de análise e coleta de dados}

Alexandra. Strategy formation in an adhocracy. Administrative Science Quarterly, p. 160-197, 1985; EISENHARDT, Kathleen M.; BOURGEOIS, L. Jay. Politics of strategic decision making in high-velocity environments: Toward a midrange theory. Academy of Management Journal, v. 31, n. 4, p. 737-770, 1988. 
Definiu-se como unidade de análise de este Estudo de Caso à organização e como unidade de coleta de dados a os indivíduos pertencentes à organização, neste caso um executivo vinculado à área de Estratégia na empresa e um executivo não vinculado à área. A ilustração 2 mostra esta escolha.

\begin{tabular}{|c|c|c|c|}
\hline & \multicolumn{2}{|c|}{ Fonte da coleta de dados } \\
\hline & & De um individuo & De uma organização \\
\hline \multirow{2}{*}{ 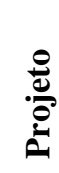 } & Sobre um individuo & & \\
\hline & Sobre uma organização & $\mathbf{X}$ & \\
\hline
\end{tabular}

Ilustração 2. Posição na escolha de unidade de análise e de coleta de dados para o Estudo de Caso.

FONTE: Elaborada com base em YIN, 2010, p. 115

\subsection{Questões orientadoras}

Novamente deve se lembrar de que as questões incluídas no protocolo não são as questões a realizar literalmente aos entrevistados, senão questões orientadoras que o pesquisador tem que ter presentes durante a condução do estudo de caso.

\section{Questões ligadas à definição}

1. O que significa "modelo de negócios" para uma organização, no entendimento de funcionários que formam parte dela?

2. Quais elementos conformam um modelo de negócios? São as atividades? Os clientes? Outros atores? O modelo de receita, custos ou lucro? Uma mistura de alguns deles ou de todos? O que outros elementos não apontados na literatura surgem da consulta aos entrevistados?

3. O conceito de valor é importante para o modelo de negócios da organização, segundo a impressão dos consultados? Fala-se mais da sua criação ou a sua captura? Ou de ambas de forma balançada?

4. A organização está familiarizada como o conceito de cadeia de valor? Qual a diferença ou relação, se existir, com o conceito de Modelo de Negócios? 
5. A organização possui alguma representação gráfica ou similar à linha de design no campo de modelo de negócios que utilize para definir, discutir, comunicar ou implementar seu modelo de negócios próprio?

6. Os entrevistados em algum momento entendem ou expressam o modelo de negócios como uma narrativa?

\section{Questões ligadas às funções}

7. Quais as funções principais de um modelo de negócio para uma organização? Quais as vantagens e/ou desvantagens dos modelos de negócio?

8. A função do modelo de negócios para a organização é uma mais prático-operativa ou uma mais analítico-estratégica?

\section{Questões ligadas às propriedades}

9. Quais as principais propriedades de um modelo de negócio para uma organização?

10. A organização considera o conceito de Modelo de Negócios como algo abstrato ou como algo existente e presente?

11. Os modelos de negócios são planificados previamente ou são estabelecidos pela participação da organização no mundo dos negócios?

12. Os modelos de negócios se utilizam de forma explícita ou implícita? A organização pode descrever seu próprio modelo de negócios ou algum outro?

13. Os modelos de negócios podem ser copiados? patenteados? adaptados?

14. Os modelos de negócios mudam no tempo? Têm um caráter mais estático ou mais dinâmico? Do que depende isso? 


\section{Questões ligadas à Estratégia}

15. Qual a relação entre Modelo de Negócios e Estratégia?

16. Quais as diferenças e similitudes principais entre Modelo de Negócios e Estratégia?

17. A Estratégia de uma organização precede o Modelo de Negócios ou vice-versa?

18. Qual a hierarquia na abstração entre os conceitos de Estratégia, Modelo de Negócios e outros?

\section{Esboço do relatório de Estudo de Caso}

O relatório do estudo de caso conformará parte do presente trabalho de dissertação. $\mathrm{O}$ esquema da mesma contempla a seguinte estrutura de capítulos:

1. Introdução

2. Método

3. Revisão de literatura

4. Análise dos dados

5. Conclusões e Recomendações

Pretende-se que a estratégia analítica para tratar a evidência coletada (YIN, 2010, p. 155-163) seja uma combinação entre a estratégia baseada em proposições teóricas (Ibid., p. 158-159) e as explanações rivais (Ibid., p. 162-163). No que se refere à técnica analítica se planeja recorrer às alternativas de combinação de padrão (Ibid., p. 165-169) ou síntese cruzada de casos (Ibid., p. 184-188).

Na composição, especificamente, o relatório do estudo de caso adoptará a Estrutura analítica linear (YIN, 2010, p. 206-207) por ser indicada como uma opção conveniente quando o público ao que está dirigido o estudo de caso está conformado por outros investigadores e bancas de dissertação. 


\section{APÊNDICE B - ROTEIRO E QUESTIONÁRIO DA ENTREVISTA SEMIESTRUTURADA}

Elaborado em função às orientações gerais de Sampieri, Collado e Lucio (2010, p. 422-423).

\section{$\underline{\text { Roteiro de entrevista no estudo de caso sobre teoria e prática dos modelos de negócios }}$}

Data: Hora:

Local (cidade e sitio específico):

Nome do Entrevistador:

Entrevistado(a):

Nome: / Idade: / Género

Posição e anos na empresa: /Departamento:

Email-contato (preencher ao final):

\section{Apresentação}

- Apresentar-se novamente: nome, programa acadêmico atual, universidade.

- Indicar que por razões técnicas, o depoimento precisa ser gravado desde esse momento, salvo pedido expresso do entrevistado, caso no qual se procederá a tomar só anotações sobre as respostas. Assegurar que a informação gravada será tratada confidencialmente.

- Descrição breve e geral da pesquisa:

Propósito: Estudar os componentes, propriedades e funções que constituem o conceito "Modelo de Negócios" coletando depoimentos de executivos brasileiros vinculados ao tema. Menção do motivo pelo qual foram selecionados: Perfil desejado para a pesquisa, Indicação, Sugestão.

Breve explicação da utilização dos dados: Análise de dados como parte de um estudo de caso que integra o projeto de dissertação de mestrado e suas publicações resultantes.

\section{Características da entrevista}

- Explicar que a entrevista será guiada por perguntas estabelecidas, mas com a possibilidade de que o entrevistador e/ou entrevistado introduzam temas ou informação no percurso da mesma.

- Reiterar que a informação coletada será tratada confidencialmente e qualquer requerimento especial do entrevistado ou empresa ao respeito pode ser manifestado. 
- Se o entrevistado consultar pela duração, indicar que se estima aproximadamente de uma a duas horas de entrevista para completar as perguntas.

\section{Questões}

Nota: Ajudar ao entrevistado com conceitos predefinidos em base à literatura, segundo o apêndice $C$, se ele(a) tiver alguma dificuldade em compreender algum deles.

\section{Definição}

1. O que é modelo de negócios, segundo seu entendimento?

2. Quais são, para você, as funções do modelo de negócio?

3. Como você descreve o modelo de negócios de sua companhia?

4. Alguns autores têm falado da existência e importância de alguns elementos na constituição do modelo de negócios de uma empresa, dos quais se ressaltam os seguintes:

- As atividades fim da empresa;

- O posicionamento da empresa em relação à indústria: fornecedores, parceiros, etc.;

- O posicionamento da empresa em relação ao mercado: segmentação, posicionamento estratégico, etc.;

- O modelo de receita, custos ou lucro da empresa.

Por favor, fale um pouco sobre estes elementos no caso de sua organização, sua concordância com sua consideração na construção do conceito de modelo de negócios e o grau de importância que você atribui ao elemento para seu modelo de negócios (entre as opções a ser oferecidas depois):

a) Atividades da empresa: 


\section{Importância:}

Nada importante ( ) Pouco importante ( ) Nem importante nem não importante ( ) Muito importante ( ) Totalmente importante ( )

b) O posicionamento da empresa em relação à indústria: fornecedores, parceiros, etc.:

\section{Importância:}

Nada importante ( ) Pouco importante ( ) Nem importante nem não importante ( ) Muito importante ( ) Totalmente importante ( )

c) O posicionamento da empresa em relação ao mercado: segmentação, posicionamento estratégico, etc.:

\section{Importância:}

Nada importante ( ) Pouco importante ( ) Nem importante nem não importante ( ) Muito importante ( ) Totalmente importante ( )

d) O modelo de receita, custos ou lucro da empresa:

\section{Importância:}

Nada importante ( ) Pouco importante ( ) Nem importante nem não importante ( ) Muito importante ( ) Totalmente importante ( )

5. O conceito de "Valor" é apontado como parte importante quando se discute o tema de modelo de negócios. No seu caso qual seria a relação entre valor e o modelo de negócios de sua empresa?

6. Distinguindo entre a criação de valor, que seria a qual se origina na organização e vá para o cliente, e a captura do valor, que seria a qual a empresa busca conseguir de sua base de clientes; qual, segundo sua organização, tem importância para seu modelo de negócios? Se ambas são importantes alguma é mais importante do que outra para sua organização? 
7. Você conhece o conceito de Cadeia de Valor? Se a resposta fosse afirmativa, você acha alguma relação com o conceito de Modelo de Negócios?

8. Sua organização possui algum tipo de documento, esquema, plano, gráfico, ou similar que represente o modelo de negócios da empresa? Se assim for, elabore ao respeito, por favor?

9. A organização utiliza/ou alguma vez alguma narrativa para descrever seu modelo de negócios? Por exemplo, seria fácil para você descrever ou explicar seu modelo, narrando o mesmo como uma espécie de historinha?

\section{Funções}

10. Poderia citar quais são as principais funções do modelo de negócios para sua organização?

11. Alguns autores têm citado como funções dos modelos de negócios as seguintes. Pode indicar sua concordância e avaliar sua importância? Se você puder, amplie ao respeito.

i) Alinhamento da Organização:

Concorda? Sim ( ) Não ( )

Importância:

Nada importante ( ) Pouco importante ( ) Nem importante nem não importante ( ) Muito importante ( ) Totalmente importante ( )

ii) Análise e Formulação da estratégia:

Concorda? Sim ( ) Não ( )

Importância:

Nada importante ( ) Pouco importante ( ) Nem importante nem não importante ( ) Muito importante ( ) Totalmente importante ( ) 
iii) Execução da estratégia:

Concorda? Sim ( ) Não ( )

Importância:

Nada importante ( ) Pouco importante ( ) Nem importante nem não importante ( ) Muito importante ( ) Totalmente importante ( )

iv) Exploração (descoberta) e Exploração (aproveitamento) de ideias de negócio:

Concorda? Sim ( ) Não ( )

Importância:

Nada importante ( ) Pouco importante ( ) Nem importante nem não importante ( ) Muito importante ( ) Totalmente importante ( )

\section{Propriedades}

12. No caso de sua empresa, você diria que o modelo de negócios é considerado como algo abstrato ou é algo presente no funcionamento da empresa?

13. O modelo de negócios vigente na sua empresa foi planificado previamente ou foi algo meramente resultante da atuação da empresa no mundo dos negócios?

14. A organização tem explicitado e compartilhado qual é o seu modelo de negócios de forma interna? A quais níveis da organização? A organização comunica este modelo de negócios a agentes externos?

15. Você acredita que os modelos de negócio mudam no tempo? Poderia dar um exemplo na sua organização? Qual a velocidade da mudança?

16. Você acredita que um modelo de negócios pode ser copiado ou adaptado? Por que sim ou por que não? Poderia dar um exemplo na sua organização? 


\section{Estratégia}

17. Poderia citar alguma vantagem e/ou desvantagem dos modelos de negócio? No caso de sua organização se aplica algum deles?

18. Por favor, cite brevemente qual é sua definição de Estratégia.

19. Considerando a definição dada na resposta anterior, quais similitudes ou diferenças você poderia citar entre Estratégia e Modelos de Negócio? Existe alguma relação que você identifique?

20. Você considera que a estratégia precede ao modelo de negócios ou vice-versa? Como é no caso de sua empresa?

21. Se você considera conceitos como Estratégia, Modelo de Negócios, Tarefas operacionais, ou qualquer outro que se ocorra a você agora, poderia ordenar eles de acordo a seu grau de tangibilidade (do menos abstrato ao mais abstrato). Pode se ajudar com o seguinte esquema:

\begin{tabular}{|l|}
\hline 1. \\
\hline 2. \\
\hline 3. \\
\hline$\cdots$ \\
\hline n. \\
\hline
\end{tabular}

Mais abstrato / Menos objetivo
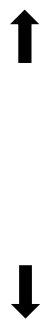

Menos abstrato / Mais objetivo

\section{Agradecimento e Observações finais}

- Agradecer ao entrevistado pelo tempo concedido para realizar a entrevista. 
- Dar ao entrevistado a possibilidade de providenciar qualquer outra informação que considere útil e que não foi tratada previamente e agradecer se pode indicar outra pessoa que possa contribuir à pesquisa

- Reiterar sobre o tratamento confidencial da informação coletada e assinar junto a ele(a) a autorização.

- Combinar com o entrevistado o endereço de contato para fazer chegar o consolidado de suas respostas para sua revisão, para fins de critérios de validade, e oferecer enviar as publicações finais decorrentes, esperadas uma vez que a pesquisa esteja concluída.

\section{Informação complementar (que pode ser averiguada fora da entrevista)}

Empresa:

Setor:

Anos de funcionamento:

Número de empregados:

Faturamento aproximado anual? (opcional): 


\section{APÊNDICE C - DEFINIÇÕES AUXILIARES PARA OS ENTREVISTADOS}

\begin{tabular}{|c|c|c|}
\hline TERMO & DEFINIÇÃO & REFERENCIA BASE $^{66}$ \\
\hline Atividades & $\begin{array}{l}\text { Comprometimento de recursos humanos, físicos } \\
\text { e/ou de capital para servir um propósito específico. }\end{array}$ & (ZOTT; AMIT, 2010) \\
\hline Parceiro Estratégico & $\begin{array}{l}\text { Relacionamentos que mantêm uma empresa com } \\
\text { outras, onde as parcerias são investimentos } \\
\text { intensivos em recursos nos quais não só existe risco } \\
\text { financeiro, mas risco estratégico. }\end{array}$ & $\begin{array}{l}\text { (CHRISTOPHER; JUTTNER, } \\
\text { 2000) }\end{array}$ \\
\hline Valor & Resultado do trade-off entre benefícios e sacrifícios & $\begin{array}{l}\text { (SÁNCHEZ-FERNÁNDEZ; } \\
\text { INIESTA-BONILLO; } \\
\text { HOLBROOK, 2009) }\end{array}$ \\
\hline Cadeia de Valores & $\begin{array}{l}\text { Atividades de valor relevantes com economias e } \\
\text { tecnologias distintas numa organização: Logística } \\
\text { interna, Operações, Logística externa, MKT \& } \\
\text { Vendas, Serviço, Infraestrutura, Gerência RH, } \\
\text { Desenvolvimento e Tecnologia, Aquisição. }\end{array}$ & (PORTER, 1989) \\
\hline
\end{tabular}

66 CHRISTOPHER, Martin; JÜTTNER, Uta. Developing strategic partnerships in the supply chain: a practitioner perspective. European Journal of Purchasing \& Supply Management, v. 6, n. 2, p. 117-127, jun. 2000.

PORTER, Michael E. Vantagem competitiva: criando e sustentando um desempenho superior. 19. ed. Tradução Elizabeth Braga. Revisão técnica Jorge Gomez. Rio de Janeiro: Campus, 1989. 512 p.

SÁNCHEZ-FERNÁNDEZ, Raquel; INIESTA-BONILLO, M. Ángeles; HOLBROOK, Morris B. The conceptualisation and measurement of consumer value in services. International Journal of Market Research, v. 51 n. 1, 2009.

ZOTT, Christoph; AMIT, Raphael. Business model design: an activity system perspective. Long Range Planning, v. 43, n. 2/3, p. 216-226, apr./jun. 2010. 
ANEXOS

ANEXO A - QUESTÕES PARA AVALIAÇÃO DE ENTREVISTAS 


\section{ANEXO A - QUESTÕES PARA AVALIAÇÃO DE ENTREVISTAS}

Questões traduzidas e adaptadas de Sampieri, Collado e Lucio (2010, p. 425).

1. O ambiente físico da entrevista foi adequado?

2. A entrevista foi interrompida? Com que frequência? Afetaram as interrupções o curso da entrevista, a profundidade e a cobertura das perguntas?

3. O ritmo da entrevista foi adequado ao entrevistado(a)?

4. Funcionou o roteiro de entrevista? Fizeram-se todas as perguntas? Obtiveram-se os dados necessários? O que pode se aprimorar do roteiro?

5. Quais dados não contemplados originalmente emanaram da entrevista?

6. O entrevistado se mostrou honesto e aberto nas suas respostas?

7. O equipamento de gravação funcionou adequadamente? Gravou-se toda a entrevista?

8. Você evitou influir nas respostas do entrevistado? O conseguiu? Introduziram-se vieses?

9. As últimas perguntas foram respondidas com a mesma profundidade das primeiras?

10. Seu comportamento com o entrevistado(a) foi cortês e amável?

11. O entrevistado se incomodou, irritou ou teve alguma outra reação emocional significativa?

Qual? Afetou isto a entrevista? Como?

12. Você foi um entrevistador ativo?

13. Esteve presente alguém mais além de você e o entrevistado? Isto afetou? De que maneira? 